\title{
Plutonium
}

\section{WORKING GROUP REPORT}

\section{on}

Environmental, Safety and Health

VulNerabILITIES ASSOCIATED WITH THE

Department's Plutonium Storage

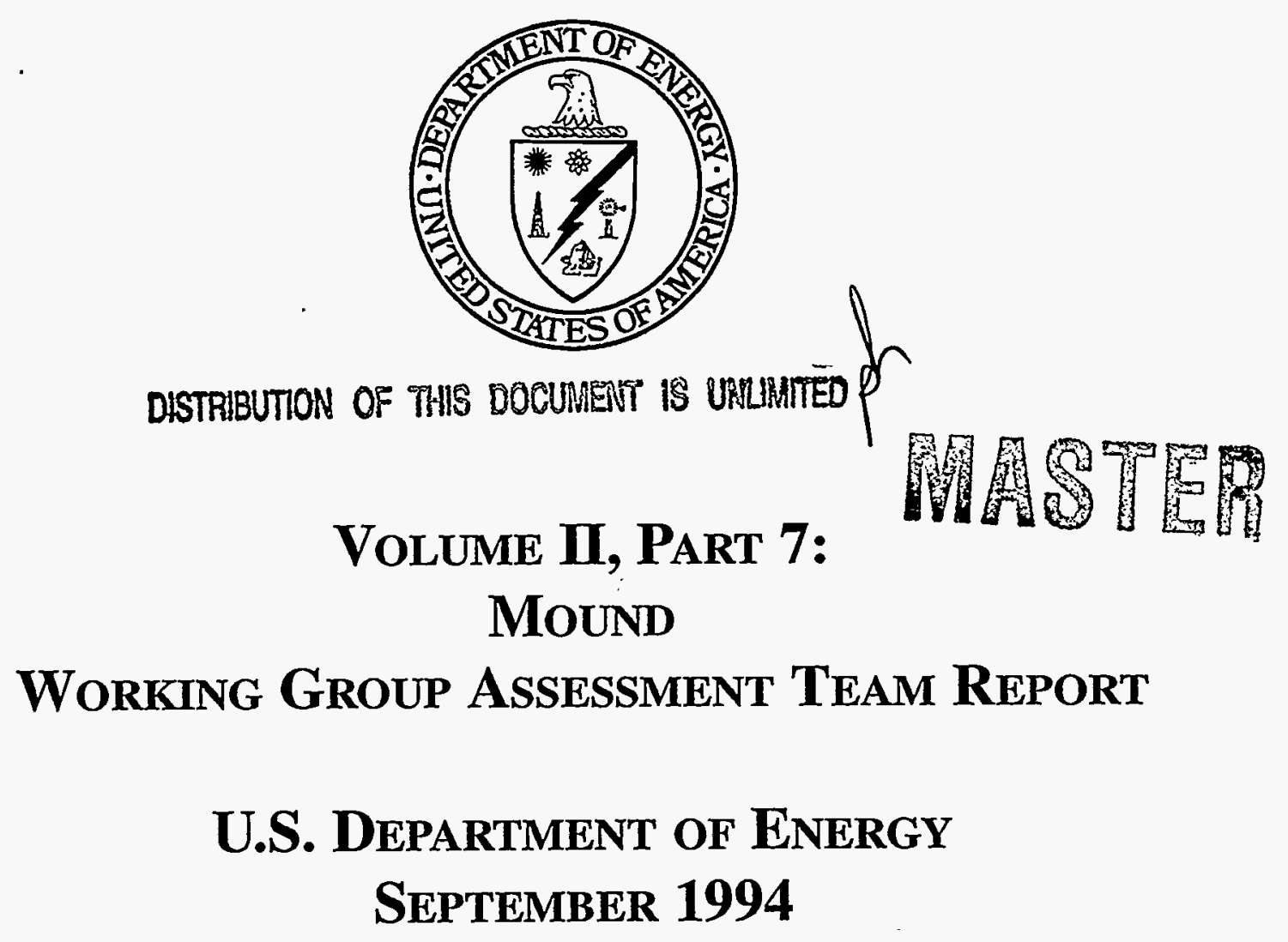




\section{memorandum}

DATE: September 1,1994

REPLY TO

ATTN OF: Allen Gunter, Working Group Assessment Team Leader, Mound \& Oak Ridge National Laboratory Sites

SUBJECT: Addendum to Plutonium ES\&H Vulnerability Assessment Working Group Assessment Team Report

TO: S. Acharya, EH-12

During the August 8-12, 1994 meeting at the Gaithersburg Hilton, Maryland, the assessment team leaders decided that the consequence levels estimated in the Working Group Assessment Team (WGAT) reports should be modified to reflect the meeting's consensus on: (1) the nominal values for leak path fractions through single- and multiple-stage HEPA filters, (2) the decision not to take credit for the use of respirators in the work place, and (3) the reference level for ground contamination. Accordingly, the consequence levels of vulnerabilities in this WGAT report have been revised.

Therefore, the consequence levels in the attached Table supersede the levels presented in this WGAT report.

This memorandum with its attachment is recognized as an addendum to this WGAT report.

Allen Gunter

Working Group Assessment Team Leader

Mound \& Oak Ridge National Laboratory Sites

Enclosure: Table of revised consequence levels of vulnerabilities 
VAP

Number

site:

MD - OI

MD- 02

$M D-02$
$M D-03$

$M D-03$
$M D-04$

MD-05

MD-06

MD-07

MD-08

MD-09

MD-10

MD-11

MD-12
Titie

Volume II

Reference

Part/Sact

Iike

-1i-

hood

Consequences W $\mathbf{P} E$

Kound Applied Technologies Inc.

Safeguards and Security Versus Radiological Safety (T-Building).

Uncertain Material Composition (T-Building)

Iack of Analysis for Potential Plutonium Release in $T$ Building.

Lack of Thorough Assessment of Consequence ( $T, 38,50 \& \mathrm{SW} / \mathrm{R}$ ).

Incomplete Authorization Basis ( $T, 38 \& \mathrm{SW} / \mathrm{R}$ )

Excess Fire Loading in Buildings 38 and $S W / R$.

Non-Adherence to Existing ALARA Program $(T, 38 \& S W / R)$.

Loss of Institutional Memory (Sitewide).

Unneeded Plutonium Stored On-Site $(T, 38,50 \& S W / R)$.

Uncertanity of inner packaging configuration of several older

plutonium packaging in vault storage that could result in

barrier deficiencies (T-Building).

Contaminated fumehoods, gloveboxes, ducts, and drains have the potential to release plutonium into the operating areas of

nuclear facilities (38\& SW/R).

Uncertainties exist about the consequences at two facilities to

natural phenomena such as earthquake and tornados ( $38 \& \mathrm{SW} / \mathrm{R}$ ).
7/2.5.1 -INST-

$7 / 2.5 .1 \quad L$

$\stackrel{\text { L }}{- \text { INST- }}$

- INST-

- INST-

- INST-

-INST-

$7 / 2.5$.

$7 / 2.5 .1$

$7 / 2.5 .1$

$7 / 2.5 .1$

-TNST-

$7 / 2.5 .1$-INST

$7 / 2.5 .2$

I

H $\mathrm{M} \mathrm{H}$

$7 / 2.5 .2$

$\mathbf{L}$

$\mathbf{L} * \mathbf{L}$

$7 / 2.5 .2 \quad$-INST-

H $\quad M \quad H$

* Consequence Below Threshold for Characterization

** VAF not accepted as vulnerability by WGAT 


\section{DEPARTMENT OF ENERGY \\ PLUTONIUM ES\&H VULNERABILITY ASSESSMENT \\ WORKING GROUP ASSESSMENT TEAM REPORT \\ MOUND}

July 18,1994

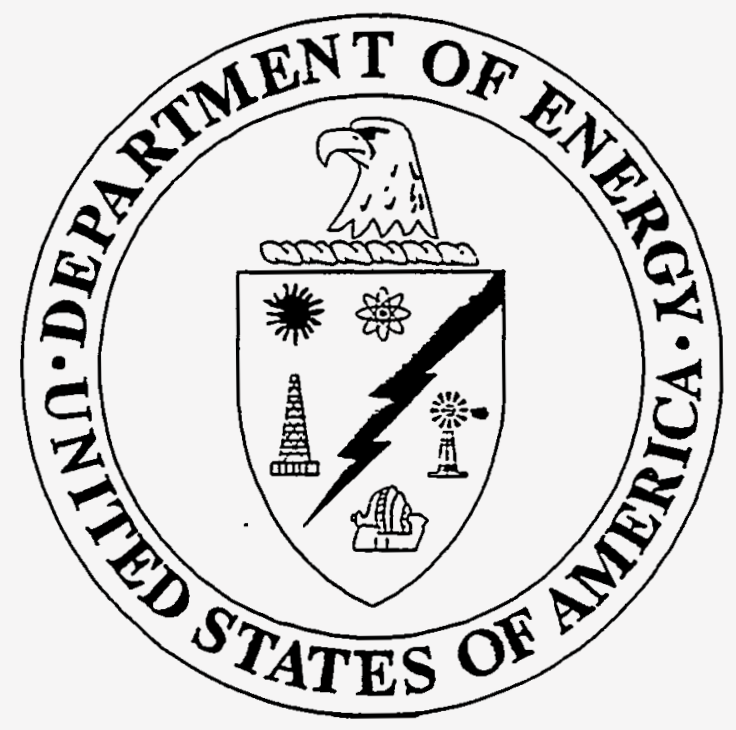

This report has been reviewed by an Authorized Derivative Classifier, and determined to contain no Classified or Unclassified Controlted Nuclear Information (UCNI) 


\section{DISCLAIMIER}

Portions of this document may be illegible in electronic image products. Images are produced from the best available original document. 


\section{DISCLAIMER}

This report was prepared as an account of work sponsored by an agency of the United States Government. Neither the United States Government nor any agency thereof, nor any of their employees, make any warranty, express or implied, or assumes any legal liability or responsibility for the accuracy, completeness, or usefulness of any information, apparatus, product, or process disclosed, or represents that its use would not infringe privately owned rights. Reference herein to any specific commercial product, process, or service by trade name, trademark, manufacturer, or otherwise does not necessarily constitute or imply its endorsement, recommendation, or favoring by the United States Government or any agency thereof. The views and opinions of authors expressed herein do not necessarily state or reflect those of the United States Government or any agency thereof. 
PLUTONIUM ES\&H VULNERABILITY ASSESSMENT

WORKING GROUP ASSESSMENT TEAM REPORT

MOUND

H. Allen Sent

H. Allen Gunter, Team Leader, Department of Energy, Savannah River Site
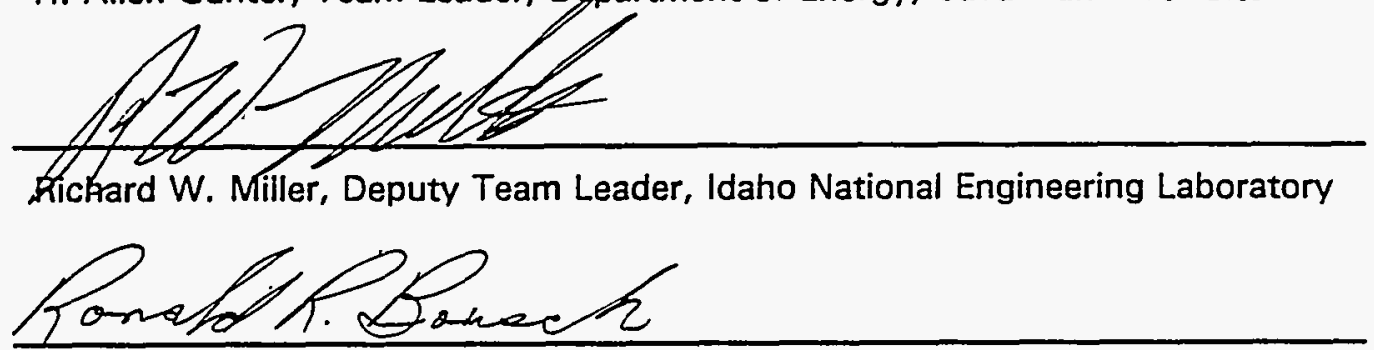

Ronald R. Borsch, Westinghouse Hanford Co.

Aonuldellien

Ronald A. Kief, Ogden Environmental \& Energy Services Co., Inc.

Colet $A$ moushale

Robert, A. Marshall, Ogden Environmental \& Energy Services Co., Inc.

Paula

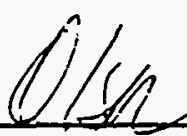

Paula L. Olson, Idaho National Engineering Laboratory
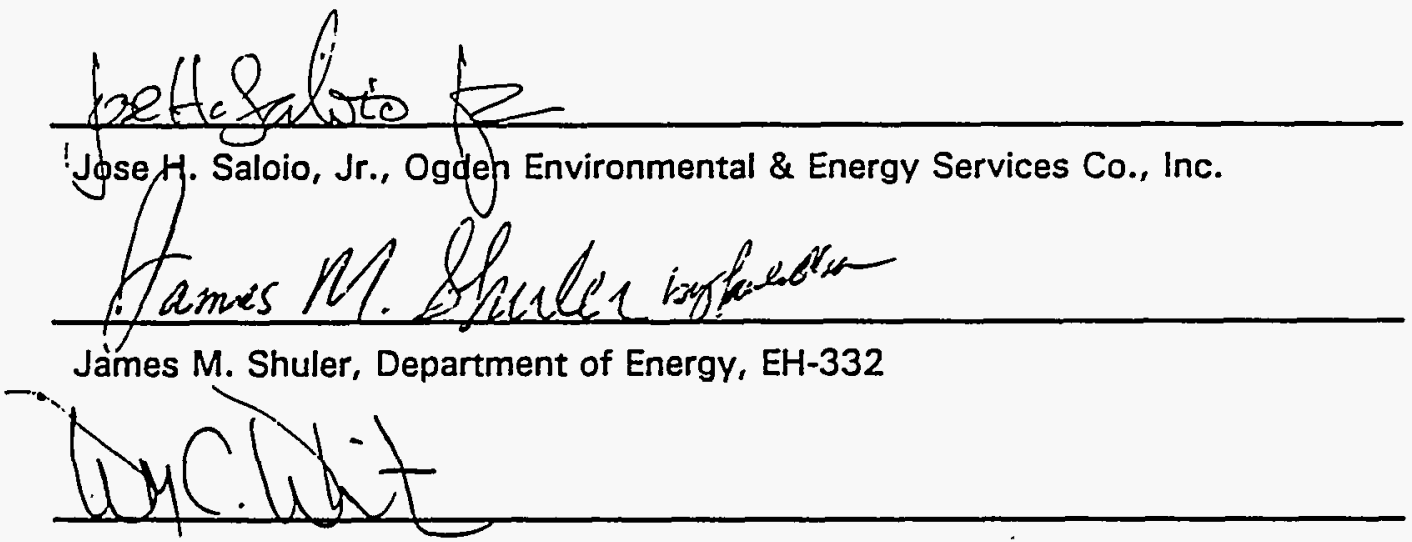

William C. White, Department of Energy, DP-22 


\section{ACRONYMS}

$\begin{array}{ll}\text { ALARA } & \text { As Low As Reasonably Achievable } \\ \text { BIO } & \text { Basis for Interim Operation } \\ \text { CAM } & \text { Continuous Air Monitor } \\ \text { DOE } & \text { Department of Energy } \\ \text { ES\&H } & \text { Environmental Safety and Health } \\ \text { GPHS } & \text { General Purpose Heat Source } \\ \text { HSP } & \text { Health Safety Program } \\ \text { NMDP } & \text { Nuclear Material Disposition Project } \\ \text { OSR } & \text { Operational Safety Requirement } \\ \text { RTG } & \text { Radioisotope Thermoelectric Generator } \\ \text { RWP } & \text { Radiation Work Permit } \\ \text { SAR } & \text { Safety Analysis Report } \\ \text { SAT } & \text { Site Assessment Team } \\ \text { UCNI } & \text { Unclassified Controlled Nuclear Information } \\ \text { VAF } & \text { Vulnerability Assessment Form } \\ \text { WGAT } & \text { Working Group Assessment Team }\end{array}$




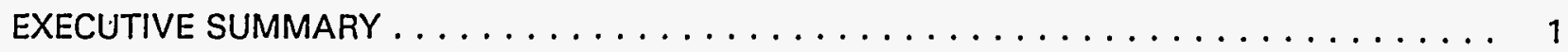

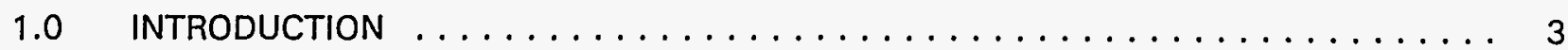

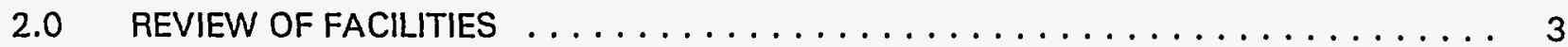

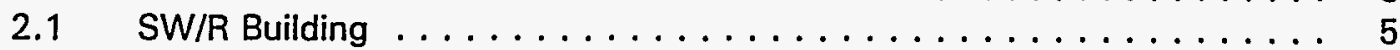

2.1.1 Table Top Discussions . . . . . . . . . . . . . 5

2.1.2 SW/R Building Walkdown ............... 7

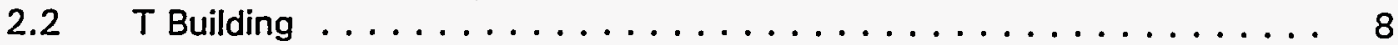

2.2.1 Table Top Discussions $\ldots \ldots \ldots \ldots \ldots \ldots \ldots$. . . . . 8

2.2.2 T Building Walkdown .................. 9

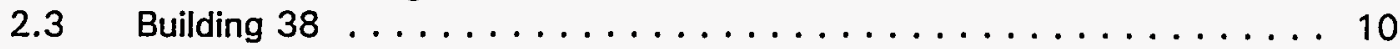

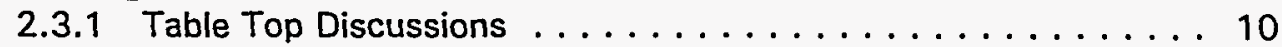

2.3.2 Building 38 Walkdown $\ldots \ldots \ldots \ldots \ldots \ldots \ldots \ldots \ldots$

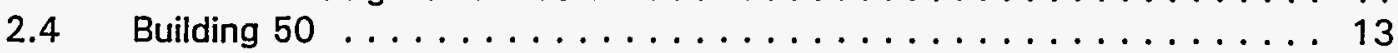

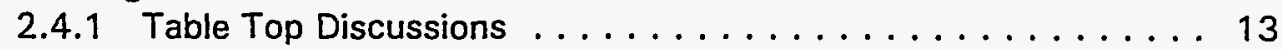

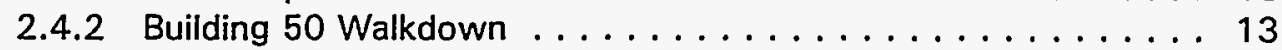

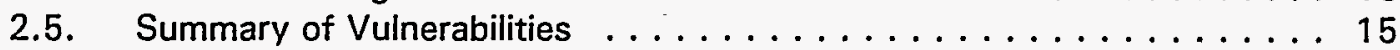

2.5.1 WGAT Generated Vulnerabilities ............. 15

2.5.2 SAT Generated Vulnerabilities . . . . . . . . . . . 16

2.5.3 WGAT Comments on SAT Draft Vulnerabilities . . . . . . . 16

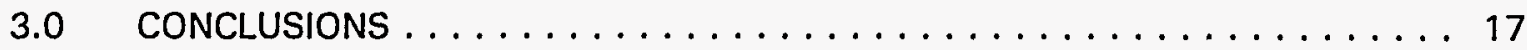

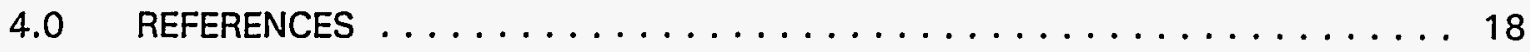

\section{APPENDICES}

APPENDIX A WORKING GROUP ASSESSMENT TEAM VULNERABILITY ASSESSMENT FORMS APPENDIX B MOUND SITE ASSESSMENT TEAM REPORT

APPENDIX C WORKING GROUP ASSESSMENT TEAM MEMBER LIST

APPENDIX D VULNERABILITY EVALUATION MATRIX

APPENDIXE PUBLIC PARTICIPATION

APPENDIX F PHOTOGRAPHS

APPENDIX G MOUND SITE REFERENCES 


\section{EXECUTIVE SUMMARY}

This is the report of a visit to the Mound site by the Working Group Assessment Team (WGAT) to assess plutonium vulnerabilities. Purposes of the visit were: to review results of the site's self assessment of current practices for handling and storing plutonium; to conduct an independent assessment of these practices; to reconcile differences and assemble a final list of vulnerabilities; to calculate consequences and probability for each vulnerability; and to issue a report to the Working Group. This report, representing completion of the Mound visit, will be compiled along with those from all other sites with plutonium inventories as part of a final report to the Secretary of Energy.

Another objective of the visit by the WGAT was to inform the public and local stakeholders of the project's mission, its modus operandi, and the specific results of the Mound assessment. To this end, an "In Briefing" was held at the outset of the WGAT visit to explain purposes and actions to be taken, and an "Exit Briefing" was held at the conclusion of the visit to reveal results. Both meetings were announced publicly and were accessible to the public. Questions from the public as well as from Mound personnel were addressed at each of the briefings. This report also provides an accounting of these meetings.

The Site Assessment Team (SAT) had conducted its self assessment and had drafted a report of its findings prior to the visit by the WGAT. Three proposed "vulnerabilities" were identified by the SAT. The WGAT reviewed the SAT report and found that it needed to be supplemented in

order to provide sufficient detail to substantiate the objectives of the assessment. Discussions between the two teams explored the deficiencies, and necessary corrections were identified for implementation by the SAT. The WGAT conducted "walkdowns" of the four facilities identified by the SAT as containing plutonium, namely SW/R Building, $T$ Building, Building 38 and Building 50. The team interviewed a number of workers and managers, discussed impressions with the SAT, and concluded the visit by identifying nine additional vulnerabilities.

Two of the vulnerabilities identified at Mound are believed to be generic to all sites within the DOE weapons complex. The first of these relates to the loss of institutional memory for the processes and configurations associated with the buildings, equipment, and material packaging. Such loss of institutional memory is exacerbated by continuing reduction in operating budgets. Most replacement personnel do not have, nor can they acquire, "hands-on" experience with plutonium because operations and facilities are shut down.

The second generic vulnerability for Mound is the presence of plutonium for which there is no identified mission. This is a common occurrence when defense facilities are shut down because much of the plutonium-bearing material remains at the site. Most of the vulnerabilities identified during this assessment could, in fact, be eliminated if such unneeded materials were shipped off-site to facilities currently storing similar materials. Neither the Department of Energy nor the Mound Site has developed definitive plans to relocate materials from this site, or from any other DOE site. Such planning should be given high priority for Mound and for the entire DOE weapons complex.

Overall, the Mound site has low inventory of plutonium, only a small fraction of which is associated with ES\&H plutonium vulnerabilities. 
Although some of the vulnerabilities identified in this report have high consequences for workers, public or the environment, the likelihood of such events was always judged to be extremely low by the WGAT. Therefore the risks are judged to be minor.

The twelve vulnerabilities identified at the Mound Site are described briefly below. The first nine vulnerabilities were developed by the WGAT. The last three were developed by the SAT. Complete descriptions are contained in the body of the report and on the forms in Appendix A.

MD-1. Safeguards and Security Versus Radiological Safety

A conflict between the principle of ALARA (i.e., that radiological doses should be kept as low as reasonably achievable) and Mound's current safeguards and security practices.

MD-2. Uncertain Material Composition Uncertainties exist about other materials that may be packaged with stored plutonium.

MD-3. Lack of Analysis for Potential Plutonium Release in T Building

The potential for plutonium release from storage and staging operations in $T$ Building is not addressed in the safety analysis report.

MD-4. Lack of Thorough Assessment of Consequence

Several accident scenarios do not have quantitative assessments for each potentially affected population.

MD-5. Incomplete Authorization Basis Incomplete formal authorization bases exists for several buildings. This problem arises from the lack of approved Safety Analysis Reports (SARs) and other safety documents.
MD-6. Excess Fire Loading in Buildings 38 and SW/R

Excessive fire loadings exist in two gloveboxes.

MD-7. Non-Adherence to Existing ALARA Program

Observations at the site indicate a need for more rigor in the ALARA program.

MD-8. Loss of Institutional Memory

Mound is rapidly shedding missions and operations and reducing staffing in preparation for decommissioning and conversion to commercial purposes. Loss of experienced personnel and knowledge of processes and facilities is seen as a vulnerability if the residual staff is no longer adequate to provide key safety functions while fissile and transuranic materials still reside at the site.

MD-9. Unneeded Plutonium Stored On-Site

The Department of Energy has a de facto practice of keeping unnecessary quantities of transuranic material stored on the Mound site. Relocating the material to a site with a continuing mission for it would eliminate many vulnerabilities at Mound, while creating no others.

\section{MD-10. Packaging Uncertainties}

There are uncertainties in primary packaging of some of the stored plutonium due to age and incompleteness of original documentation.

MD-11. Holdup in Process Equipment

The amount of plutonium held up or sequestered in ducts, as a result of operations over the years, is not known.

MD-12 Response of Facilities to Accidents Caused by Natural Phenomena

A current disparity of conclusions exists among independent teams analyzing design basis 
earthquake and tornado events for SW/R Building and Building \#38.

\subsection{INTRODUCTION}

The objective of the Plutonium Environmental Safety and Health (ES\&H) Vulnerability Assessment at the Mound Site was to conduct a comprehensive assessment of ES\&H vulnerabilities arising from the storage and handling of current plutonium holdings. The term "ES\&H Vulnerability" is defined for the purpose of this project to mean conditions or weaknesses that could lead to unnecessary or increased radiation exposure of workers, release of radioactive materials to the environment, or radiation exposure to the public. This assessment was intended as a "snap-shot" of Mound's plutonium holdings and associated ES\&H vulnerabilities in the time frame of May to June 1994.

The process began with a self-assessment by the Mound Site Assessment Team (SAT) which generated a self-assessment report including proposed vulnerabilities. The SAT identified four facilities -- SW/R Building, $T$ Building, Building 38, and Building 50 -- which contain plutonium considered to be in-scope for purposes of this study. Reference numbers 1 and 2, the Project Plan and the Assessment Plan, contain characteristics of plutonium holdings used as criteria for inclusion in this study. The Working Group Assessment Team (WGAT) then performed an independent assessment of the SATs report, conducted facility tours, and reviewed reference

documents such as Safety Analysis Reports (SARs), Operational Safety Requirements (OSRs), emergency preparedness plans, and procedures. The results of the WGAT review and "walkdowns" (consisting of the tours, document reviews, and detailed discussions with cognizant personnel) along with additional identified ES\&H vulnerabilities are discussed in Section 2.0, Review of Facilities.

\subsection{REVIEW OF FACILITIES}

This section describes activities of the Working Group Assessment Team (WGAT) at the Mound site. It concludes with a summary of the twelve ES\&H vulnerabilities identified by the Site Assessment Team (SAT) and the WGAT.

As defined in the Project Plan [Ref. 1], the SAT was charged with the responsibility of conducting a plutonium vulnerability assessment of the Mound site and drafting a report of the results. When the draft report was complete, the WGAT reviewed the draft report and visited the site. Because of the small number of facilities identified as containing plutonium (i.e., four buildings), tours and assessments were performed for each. Joint (Table Top) discussions were held with the SAT to understand fully the SAT conclusions and to generate a final, revised set of vulnerabilities.

The WGAT arrived at the Mound site on Monday morning, May 23, 1994. It was met by the SAT and provided with a conference room which would serve for temporary meeting and office facilities. During the ensuing morning hours, members of the WGAT were briefed on the Mound facility and the schedule of activities for the day. The WGAT members were fitted with respirators in preparation for subsequent tours of the four facilities designated by the SAT as containing plutonium within the scope of the assessment.

At 1:00 P.M. on this first Monday, the leadership of both teams conducted an 
In-Briefing which was open to the public. Several "stakeholders" (members of the public with personal and/or public interests in Mound activities) were at the In-Briefing and asked a number of questions (Appendix $E$ contains a review of this meeting). At about 2:00 P.M., the In-Briefing concluded and the two teams returned to the conference room to resume their discussions of the draft self-assessment report.

On Tuesday morning, May 24, 1994, the WGAT was escorted on tours of the SW/R Building and the $T$ Building. Results of the tours in the overall context of facility walkdowns are discussed below in sections 2.1.2 and 2.2.2 for the two buildings, respectively. On Tuesday afternoon, the two teams reconvened and discussed observations for these two buildings relative to the SAT draft report.

On Wednesday morning, tours were conducted for the remaining two facilities with plutonium holdings, namely Buildings 38 and 50 . Results of the latter two tours are reviewed, respectively, in Sections 2.3.2 and 2.4.2 below. Following the tours, the two teams again reconvened and discussed further observations for these two building relative to the SAT draft report.

On Wednesday afternoon the WGAT members met in individual and group interviews with the Mound SAT and subject-matter-expert personnel on a variety of subjects pursuant to assessment of plutonium vulnerabilities. (Although these interviews were summarized, records are included in this report only to the extent necessary to support identified vulnerabilities.) Interviews, discussions and research continued for the remainder of the week. Prior to WGAT departure on Friday, a detailed list of subjects was prepared as the basis for Table Top discussions to be conducted early the second week. The principle topics were:

- comments and questions regarding each SAT self-assessment response for each of the four buildings;

- comments and questions regarding observations made during the walkdowns (i.e., tours, interviews, and document reviews);

- $\quad$ clarification questions on the three draft vulnerabilities proposed by the SAT; and

- a tentative list of vulnerabilities over and above those identified by the SAT self-assessment report

On Tuesday morning, May 31, 1994, the second week of the WGAT assessment began. The two teams discussed the Table Top issues identified above. Subject matter experts were present for specific discussions. Results of Table Top discussions for each of the four buildings are reviewed below (in Sections 2.x.1, respectively). Following the Table Top discussions, the WGAT presented proposed vulnerabilities to the SAT and explained the rationale associated with each. Discussions were open and frank with very little disagreement. Some issues associated with potential WGAT vulnerabilities were reasoned to be more appropriately included in the SATs vulnerabilities and were so dispositioned. Other issues were clarified and combined as appropriate to generate the vulnerabilities summarized in Section 2.5 and listed in final form in Appendix A.

For the remainder of the week, the WGAT completed interviews and document reviews 
and drafted its report. An Exit-Briefing was held at 1:00 PM on Thursday, June 2, 1994. The same external stakeholders were present at this meeting as had attended the earlier InBriefing. (Appendix E contains a review of this meeting).

At the end of the day on Thursday, a first-draft report was completed and subjected to a classification review at Mound. Subsequently, the report was reviewed by the SAT for technical accuracy, finalized by the WGAT, and issued on the date noted on the cover sheet.

Occasionally, difficulty was encountered in determining whether specific observations or proposed vulnerabilities were appropriate to the scope of the assessment. To help in this determination, the WGAT recalled that the study is being conducted specifically to identify plutonium vulnerabilities and is not intended to

- assess compliance to Department of Energy (DOE) Orders, standards, or perceived good practices. Even so, absolute separation of "vulnerabilities" from "compliance" items was not always possible. A line of reasoning could often be constructed that linked a perceived non-compliance (or lack of rigor) to a putative vulnerability. Whenever this occurred, i.e., whenever the rationale for a proposed vulnerability reflected either directly or indirectly an increase in risk, the WGAT opted to include the vulnerability. The SAT concurred with this approach in each case.

\section{$2.1 \quad$ SW/R Building}

The first facility to be toured was the Semi Works/Research (SW/R) Tritium Complex. This extensive steel frame, masonry and brick structure was constructed in 1950. Having over 38,000 square feet of floor area, it supported many of Mound's tritium missions, most of which have now ceased. The complex now has a very small quantity of plutonium and other transuranic fissionable isotopes left over from these earlier activities. All these materials are confined to a few small areas.

\subsubsection{Table Top Discussions}

Table Top discussions for the SW/R Building were held on Tuesday, May 31, 1994, to review concerns and observations held by the WGAT following detailed review of the draft SAT self-assessment report, including the identified vulnerabilities. In preparation for the meeting, the WGAT assembled comments on the response to each question in the SAT draft report (not reproduced here). These comments, and the responses by the SAT (if any), are provided below. The numbering corresponds directly with the items in the Question Set provided in the Assessment Plan [Ref. 2].

\section{Question 1. Comment on Draft Report:}

The WGAT found the initial response to this question to be very weak. Descriptions of the facility, its mission, and its features needed to be augmented significantly so that the report is generally able to stand alone without the need for a reader to consult other documents. In addition, the response referenced safety analysis reports which, as Unclassified Controlled Nuclear Information (UCNI) documents, are not directly available to the public.

\section{Site Response:}

General agreement. Some discussion followed of the level of detail needed.

\section{Question 2. Comment on Draft Report:}

The response was acceptable. However, material classified as "OT" or "other" needed to be defined, as there was no way for a reader to 
identify specific containers, such as the "valved development" type containers of plutonium. No response was provided for Question 2A the classified version of Question 2).

\section{Site Response:}

Agreement. The SAT agreed to provide a response to Question 2A.

Question 3. Comment on Draft Report:

Holdup of plutonium in ducts is a vulnerability until measured and shown to be non-existent or insignificant. "Room" needed to be listed as a barrier type.

\section{Site Response:}

Agreement.

Question 4. Comment on Draft Report:

The report needed to acknowledge the combustible loadings found in the gloveboxes as an "adverse condition," and, possibly, also as a concern related to configuration control.

\section{Site Response:}

Agreement. The SAT also noted that adverse conditions might include mission changes and recent budget cuts which affect morale.

\section{Question 5. Comment on Draft Report:}

A. An explosion of acetylene tanks was listed in the SAR as a major event, but was not acknowledged as an event here. Why?

B. Why wasn't worker external dose listed as an event?

C: The report should have described each event instead of simply referencing the SAR.

\section{Site Response:}

A. Agreement. It will be included.

B. The internal dose is due to tritium which does not cause an external dose.

\section{Agreement.}

Question 6. Comment on Draft Report:

The response was acceptable.

\section{Question 7. Comment on Draft Report:}

A. Risk assignment was not defined.

B. There was need to explain damage from stack failure and expand the discussion to acknowledge the potential for stack collapse from earthquake and tornado. (Further discussion of this item is provided below.)

C. Everything included in the response to Question 5 also should be included here.

\section{Site Response:}

Agreement. -

In other Table Top discussions, the WGAT advised the SAT that there appeared to be no authorization basis for the SW/R Building. The SAT confirmed that there was not an approved SAR nor an approved Basis for Interim Operation (BIO), but that the DOE Albuquerque Operations Office had approved continued operation verbally. In addition, there is an approved set of OSRs. However, there exists no written authorization for existing operations. The WGAT and SAT agreed that the absence of such authorization constituted a vulnerability.

During pre-visit examination of safety documents provided to the WGAT, the team noted that building failures resulting from earthquakes were not listed as events which could lead to releases. Further, it was noted that a brick stack near another building, Building 38 may be toppled by a design basis tornado and therefore compromise the building (see Section 2.3). Building SW/R lies within reach of another stack with essentially the same design, yet this same event had not been 
considered in the SAT report. Discussion on these subjects broadened and revealed that indeed the issue of earthquake-induced failure of Building SW/R, either directly or through the combined effect of toppling stacks, is a live issue at the site and currently unresolved. The reason for lack of resolution lies in the fact that analyses conducted by two independent groups have reached disparate conclusions. The next steps in resolving the issue are currently under consideration. The SAT agreed with the WGAT that such an uncertainty, until resolved to the contrary, constitutes a vulnerability.

\subsubsection{SW/R Building Walkdown}

The SW/R Building is a two story building which is used primarily for handling tritium, but also contains Category II quantities of plutonium (according to DOE Order 5633.2B). Two rooms of interest in the SW/R complex were previously used for plutonium operations. The small quantities of plutonium stored in this . building do not have a mission.

Upon entering the building, personnel went to the health physics office and signed in on a Radiation Work Permit (RWP) form. It was noted at the start of the tour that warning signs were stored in racks in the hallway. This caused some confusion to the WGAT members until it was realized that the signs which were readily visible in the rack did not constitute "postings." The tour of SW/R Building consisted of a 10-15 minute stop in one room, a small glovebox line currently used only for storage of miscellaneous plutonium metal parts. One other area, designated SW 22, has only residual plutonium contamination that is not considered in-scope for purposes of this assessment. Currently there are no plutonium operations being performed in this facility.
The glovebox area, equipment, and form of the plutonium inventory appeared as expected from the descriptions in the draft safety analysis report. In one of the two gloveboxes, many used gloves were kept inside along with cutting oils and, potentially, plutonium metal turnings. This contributes to an unnecessarily high fire loading. The practice of storing used gloves coupled with overall poor housekeeping in the glovebox also could lead to higher than necessary radiation exposure to workers.

Also during the tour, it was noted that shoe covers were located on the wrong side of the radiation boundary and that exit monitoring took place a significant distance inside the radiation boundary. Protective clothing was not removed until after the team crossed the radiation boundary.

Information from interviews indicated a potential natural-phenomenon concern for this building in the form of unknown ability of the nearby ceramic (brick) stack to withstand a design-basis earthquake or tornado. Based on the tour, it appeared that the accident analysis contained in the safety analysis report for SW/R Building included appropriate scenarios with which to bound the inherent hazards. However, it was also noted that several accident scenarios do not have quantitative consequence assessments for each of the potentially impacted populations.

The SW/R Building complex contains less than $450 \mathrm{~g}$ of plutonium, i.e., less than the quantity for a minimum critical mass. As long as the plutonium inventory remains below this level, a critical excursion is not possible.

If the small amount of accountable plutonium stored in SW/R were removed, the minor concerns relating to its storage would be eliminated. 


\section{$2.2 \quad$ T Building}

The second building addressed by the WGAT was the $T$ Building. This is a massive underground structure, made with thick, heavily reinforced concrete walls and roof. The gross floor space is 173,000 square feet. Operations in the building include storage of nuclear materials in containers, heat source calibrations, calorimeter fabrication, non-destructive testing, and operation of a Plutonium Verification Laboratory.

\subsubsection{Table Top Discussions}

Table Top discussions again involved both teams as well as selected subject matter experts. The discussion was held on Tuesday, May 31, 1994. The comments and the responses by the SAT during this Table Top meeting are described below. The numbering corresponds directly with the items in the Question Set provided in the Assessment Plan [Ref: 2].

Question 1. Comment on Draft Report: The description of the facility, its mission, and its features was weak. Classified SARs which are not available to the public were referenced. Descriptions of the facility, its mission, and its features needed to be augmented significantly so that the self-assessment report would stand alone.

\section{Site Response:}

Agreement.

Question 2. Comment on Draft Report:

The draft report did not the answer the question or represent an accurate description. The response to Question 2 should be exactly the same as $2 \mathrm{~A}$ except for deletion of the (classified) quantity data. The response to Question 2A was good.

Site Response:

Agreement.

\section{Question 3. Comment on Draft Report:}

There was too much aggregation (NOTE: the term "aggregation" was adopted in the Assessment Plan [Ref. 2] to denote a freedom granted to the SAT to respond only once when a multitude, or aggregate, of "packages" of subject material have the same material and barrier attributes.) The response to this question did not provide an adequate description of each physical barrier providing protection to the workers, the environment, or the public.

\section{Site Response:}

Agreement.

Question 4. Comment on Draft Report:

Responses demonstrated very narrow interpretation and needed to be reevaluated to define conditions that could cause adverse consequences. It was recommended that responses be modelled after those for the same questions for SW/R Building and Building 38.

\section{Site Response:}

Agreement. The SAT team also agreed that change in mission, pyrophoricity and radiolysis should be listed as adverse conditions.

\section{Question 5. Comment on Draft Report:}

The response for in-facility potential events should be reevaluated for internal uptake of plutonium due to breach of containment.

\section{Site Response:}

Agreement. Human error will also be added as an Event. 
Question 6. Comment on Draft Report:

The response was inadequate. Many existing measures prevent adverse events.

\section{Site Response:}

Agreement, although the SAT pointed out that a comment at the bottom of the form (i.e., that all entries may apply to some extent) in effect, obviated the concern.

\section{Question 7. Comment on Draft Report:}

The response to this question was inconsistent with the response to Question 5. Events should be the same for both. (See also the response to this question for Building 50 ).

\section{Site Response:}

Agreement.

\subsubsection{T Building Walkdown}

$T$ Building contains Category $\mid$ quantities of plutonium. Containers with plutonium are staged in four areas of the building. Other operations in $T$ Building include heat source calibration activities, calorimeter fabrication, non-destructive testing and non-destructive examination activities, and storage of a variety of other materials.

The tour of $T$ Building consisted of viewing three staging areas by the WGAT lanonymously labelled Areas \#1, \#2, and \#3). (NOTE: A fourth area was toured at a later time by a single team member. No additional concerns were noted in that area). Area \#1 is a vault housing plutonium-bearing material in several containers ranging in size from approximately 2 gallons to 55. gallons. All containers appeared to be made of steel. There were approximately 20 containers in the vault along with a large, raised box made of steel that contained small heat source packages. The vault ventilation system is not associated with the building forced air system; however, large chiller units were secured to the vault ceiling to provide local cooling. The fire loading in the vault was extremely small, consisting mainly of paperwork kept on a steel desk. The following concerns were noted by the team while the vault was being opened:

- Security requires that three persons be present (i.e., a "three person rule") when vaults are opened where Category II or III material is stored. This is not mandated by DOE Orders but is required by the quantities of DOE Albuquerque Operations Office. One result is radiation exposure to additional workers.

- The group of storage containers in the vault holds several material packages containing plutonium. The packages, in turn, typically consist of two or three individually sealed containers placed one inside of the other. Most, but not all, of the plutonium is in the form of oxide. Many of the packages lack documentation sufficient to certify (to current standards) the exact package configuration and condition.

Routine operations appear to expose workers to unnecessary risk associated both with routine radiation dose and accident vulnerability during work. Classified paper work completed inside the vault, perhaps, could be completed outside. Alarm checks that could be completed by one person are conducted by two. Unnëcessary health physics personnel are also present during these operations. Discussions indicated that the standard operating procedures are 
not DOE Order requirements, but based on requirements imposed by DOE/AL.

Area \#2 is another vault which houses several steel containers containing plutonium. Other material is contained in steel birdcage assemblies. A single level of shelving is attached to the side and back wall of the vault. Approximately 20 containers were present in the vault. A filtered ventilation system supplies air to the vault, but there is no active exhaust system. The fire loading in the vault is extremely small, consisting mainly of paperwork kept on a steel desk. The same concerns mentioned for Area \#1 apply to this storage area.

Area \#3 is a small, walk-in vault located in a laboratory. The plutonium inventory in this area consists of several small sealed sources. Observations during the tour indicate that this material is being stored and handled in a manner that exhibits good security and health/safety practices. In fact, the custodian showed great concern for the accountability of the material in his charge.

Adequate descriptions of these areas were contained in the $T$ Building safety analysis report. Because the SAR focused primarily on the tritium hazard, analyses to bound the hazards posed by the plutonium inventories were not reported.

The overall plutonium inventory in the four vaults in $T$ Building consists of several kilograms of plutonium-239 and ten to fifteen kilograms of plutonium-238 heat-source material all in encapsulated or other packaged form. While the total amount of plutonium exceeds the minimum critical mass, a combination of limits and procedural controls for handling, packaging, and storing the material (e.g., especially not allowing material to be removed from containers while in the vault) provide very generous criticality safety margins. A report of analyses performed by a consultant confirm these qualitative conclusions. Thus, a critical excursion scenario is not credible.

\section{$2.3 \quad$ Building 38}

Building 38 was originally constructed in 1967 to process kilogram quantities of encapsulated and unencapsulated plutonium-238. It has 13inch-thick reinforced-concrete walls and a 20inch-thick prestressed concrete roof. Additions have been made to the building at various times. Most of the building has undergone decontamination and decommissioning, leaving two glovebox lines operable: The F-Line gloveboxes are used for assembly of radioisotope heat sources The A-Line gloveboxes are used principally for evaluation of orphan source materials, waste sorting, and repackaging.

\subsubsection{Table Top Discussions}

Table Top discussions for Building 38 again involved both teams as well as selected subject matter experts. The discussion was held on Tuesday, May 31, 1994. The comments and the responses by the SAT during this Table Top meeting are listed below. The numbering corresponds directly with the items in the Question Set provided in the Assessment Plan [Ref. 2].

\section{Question 1. Comment on Draft Report:}

The description of the facility, its mission, and its features was weak. References were made to SARs, which are UCNI documents and unavailable to the public. The descriptions needed to be augmented significantly so that the report is able to stand alone. 
Site Response:

Agreement.

Question 2. Comment on Draft Report:
A. Describe barriers using letter designations as specified in the Assessment Plan [Ref. 2].
B. Provide a classified response to Question 2A.
C. Orphan sources need to be included in this listing.

\section{Site Response:}

Agreement. A classified response to Question $2 A$ was to be prepared.

Question 3. Comment on Draft Report:

The vault, rooms, and the "submarine" need to be designated separately from the A-Line and FLine.

\section{Site Response:}

Agreement.

Question 4. Comment on Draft Report:

The report needs to address the fact that there are water sources but no drains in the F-Line room.

\section{Site Response:}

The SAT diminished the importance of water sources. The only supply of water in the room is from a broken glovebox window, which would be quite limited and easily cleaned up. However, the SAT then acknowledged that the room also contains a water fire-suppression system.

Question 5 and 6. Comment on Draft Report: Good response.

\section{Question 7. Comment on Draft Report:}
A. Risk assignment was not defined.

B. Potential damage from stack failure due to collapse from earthquake or tornado needed to be explained.

c. Everything listed in Question 5 also should be included here.

Site Response:

Agreement.

\subsubsection{Building 38 Walkdown}

Building 38 is a one story building with basement, constructed of concrete and steel. The building main floor has been reconfigured to house two glovebox lines instead of the original six lines. Significant modifications to the interior of the building, including removal of an overhead transfer system, were performed when the other glovebox lines were removed. The filter system and a small decontamination and decommission packaging/repackaging station are in the basement (an area not included on the tour.)

Plutonium heat source pellets are moved into this facility in shipping casks from the off-site manufacturer. They are assembled into subassemblies in the F-Line gloveboxes and then moved from Building 38 to Building 50 for the next stages of RTG fabrication. The building contains a vault where plutonium can be stored indefinitely.

One end of the A-Line is being used for orphan source and waste packaging/repackaging activities. The other end of the line is being set up for examination and repackaging of plutonium packages.

At the start of the tour, the building manager briefed the WGAT at a status board which displayed the Limiting Conditions for Operations (LCOs). He explained how the board was updated daily and described the general uses 
and layout of the building. A brief stop was made in a receiving area where casks were located that had recently brought plutonium238 to the United States from Russia. The entry area, cask receiving area, and F-Line area had outstanding housekeeping.

An extended stop was made at F-Line. Both sides of the line were toured and an informative briefing on heat-source assembly was presented. A unique layout was observed where one side of the line had manipulators and the other side had gloves. (The arrangement was noted to be primarily an artifact of previous missions.) A new inert box was being set up in the operating aisle on the glove side of the line.

The F-Line operation is very well-described in the draft safety analysis report. It was noted that the glovebox windows were water-filled and that the floor drains were plugged. Discussions on the benefit or detriment of sealing the drains brought out varying points of view including the benefits of drainage versus potentially increased contamination from having the water spreading out on the floor. No clear cut benefit of one approach over the other was identified.

An observation on the tour of the vault was that sources were thermally hot. The DOE/Mound representative who was on the tour suggested that the time inside of the vault should be very limited because the radiation levels were relatively high. It was noted that there were no conspicuous "high radiation" postings to warn personnel of the potential exposure. A briefing on the Multi Hundred Watt RTG devices was provided at this stop. Several discussions later in the week further clarified the WGAT understanding of the storage configuration for these devices.
A-Line is the site of Mound's "orphan source" program. Here sealed sources and low-level radioactive material from across the site are collected for disposition and ultimate disposal. The engineer at the line was very knowledgeable of the past history, current operations and future plans for the A-Line. ALine appeared cluttered, both inside and outside the gloveboxes. A high potential fire loading was noted throughout the room. It also was noted that the radiation survey results posted on the glovebox did not match current survey results posted on the door to the area. Thus, personnel did not have proper radiation dose information.

Another portion of A-Line was being prepared for packaging/repackaging of plutonium currently stored at Mound. A tent for initial separation of the orphan source containers was in the operating aisle midway down the line. The tent setup looked routine and showed evidence of good work practices. Two lead aprons were hanging over the front of two separate gloveboxes in such a way that the box may merely have been a convenient place to hang them or the aprons may have been placed to provide temporary shielding for box operations.

As noted previously, the facility safety analysis report provides a good description of all processing areas in Building 38. The accident analysis section identifies a bounding accident that appears conservative based on the tour of the facility and discussions with the responsible facility operators.

Building 38 contains plutonium-238 heat source materials with only gram-quantities of plutonium-239 and related isotopes in the form of "orphan sources." The total plutonium inventory is less than a credible minimum critical mass. There currently are no approved 
procedures permitting operations with larger quantities of plutonium. Thus, under these circumstances, a critical excursion is not credible.

\section{$2.4 \quad$ Building 50}

Building 50 was constructed in 1967. Currently, it is used for final assembly of Radioisotope Thermoelectric Generators (RTGs)'. It also provides capability for evaluating the ability of fueled sources to handle mechanical and thermal stresses.

\subsubsection{Table Top Discussions}

Table Top discussions for Building 50 were held on Tuesday, May 31, 1994, involving both teams as well as selected subject matter experts. The comments and the responses by the SAT during this Table Top meeting are listed below. The numbering corresponds directly with the items in the Question Set provided in the Assessment Plan [Ref. 2].

Question 1. Commènt on Draft Report:

The description of facility, its mission, and its features was weak. References are made to SARs which, as UCNI documents, are generally unavailable to the public. The descriptions need to be augmented significantly so that the report is able to stand alone.

\section{Site Response:}

Agreement.

\section{Question 2. Comment on Draft Report:}

The aggregation was confusing due to apparent double entry of material as oxide and sealed sources. Packages need to be described better and have letter designations as defined in the question set. A classified response to Question $2 A$ is needed to be provided.

\section{Site Response:}

Agreement. The SAT will enter the subject material only as oxide because the individual packages are vented.

Question 3. Comment on Draft Report: The response was adequate other than having the distance to the site boundary missing.

\section{Site Response:}

Agreement.

Questions 4 through 6. Comment on Draft Report:

Adequate Response

Question 7. Comment on Draft Report: Good response.

\subsubsection{Building 50 Walkdown}

Building 50 currently contains Category III quantities of material. Plans for future operations would increase the quantities to Category II.

The tour of Building 50 consisted of viewing the main assembly (Room 116), fuel reduction (Room 108), and other testing and support areas. All areas of the building appeared to be extremely well-maintained. The general fire loading was low.

The facility SAR appears to be consistent with the current layout and use of the facility. However, several of the accident scenarios do nothave quantitative consequence assessments for each of the potentially affected populations. The bounding accident analysis scenarios in the SAR appear to be conservative with respect to the anticipated plutonium inventory, available safety systems, and operating procedures. 
The facility representative met the WGAT at the front of the building and stayed throughout the tour. He briefly explained the operations and radiological control procedures. Lab coats were worn, but not buttoned. It was explained that although the coats were not required for current building conditions, use was continued to remind personnel that they were working in what were usually radiation areas. The WGAT questioned the practice (i.e., of using coats but not buttoning them) as potentially counterproductive. Housekeeping was good in all areas of Building 50 that were included in the tour.

Building 50 contains a small inert cell for assembly operations and three rooms for RTG test operations. Two of these rooms contain vacuum chambers with the third room used to heat the assemblies to drive off excess oxygen. These rooms have large doors that can be rolled into place when a room contains plutonium. The doors provide both radiation shielding and security.

One vacuum chamber was located in a room in which the oxygen atmosphere could be replaced with nitrogen to reduce oxygen inleakage to the devices. The tour escort indicated that personnel were very aware of the oxygen-depletion hazards associated with such a room. Seals and monitoring procedures are put in place when the room is inerted to reduce the oxygen-depletion hazard in adjacent personnel-access areas. A verbal description of reentry procedures seemed adequate to ensure personnel safety. The applicable written procedure was not reviewed.

The room in which subassemblies are heated to drive off excess oxygen was found to be rather unique. When in use, subassemblies are placed in racks installed on three sides of the room. (The fourth side contains the door to the room.)
The process of removing oxygen proceeds for several weeks with the unit maintained at elevated temperature. During that time, a number of General Purpose Heat Sources (GPHSs) would be in the room.

There is no shielding permanently installed in the room. Because entry into the room is required on a semi-routine basis for monitoring and for placement and removal of subassemblies, temporary shielding is moved in. This room when in full use (for a limited amount of time during any given year) appears to have the highest radiation levels on the entire site. Because there are only three more RTGs planned for assembly at Mound (in support of the Cassini mission) and because this approach to shielding has been used successfully in the past (i.e., with no excessive radiation exposures accrued), a process change at this date is not recommended as it could actually increase exposure due to lack of personnel familiarity with the modification.

Building 50 is devoted to operations with plutonium heat-source material. The inventory of this material, consisting nominally of $80 \%$ plutonium-238 with the remainder plutonium239 and other plutonium isotopes, may exceed the minimum critical mass (for consolidated material) during full-capacity operations. However, analyses for Mound by an outside consultant and independently at Los Alamos National Laboratory show that critical configurations of heat source pellets and modules require greater numbers than will be available, as well as virtually unobtainable geometrical arrangements. Thus, for currently approved operations, a critical excursion is not credible. 


\subsection{Summary of Vulnerabilities}

The vulnerabilities for the Mound Site are summarized below using an arbitrary numbing system. The first nine (MD-1 through MD-9) are those identified by the WGAT. The remaining three (MD-10 through MD-12) are those identified by the SAT. The WGAT vulnerabilities are summarized in Section 2.5.1 and reference supporting sections of this report. The SAT-generated vulnerabilities are summarized in Section 2.5.2. WGAT comments on the initially proposed SAT vulnerabilities and the SAT responses are provided in Section 2.5.3).

\subsubsection{WGAT Generated Vulnerabilities}

MD-1. Safeguards and Security Versus Radiological Safety

Safeguards and security procedures approved by the DOE Albuquerque are in conflict with safety. Safeguards and security procedures and practices for entry and surveillance of the $T$ Building vaults require an excessive number of personnel to be present. Consequently, the exposures received by such personnel are inconsistent with the radiological-safety principle of keeping exposures ALARA. [Referenced in Section 2.2.2 for T Building.]

\section{MD-2. Uncertain Material Composition}

In a small number of containers, uncertainty exists about constituents packaged with stored plutonium. [Referenced in Sections 2.1.2 for SW/R Building, 2.2.2 for T Building, and 2.3.2 for Building 38]
MD-3. Lack of Analysis for Potential Plutonium Release in $T$ Building

The potential for plutonium release from storage and staging operations in T Building is not addressed in the safety analysis report. [Referenced in Section 2.2.2 for T Building.]

MD-4. Lack of Thorough Assessment of Consequences

Several accident scenarios do not have quantitative assessments for all potentially affected populations (e.g., workers, the public, and the environment). Although off-site radiological consequences are analyzed quantitatively, potential consequences to on-site recipients are only assessed qualitatively in the safety analysis reports. [Referenced in Section 2.1.2 for SW/R Building, 2.2.2 for-T Building, 2.3.2 for Building 38, and 2.4.2 for Building 50]

\section{MD-5. Incomplete Authorization Basis}

The authorization bases for Buildings $T, S W / R$, and 38 are unclear due to the lack of approved SARs, and lack of approved BIO documents. The approved SARs do not contain currently required analyses. [Referenced in Section 2.1.2 for SW/R Building, 2.2.2 for T Building, and 2.3.2 for Building 38]

MD-6. Excess Fire Loading in Buildings 38 and $\underline{S W / R}$

Excessive fire loading in the A-Line glovebox in Building 38 and a glovebox in one room in Building SW/R exist as a result of inadequate procedures, practices, or limits, and as a result of failure in Conduct of Operations. [Referenced in Section 2.1.2 for SW/R Building and 2.3.2 for Building 38.] 
MD-7. Non-Adherence to Existing ALARA Program

Observations show practices which conflict with the site's existing ALARA program and which may cause unnecessary exposure to onsite workers. Examples include: a vault in Building 38 not visibly posted as a high radiation area; lack of attentiveness to the most advantageous place to conduct business to reduce exposure, and out-dated radiological survey results posted on the face of gloveboxes in A-Line in Building 38. [Referenced in Section 2.1.2 for SW/R Building, 2.2.2 for $T$ Building, 2.3.2 for Building 38, and 2.4.2 for Building 50.]

\section{MD-8. Loss of Institutional Memory}

Loss of experienced personnel and their knowledge of processes and facilities (i.e., their "institutional memory," could increase the potential for errors with potential safety consequences. In addition, critical expertise may no longer be adequate to provide key functions such as safety analysis using facility personnel. [Referenced in Section 2.5]

\section{MD-9. Unneeded Plutonium Stored On-Site}

Pu-238 and Pu-239 materials remain stored onsite although they are no longer needed to support any identified missions at the Mound Site. DOE has no approved plan to relocate this material to another site with a mission requiring inventories of like material. [Referenced in Section 2.5]

\subsubsection{SAT Generated Vulnerabilities}

The SAT developed three vulnerabilities identified number's 1, 2 and 3 as MD-10, MD11 and MD-12. The title and summary from the Executive Summary of this report are provided below.

MD-10. Uncertainties in Plutonium Packaging There are uncertainties in primary packaging of some of the stored plutonium due to age and incompleteness of original documentation.

\section{MD-11. Contaminated Facilities}

The amount of plutonium held up or sequestered in ducts as a result of operations over the years is not known.

MD-12. Uncertainties in the Natural Phenomena Accident Analysis

A current disparity of conclusions exists among independent teams analyzing design basis earthquake and tornado events for SW/R Building and Building 38 .

\subsubsection{WGAT Comments on SAT Draft Vulnerabilities}

MD-10. Packaging Uncertainties

Comment on Draft Vulnerability:

This vulnerability was also identified by the WGAT. The only comment was on the lack of completion of Block \#9.

\section{Site Response:}

The Site team agreed to incorporate the comments into the revised vulnerability assessment form.

\section{MD-11. Holdup in Process Equipment}

\section{Comment on Draft Vulnerability:}

The Question Set responses provided in the draft SAT report did not support this vulnerability. This was discussed extensively with the SAT, and the SAT agreed to modify 
their responses to provide such support. In addition, Block \#9 was not completed.

\section{Site Response:}

The Site team agreed to incorporate the comments into the revised Vulnerability Assessment Form (VAF).

MD-12. Response of Facilities to Accidents Caused by Natural Phenomena

\section{Comment on Draft Report:}

It was pointed out again that Block \#9 had not been completed. The Question Set responses provided in the draft SAT report did not support this vulnerability. This was discussed extensively with the SAT, and the SAT agreed to modify its responses to provide such support. Also, SW/R building should be included in this vulnerability. Finally, it was pointed out that Block \#5 should include a brief description of the compensatory measures that reduce the severity of the vulnerability. The SAR could then be referenced for detailed descriptions of the compensatory measures.

\section{Site Response:}

The Site team agreed to incorporate the comments into the revised VAF.

\subsection{CONCLUSIONS}

The Working Group Assessment Team (WGAT) visited the Mound site as part of the Plutonium Environmental, Safety, and Health (ES\&H) Vulnerability Assessment. This program is intended to conduct a comprehensive assessment of the ES\&H vulnerabilities arising from the storage and handling of its current plutonium holdings. The term "ES\&H Vulnerability" is defined for the purpose of this project to mean conditions or weaknesses that could lead to unnecessary or increased radiation exposure of workers, release of radioactive materials to the environment, or radiation exposure to the public. This assessment was intended as a "snap-shot" of Mound's plutonium holdings and associated ES\&H vulnerabilities in the time frame of May to June 1994.

Of the twelve vulnerabilities identified at Mound, two are believed to be generic to all sites within the DOE weapons complex. The first of these (MD-8) relates to the loss of institutional memory for the processes and configurations associated with the buildings, equipment, and material packaging. Such loss of institutional memory is exacerbated by continuing reduction in operating budgets. Most replacement personnel do not have, nor can they acquire, "hands-on" experience with plutonium because operations and facilities are shut down.

The second generic vulnerability for Mound (MD-9) is the presence of plutonium for which there is no identified mission. This is a common occurrence when defense facilities are shut down, because much of the plutoniumbearing material remains at the site. Most of the vulnerabilities identified during this assessment could, in fact, be eliminated if such unneeded materials were shipped off-site to facilities currently storing similar materials. Neither the Department of Energy nor the Mound Site has developed definitive plans to relocate materials from this site, or any other DOE site. Such planning should be given high priority for Mound and the entire DOE weapons complex.

Although some of the vulnerabilities identified in this report have high consequences for workers, public, or the environment, the likelihood of such events was, always judged to 
be extremely low by the WGAT. Therefore the risks are judged to be minor.

\subsection{REFERENCES}

1. Department of Energy Plutonium ES\&H Vulnerability Assessment, Project Plan, April 25, 1994

2. Department of Energy Pluțonium ES\&H Vulnerability Assessment, Assessment Plan, April 25, 1994 
Mound

APPENDIX A

WORKING GROUP ASSESSMENT TEAM (WGAT)

VULNERABILITY

ASSESSMENT

FORMS

(VAFs) 



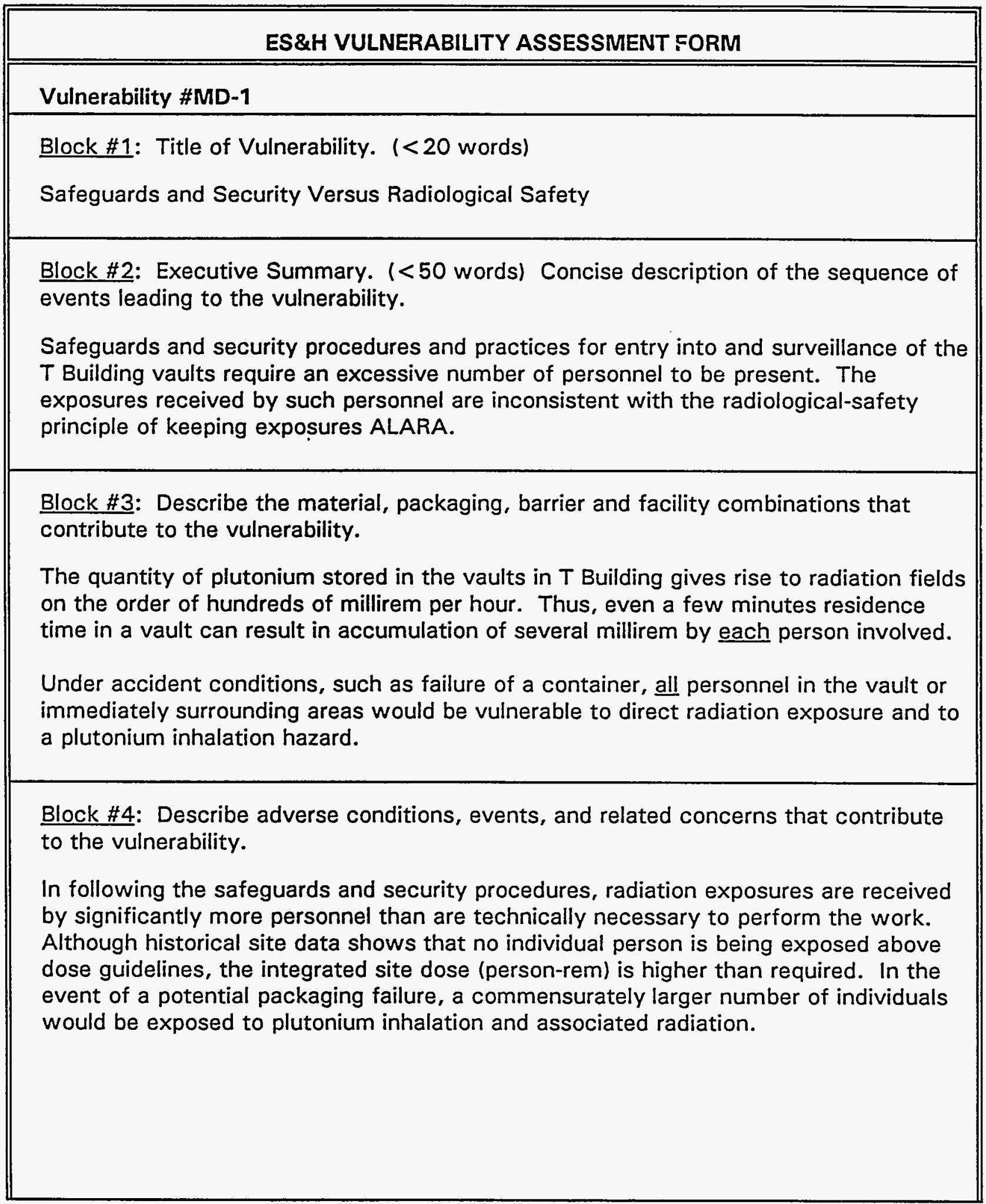


ES\&H VULNERABILITY ASSESSMENT FORM

Vulnerability \#MD-1

Block \#5: Describe the compensatory measures that reduce the severity of the vulnerability.

None.

Block \#6: Describe the likelihood of the event which causes this vulnerability and consequences which could result.

The operational aspect of the event is occurring now. Unnecessary radiation exposure to personnel is the consequence.

Accident release of plutonium is highly unlikely, but would have as a potential consequence inhalation of plutonium and associated radiation exposure to more personnel than would otherwise be at risk.

Block \#7: Describe the timing of corrective actions (if any). Use the terms immediate (imminent ES\&H issue), near-term (ES\&H issue that may become an imminent hazard with further degradation), or longer term (ES\&H issues which are being mitigated by barriers/compensatory measures).

To be identified in the Site Corrective Action Plan.

Block \#8: Additional comments, views, or plans by the site operations office and M\&O Contractor to mitigate or minimize any potential vulnerability. 


\section{ES\&H VULNERABILITY ASSESSMENT FORM}

Vulnerability \#MD-1

Block \#9: Database Criteria. (Use identifiers from question set tables.)

List adverse conditions:

- Radioactivity

List potential events/concerns:

- Worker Exposure -

- Worker Exposure - External Internal

Potential Consequences.

Environment Worker Safety and Health Public Safety and Health

- Ground L L Contamination L Contamination

- Water L Exposure $\underline{L}$ Exposure

- Air _ - Physical Injury _ Physical Injury

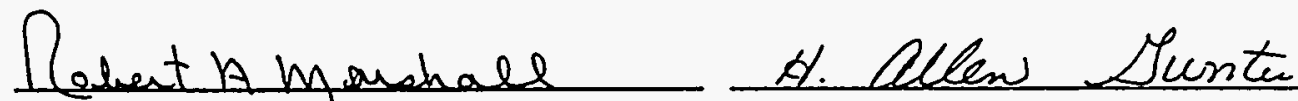
Signature, Team Member Signature, Team Leader 


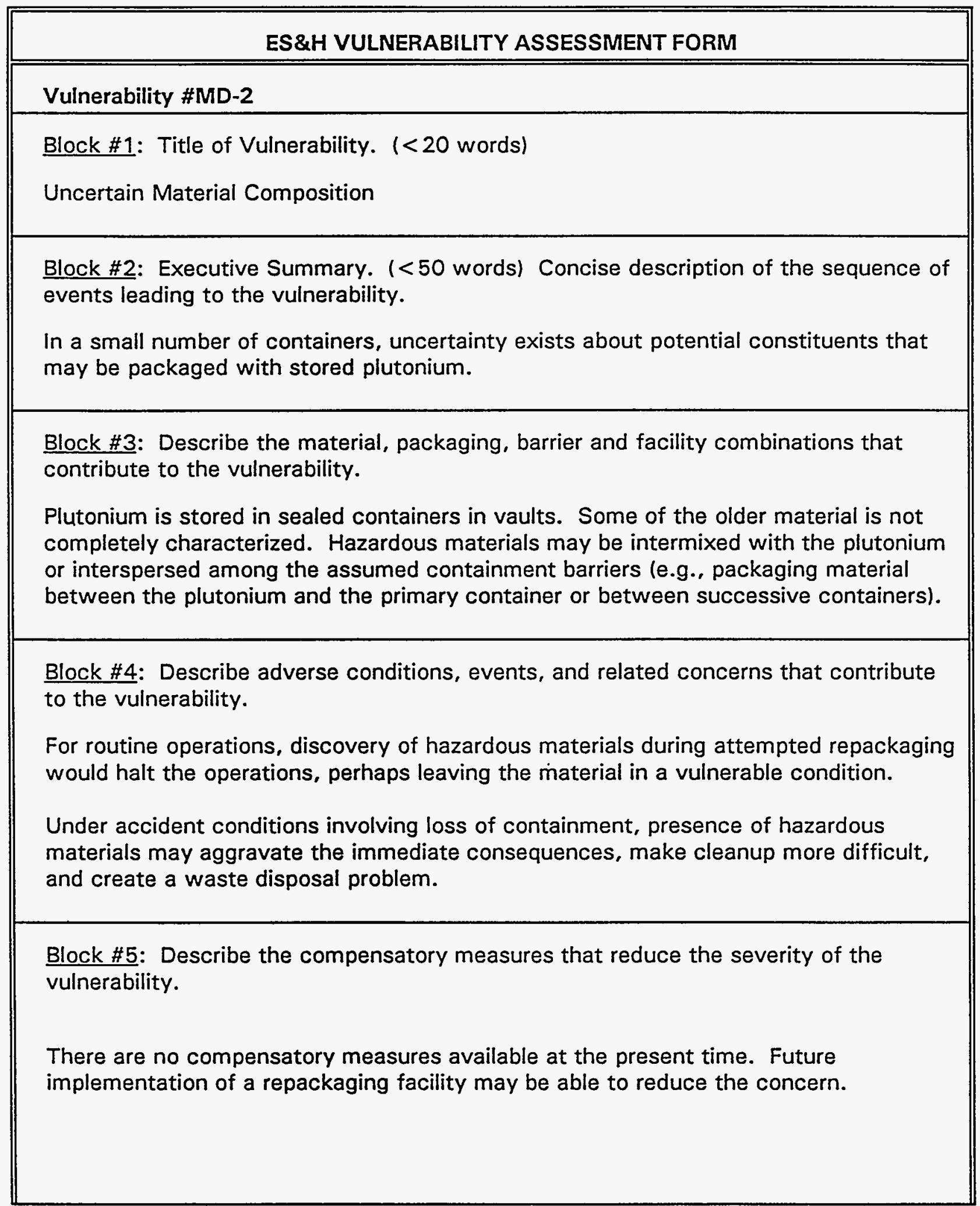




\begin{tabular}{|l|}
\hline \multicolumn{1}{|c|}{ ES\&H VULNERABILITY ASSESSMENT FORM } \\
\hline Vulnerability \#MD-2 \\
\hline $\begin{array}{l}\text { Block \#6: Describe the likelihood of the event which causes this vulnerability and } \\
\text { consequences which could result. } \\
\text { This is an existing condition of uncertainty. Consequences are the potential for a } \\
\text { slight increase in hazard to personnel if repackaging were performed or if an accident } \\
\text { occurred. }\end{array}$ \\
$\begin{array}{l}\text { Block \#7: Describe the timing of corrective actions (if any). Use the terms immediate } \\
\text { (imminent ES\&H issue), near-term (ES\&H issue that may become an imminent hazard } \\
\text { with further degradation), or longer term (ES\&H issues which are being mitigated by } \\
\text { barriers/compensatory measures). }\end{array}$
\end{tabular}

To be identified in the Site Corrective Action Plan.

Block \#8: Additional comments, views, or plans by the site operations office and M\&O Contractor to mitigate or minimize any potential vulnerability. 
ES\&H VULNERABILITY ASSESSMENT FORM

Vulnerability \#MD-2

Block \#9: Database Criteria. (Use identifiers from question set tables.)

List adverse conditions:

- Other co-located hazard's

List potential events/concerns:

- Worker exposure internal

- Contamination

Potential Consequences.

Environment Worker Safety and Health

- Ground

- Water

- Air

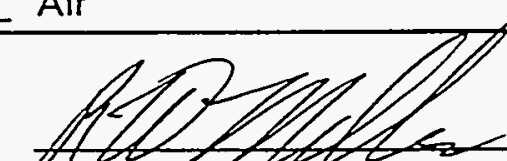

Signature, Team Member $\leq$ Contamination

- Exposure

_ Physical Injury
- Worker exposure - external

- Leakage/spills
Public Safety and Health

$\underline{L}$ Contamination

- Exposure

_ Physical Injury

\section{Allen Munt}

Signature, Team Leader 


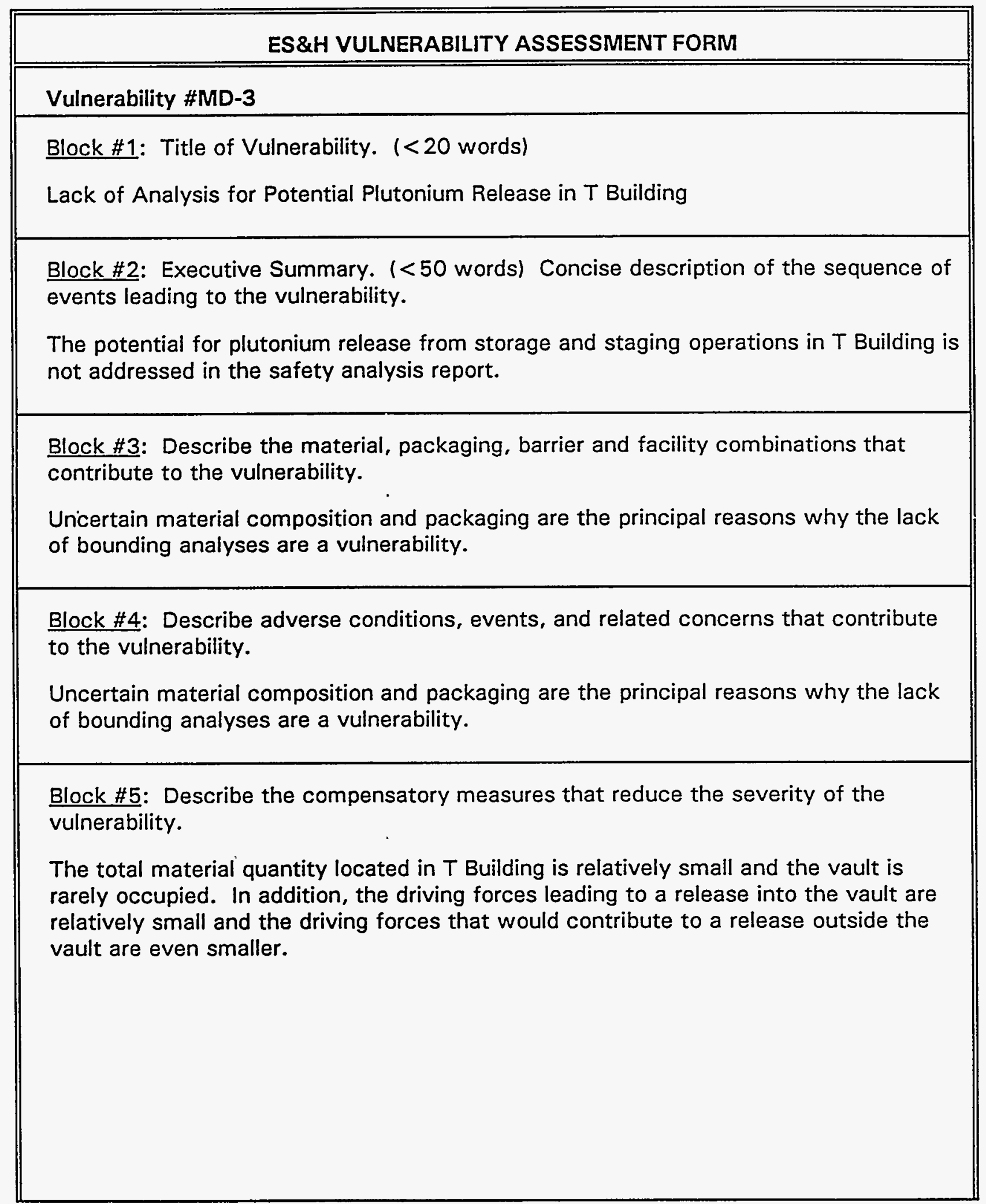




\begin{tabular}{|l||}
\hline \multicolumn{1}{|c||}{ ES\&H VULNERABILITY ASSESSMENT FORM } \\
\hline Vulnerability \#MD-3 \\
Block \#6: Describe the likelihood of the event which causes this vulnerability and \\
The likelihood of a plutonium release scenario in T Building is extremely low and the \\
consequences would most likely be limited to local contamination inside the vault and \\
potentially small releases into the areas adjacent to the vaults. \\
Block \#7: Describe the timing of corrective actions (if any). Use the terms immediate \\
(imminent ES\&H issue), near-term (ES\&H issue that may become an imminent hazard \\
with further degradation), or longer term (ES\&H issues which are being mitigated by \\
barriers/compensatory measures). \\
To be identified in the Site Corrective Action Plan. \\
Block \#8: Additional comments, views, or plans by the site operations office and \\
M\&O Contractor to mitigate or minimize any potential vulnerability. \\
Commitment from M\&O contractor to examine potential plutonium release scenarios \\
when new T Building SAR is drafted.
\end{tabular}


ES\&H VULNERABILITY ASSESSMENT FORM

Vulnerability \#MD-3

Block \#9: Database Criteria. (Use identifiers from question set tables.)

List adverse conditions:

- Inadequate

- Inadequate Seals

Configuration

Knowledge

- Pressurization

- Radioactivity

List potential events/concerns:

- Worker Exposure (Internal, External)

- Breach of Container

Potential Consequences.

Environment Worker Safety and Health Public Safety and Health

- Ground L L Contamination - Contamination

- Water L $L$ Exposure - Exposure

L Air

_ Physical Injury

_ Physical Injury

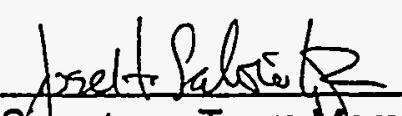




\begin{tabular}{|c|}
\hline ES\&H VULNERABILITY ASSESSMENT FORM \\
\hline Vulnerability \#MD-4 \\
\hline Block \#1: Title of Vulnerability. $\quad(<20$ words $)$ \\
\hline \\
\hline $\begin{array}{l}\text { Block \#2: Executive Summary. ( }<50 \text { words) Concise description of the sequence of } \\
\text { events leading to the vulnerability. }\end{array}$ \\
\hline $\begin{array}{l}\text { Several accident scenarios do not have quantitative assessments for all potential } \\
\text { recipients (e.g., workers, the public, and the environment). Although off-site } \\
\text { radiological consequences are analyzed quantitatively, potential consequences to on- } \\
\text { site recipients are only assessed qualitatively in the safety analysis reports. }\end{array}$ \\
\hline $\begin{array}{l}\text { Block \#3: Describe the material, packaging, barrier and facility combinations that } \\
\text { contribute to the vulnerability. }\end{array}$ \\
\hline Not Applicable \\
\hline $\begin{array}{l}\text { Block \#4: Describe adverse conditions, events, and related concerns that contribute } \\
\text { to the vulnerability. }\end{array}$ \\
\hline $\begin{array}{l}\text { Lack of thorough, quantitative analyses for all potential accident scenarios contributes } \\
\text { to uncertainties in emergency response, identification of critical safety systems, etc. }\end{array}$ \\
\hline $\begin{array}{l}\text { Block \#5: Describe the compensatory measures that reduce the severity of the } \\
\text { vulnerability. }\end{array}$ \\
\hline $\begin{array}{l}\text { The preparation of revised safety analysis reports in accordance with DOE Order } \\
5480.23 \text { will greatly reduce the uncertainties due to incomplete or qualitative } \\
\text { analyses. }\end{array}$ \\
\hline
\end{tabular}

July 18,1994 


\begin{tabular}{|l||}
\hline \multicolumn{1}{|c||}{ ES\&H VULNERABILITY ASSESSMENT FORM } \\
\hline \hline Vulnerability \#MD-4 \\
\hline Block \#6: Describe the likelihood of the event which causes this vulnerability and \\
consequences which could result. \\
Although the lack of quantitative analyses presents a lack of detailed knowledge, it is \\
believed that the likelihood of accident scenarios is essentially unchanged from those \\
identified in the approved and draft safety analysis reports (low probability). \\
Block \#7: Describe the timing of corrective actions (if any). Use the terms immediate \\
(imminent ES\&H issue), near-term (ES\&H issue that may become an imminent hazard \\
with further degradation), or longer term (ES\&H issues which are being mitigated by \\
barriers/compensatory measures). \\
To,be identified in the Site Corrective Action Plan. \\
Block \#8: Additional comments, views, or plans by the site operations office and \\
M\&O Contractor to mitigate or minimize any potential vulnerability. \\
The existing analyses indicate that the consequences of all accident scenarios \\
previously analyzed qualitatively have minor to negligible consequences. \\
$\cdot$
\end{tabular}

July 18,1994 


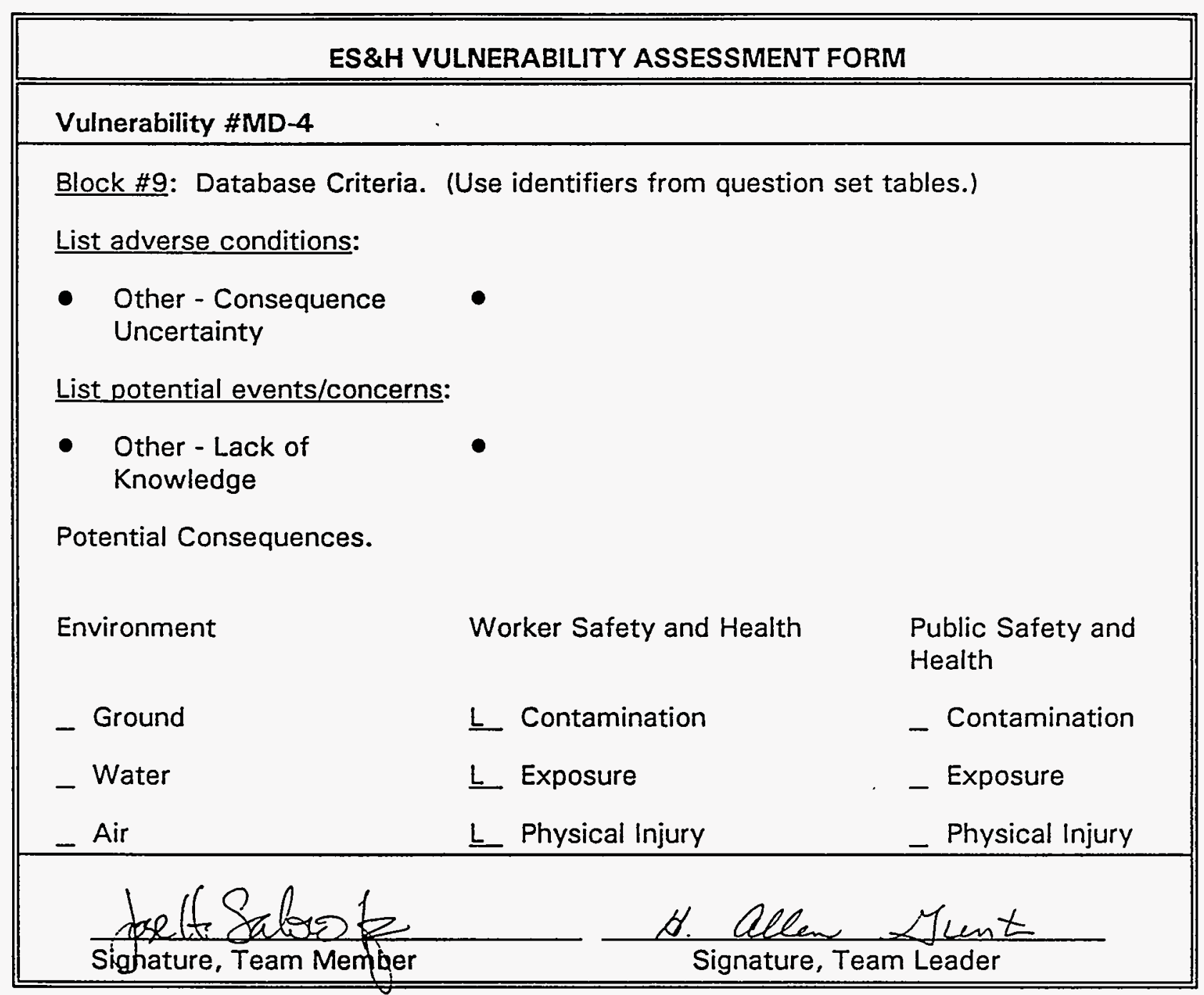




\begin{tabular}{|c|}
\hline ES\&H VULNERABILITY ASSESSMENT FORM \\
\hline Vulnerability \#MD-5 \\
\hline \multirow{2}{*}{$\begin{array}{l}\text { Block \#1: Title of Vulnerability. ( }<20 \text { words) } \\
\text { Incomplete Authorization Basis }\end{array}$} \\
\hline \\
\hline $\begin{array}{l}\text { Block \#2: Executive Summary. }(<50 \text { words) Concise description of the sequence of } \\
\text { events leading to the vulnerability. }\end{array}$ \\
\hline $\begin{array}{l}\text { The authorization basis for Buildings } T, S W / R \text {, and } 38 \text { are unclear due to the lack of } \\
\text { approved safety analysis reports and the lack of approved BIO documents. The } \\
\text { approved safety analysis reports do not contain current required analyses. }\end{array}$ \\
\hline $\begin{array}{l}\text { Block \#3: Describe the material, packaging, barrier and facility combinations that } \\
\text { contribute to the vulnerability. }\end{array}$ \\
\hline Not Applicable \\
\hline $\begin{array}{l}\text { Block \#4: Describe adverse conditions, events, and related concerns that contribute } \\
\text { to the vulnerability. }\end{array}$ \\
\hline $\begin{array}{l}\text { The work being performed in these building may not be bounded by the current } \\
\text { authorization basis, which was developed years before for previous missions. }\end{array}$ \\
\hline $\begin{array}{l}\text { Block \#5: Describe the compensatory measures that reduce the severity of the } \\
\text { vulnerability. }\end{array}$ \\
\hline $\begin{array}{l}\text { Revised safety analysis reports are currently being prepared for Building } 38 \text { and T } \\
\text { Building. Drafts of these reports are scheduled to be completed by January } 1995 \text {. } \\
\text { There are currently no plans to revise the draft } 1992 \text { SW/R safety analysis report. }\end{array}$ \\
\hline $\begin{array}{l}\text { Block \#6: Describe the likelihood of the event which causes this vulnerability and } \\
\text { consequences which could result. }\end{array}$ \\
\hline $\begin{array}{l}\text { The probability of consequences due to the potential lack of an authorization are } \\
\text { unknown, but are believed to be consistent with the current findings of the existing } \\
\text { and draft safety analysis report (i.e., low probability of plutonium release). }\end{array}$ \\
\hline
\end{tabular}




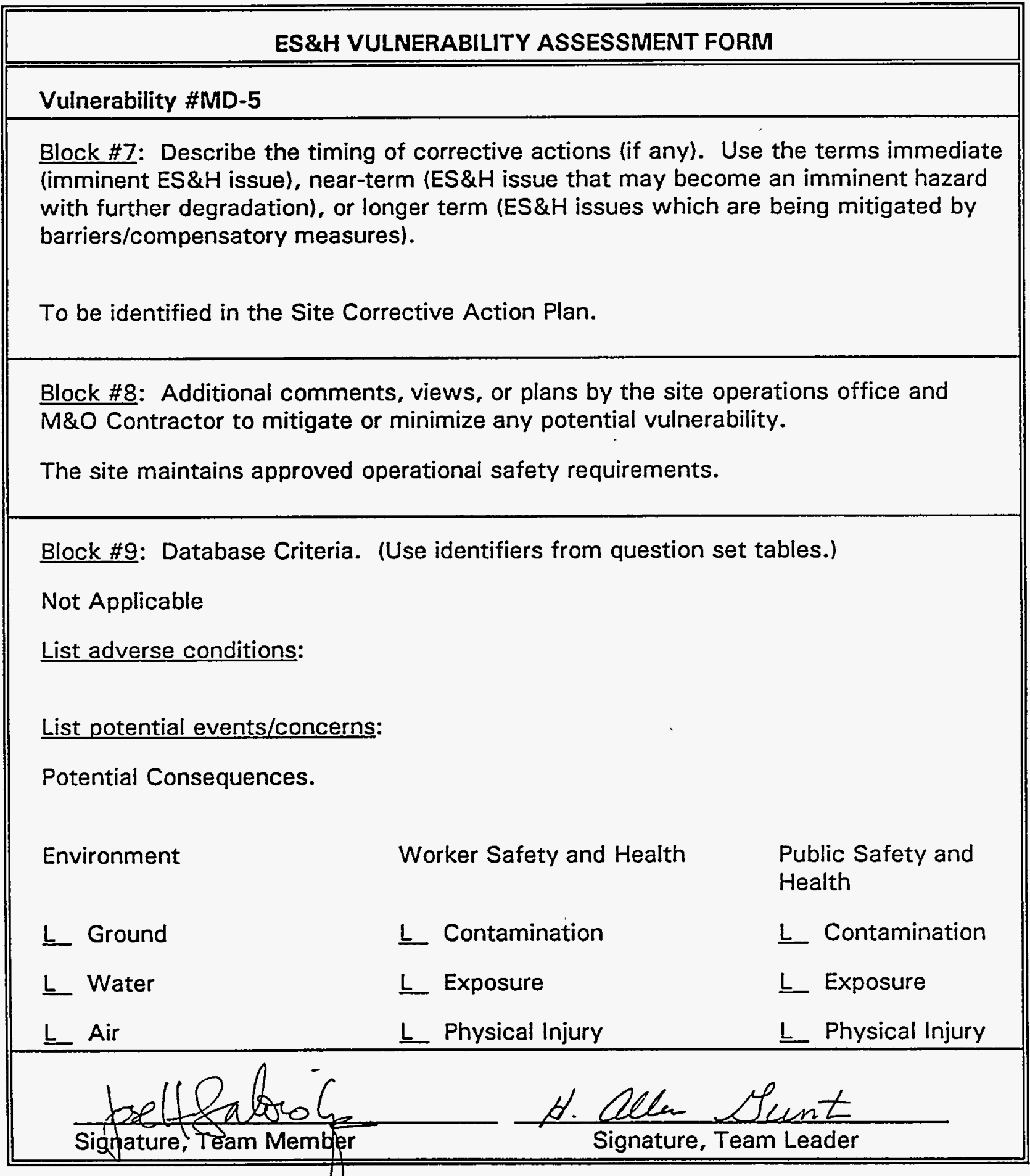

July 18,1994 


\begin{tabular}{|c|}
\hline ES\&H VULNERABILITY ASSESSMENT FORM \\
\hline Vulnerability \#MD-6 \\
\hline Block \#1: Title of Vulnerability. ( $<20$ words) \\
\hline Excess Fire Loading in Buildings 38 and SW/R \\
\hline $\begin{array}{l}\text { Block \#2: Executive Summary. ( }<50 \text { words) Concise description of the sequence of } \\
\text { events leading to the vulnerability. }\end{array}$ \\
\hline $\begin{array}{l}\text { Excessive fire loading in the A-line glovebox in Buildings } 38 \text { and a glovebox in one } \\
\text { room in Building SW/R exist as a result of inadequate limits, procedures, or practices, } \\
\text { and/or as a result of failure in conduct of operations. }\end{array}$ \\
\hline $\begin{array}{l}\text { Block \#3: Describe the material, packaging, barrier and facility combinations that } \\
\text { contribute to the vulnerability. }\end{array}$ \\
\hline Plutonium inventory located in gloveboxes is at risk if a fire initiates. \\
\hline $\begin{array}{l}\text { Block \#4: Describe adverse conditions, events, and related concerns that contribute } \\
\text { to the vulnerability. }\end{array}$ \\
\hline $\begin{array}{l}\text { Excessive combustible loading leads to a higher fire initiation probability than } \\
\text { necessary. The success of fire suppression equipment is also diminished if the fire } \\
\text { loading is high. }\end{array}$ \\
\hline $\begin{array}{l}\text { Block \#5: Describe the compensatory measures that reduce the severity of the } \\
\text { vulnerability. }\end{array}$ \\
\hline In-glovebox fire suppression system, SW/R glovebox inerted, periodic housekeeping. \\
\hline $\begin{array}{l}\text { Block \#6: Describe the likelihood of the event which causes this vulnerability and } \\
\text { consequences which could result. }\end{array}$ \\
\hline $\begin{array}{l}\text { The likelihood that a fire initiates in the gloveboxes in Building } 38 \text { and SW/R is } \\
\text { extremely small, even with a higher-than-necessary fire loading present in the } \\
\text { gloveboxes. }\end{array}$ \\
\hline
\end{tabular}




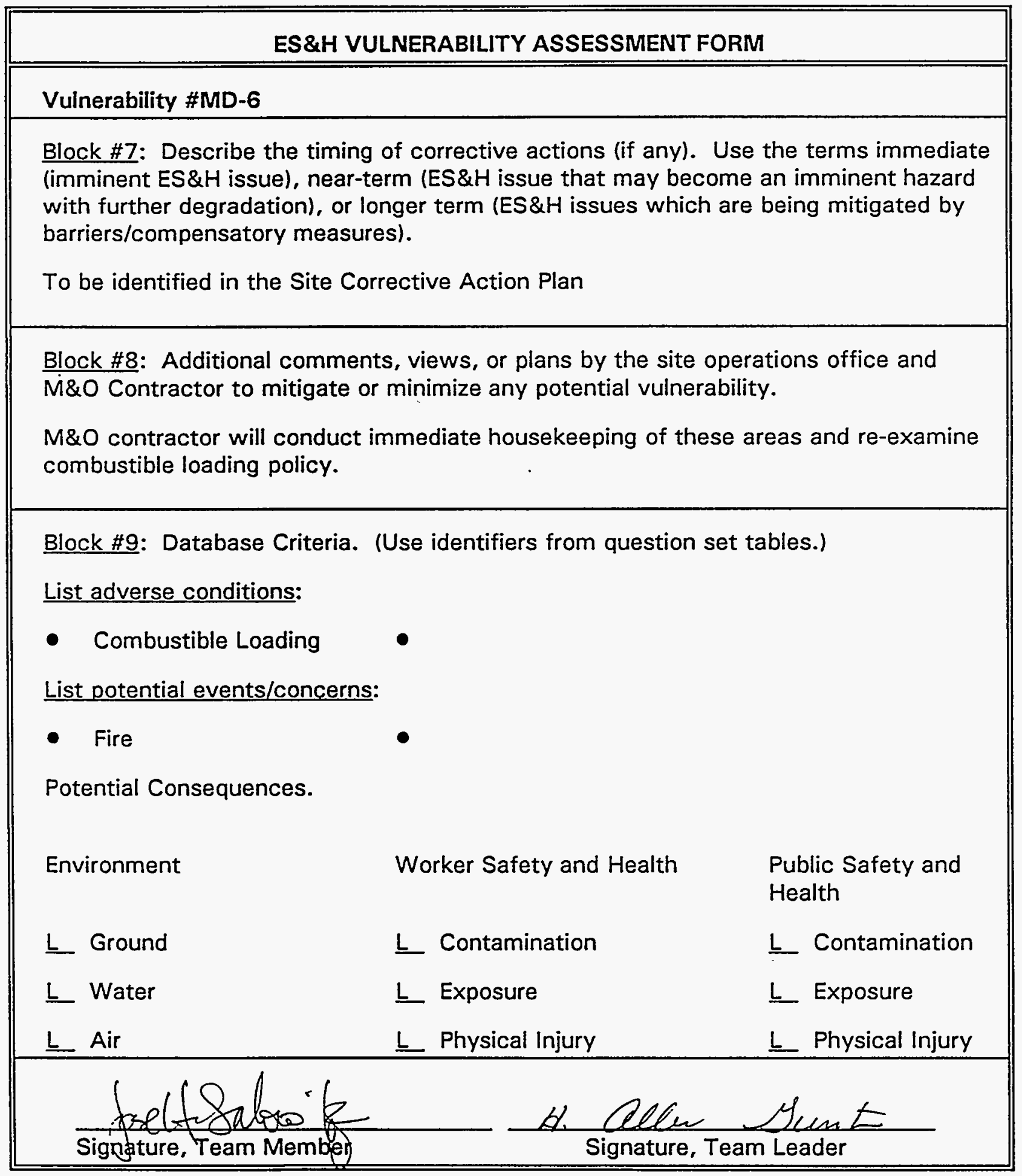

July 18,1994 


\begin{tabular}{|c|}
\hline ES\&H VULNERABILITY ASSESSMENT FORM \\
\hline Vulnerability \#MD-7 \\
\hline Block \#1: Title of Vulnerability. $(<20$ words) \\
\hline Non-Adherence to Existing ALARA Program \\
\hline $\begin{array}{l}\text { Block \#2: Executive Summary. ( }<50 \text { words) Concise description of the sequence of } \\
\text { events leading to the vulnerability. }\end{array}$ \\
\hline $\begin{array}{l}\text { Gloveboxes in Building } 38 \text { were not labelled with the current radiation dose rates. } \\
\text { Poor housekeeping in gloveboxes located in Building SW/R and Building } 38 \text { can lead to } \\
\text { higher radiation exposure to workers. A vault in Building } 38 \text { was not visibly posted as } \\
\text { a high radiation area. There was a lack of attentiveness to the most advantageous } \\
\text { place to conduct business to reduce exposure in Building } 38, \text { SW/R and T. There was } \\
\text { no monitoring upon final exiting of the radiologically controlled area in SW/R. }\end{array}$ \\
\hline $\begin{array}{l}\text { Block \#3: Describe the material, packaging; barrier and facility combinations that } \\
\text { contribute to the vulnerability. }\end{array}$ \\
\hline $\begin{array}{l}\text { Plutonium and other radioactive materials provide the radiation and contamination that } \\
\text { may lead to increased worker exposure. }\end{array}$ \\
\hline $\begin{array}{l}\text { Block \#4: Describe adverse conditions, events, and related concerns that contribute } \\
\text { to the vulnerability. }\end{array}$ \\
\hline $\begin{array}{l}\text { The issues described in Block \#2 can lead to increased worker exposure to radiation } \\
\text { and contamination. }\end{array}$ \\
\hline $\begin{array}{l}\text { Block \#5: Describe the compensatory measures that reduce the severity of the } \\
\text { vulnerability. }\end{array}$ \\
\hline $\begin{array}{l}\text { Increase rigor in the radiation protection program through } 1 \text { ) training, 2) feedback to } \\
\text { employees by supervisors and health physics personnel, and 3) modification of } \\
\text { radiological procedures. }\end{array}$ \\
\hline
\end{tabular}




\begin{tabular}{|c|}
\hline ES\&H VULNERABILITY ASSESSMENT FORM \\
\hline Vulnerability \#MD-7
\end{tabular}

Block \#6: Describe the likelihood of the event which causes this vulnerability and consequences which could result.

The probability of increased exposure to a worker is $100 \%$.

Block \#7: Describe the timing of corrective actions (if any). Use the terms immediate (imminent ES\&H issue), near-term (ES\&H issue that may become an imminent hazard with further degradation), or longer term (ES\&H issues which are being mitigated by barriers/compensatory measures).

To be identified in the Site Corrective Action Plan.

Block \#8: Additional comments, views, or plans by the site operations office and M\&O Contractor to mitigate or minimize any potential vulnerability.

The contractor is in the process of modifying its radiation protection program per the requirements of the Radiological Control Manual and 10 CFR 835. 


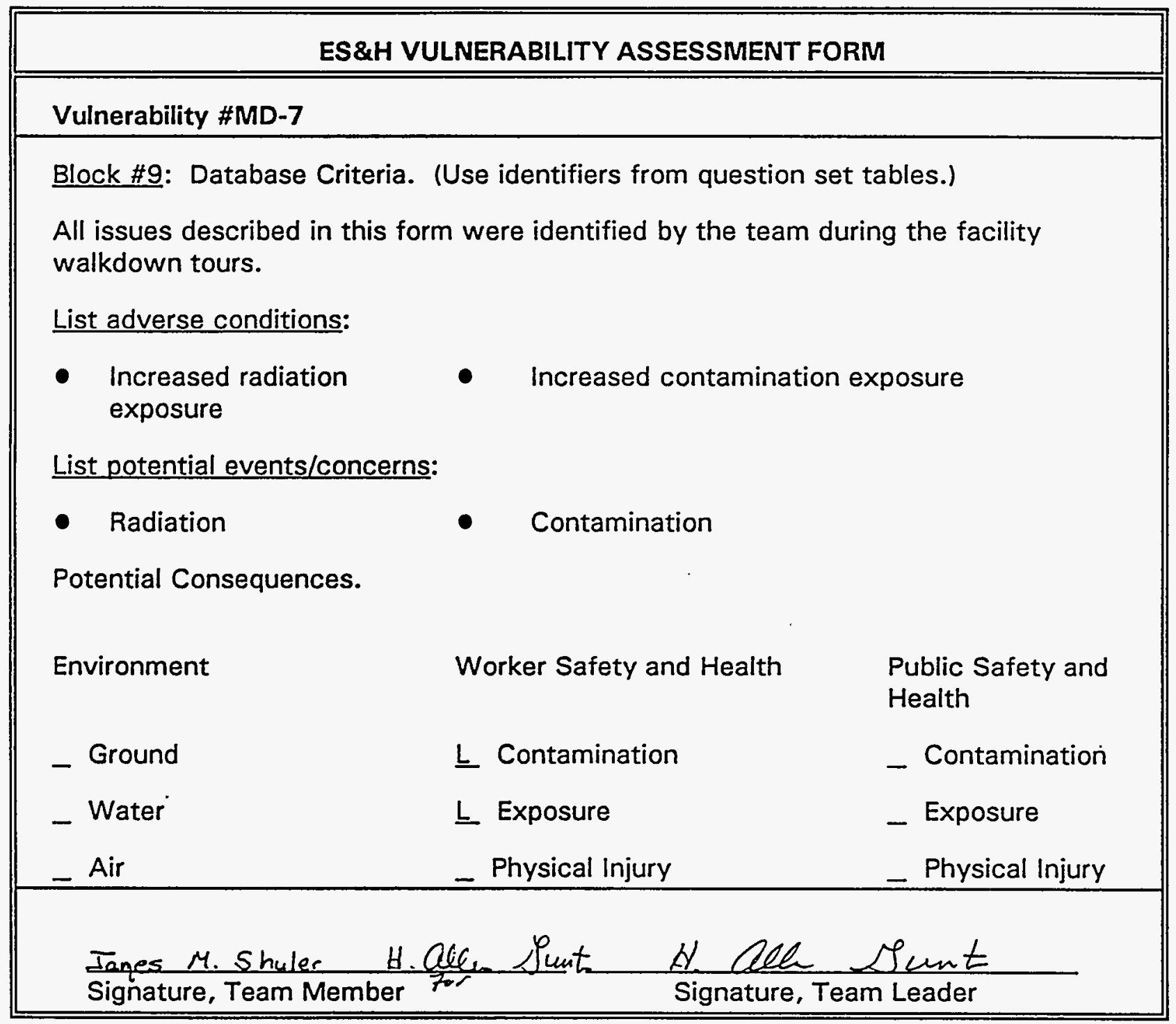




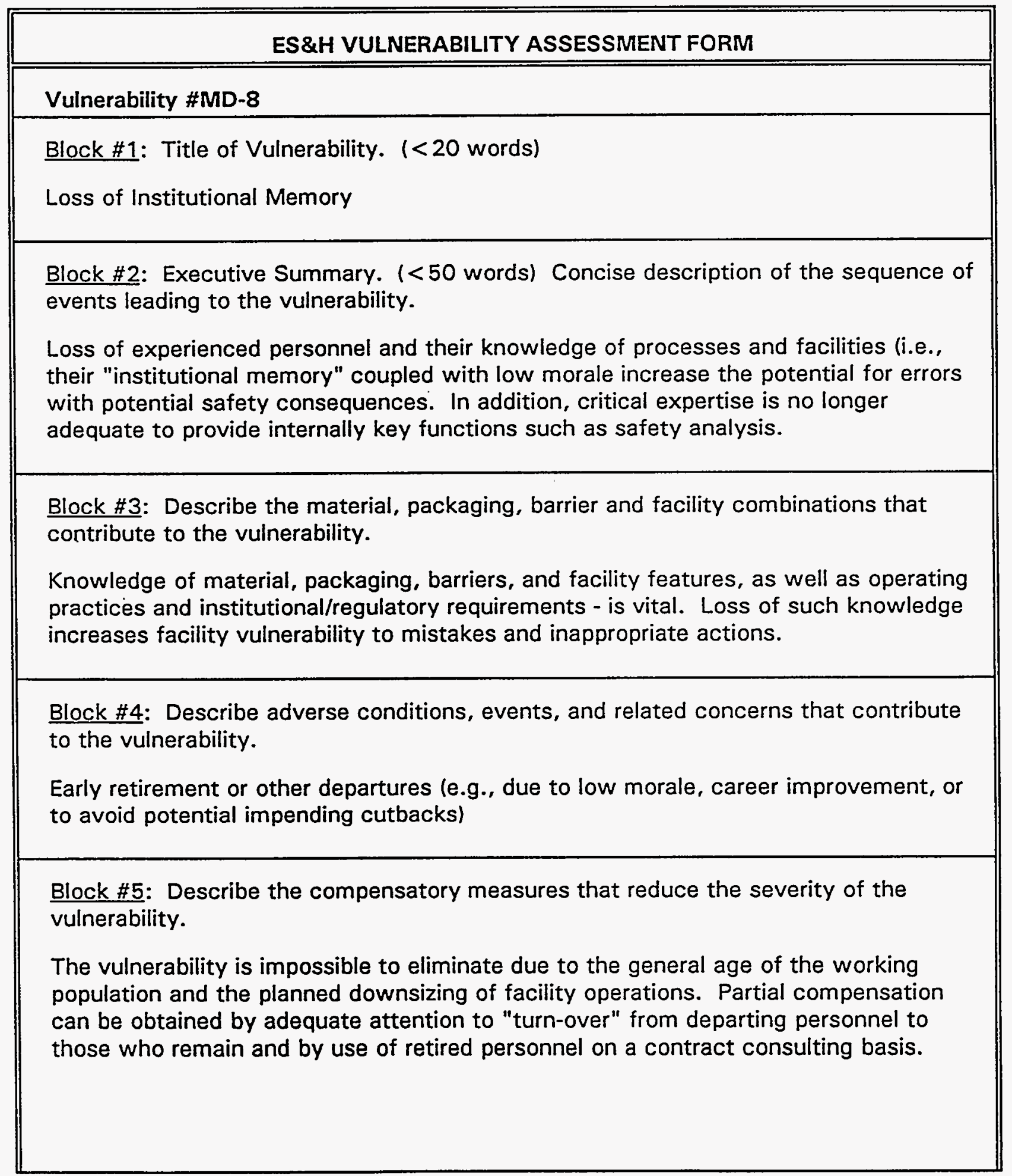

\section{A-21}

July 18, 1994 


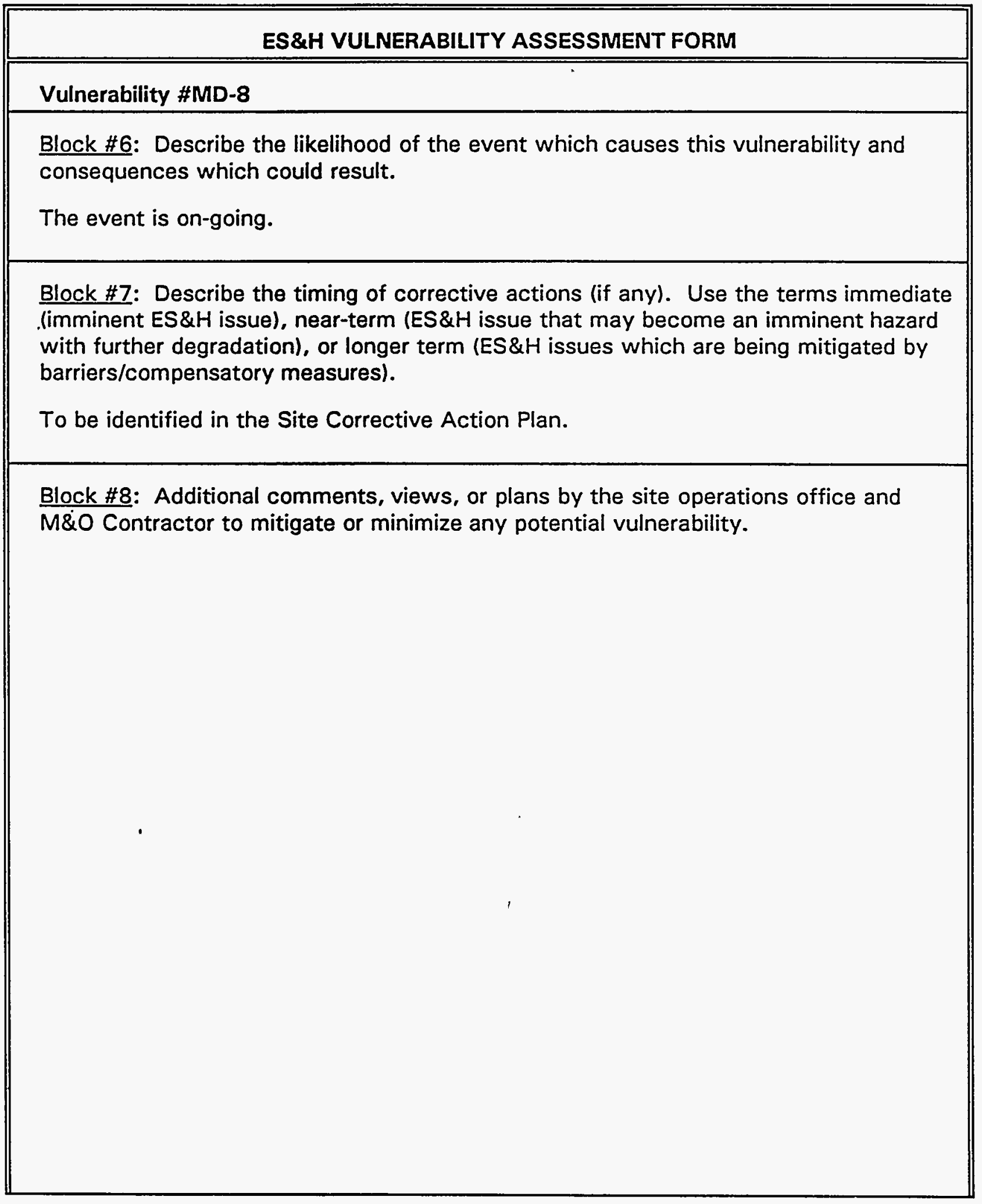




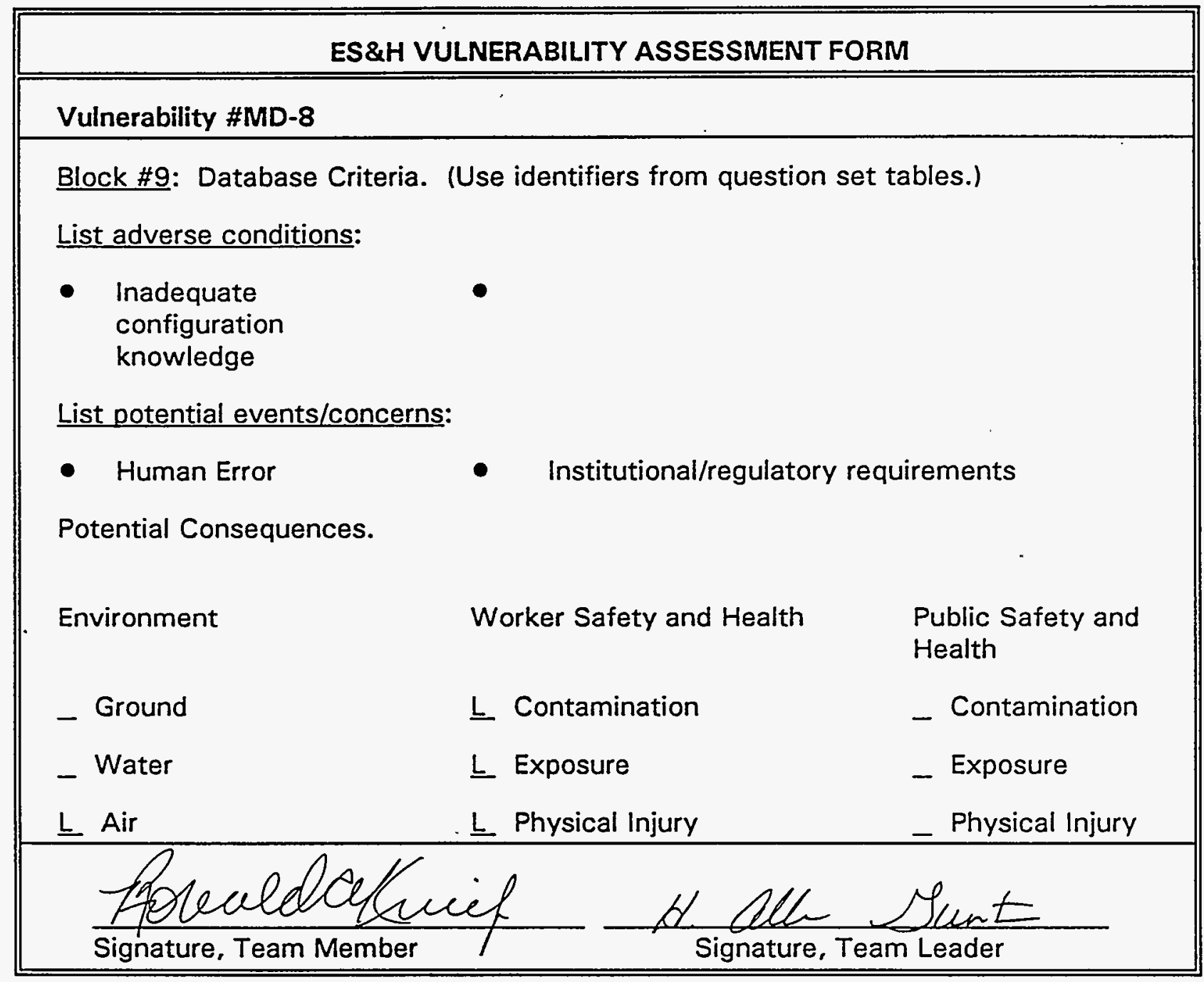




\begin{tabular}{|c|}
\hline ES\&H VULNERABILITY ASSESSMENT FORM \\
\hline Vulnerability \#MD-9 \\
\hline Block \#1: Title of Vulnerability. ( $<20$ words) \\
\hline Unneeded Plutonium Stored On-Site \\
\hline $\begin{array}{l}\text { Block \#2: Executive Summary. ( }<50 \text { words) Concise description of the sequence of } \\
\text { events leading to the vulnerability. }\end{array}$ \\
\hline $\begin{array}{l}\text { Essentially all weapon-grade plutonium and certain heat-source-grade plutonium stored } \\
\text { on the Mound site has no identified mission and, thus, is unneeded. A majority of the } \\
\text { other identified vulnerabilities would be reduced significantly or, possibly, eliminated if } \\
\text { such material were transferred to a DOE site having an inventory of similar material. } \\
\text { DOE has no written plan to facilitate such transfer. }\end{array}$ \\
\hline $\begin{array}{l}\text { Block \#3: Describe the material, packaging, barrier and facility combinations that } \\
\text { contribute to the vulnerability. }\end{array}$ \\
\hline $\begin{array}{l}\text { See VAF MD-2, "Uncertain Material Composition," and MD-10, "Package } \\
\text { Uncertainties." }\end{array}$ \\
\hline $\begin{array}{l}\text { Block \#4: Describe adverse conditions, events, and related concerns that contribute } \\
\text { to the vulnerability. }\end{array}$ \\
\hline $\begin{array}{l}\text { See VAFs MD-2, "Uncertain Material Composition," and MD-10, "Package } \\
\text { Uncertainties." }\end{array}$ \\
\hline $\begin{array}{l}\text { Block \#5: Describe the compensatory measures that reduce the severity of the } \\
\text { vulnerability. }\end{array}$ \\
\hline Transfer the plutonium to a DOE site having a large inventory of similar material \\
\hline $\begin{array}{l}\text { Block \#6: Describe the likelihood of the event which causes this vulnerability and } \\
\text { consequences which could result. }\end{array}$ \\
\hline This is an existing condition. See also MD-2 and MD-10. \\
\hline
\end{tabular}




\section{ES\&H VULNERABILITY ASSESSMENT FORM}

\section{Vulnerability \#MD-9}

Block \#7: Describe the timing of corrective actions (if any). Use the terms immediate (imminent ES\&H issue), near-term (ES\&H issue that may become an imminent hazard with further degradation), or longer term (ES\&H issues which are being mitigated by barriers/compensatory measures).

To be identified in the Site Corrective Action Plan.

Block \#8: Additional comments, views, or plans by the site operations office and M\&O Contractor to mitigate or minimize any potential vulnerability. 


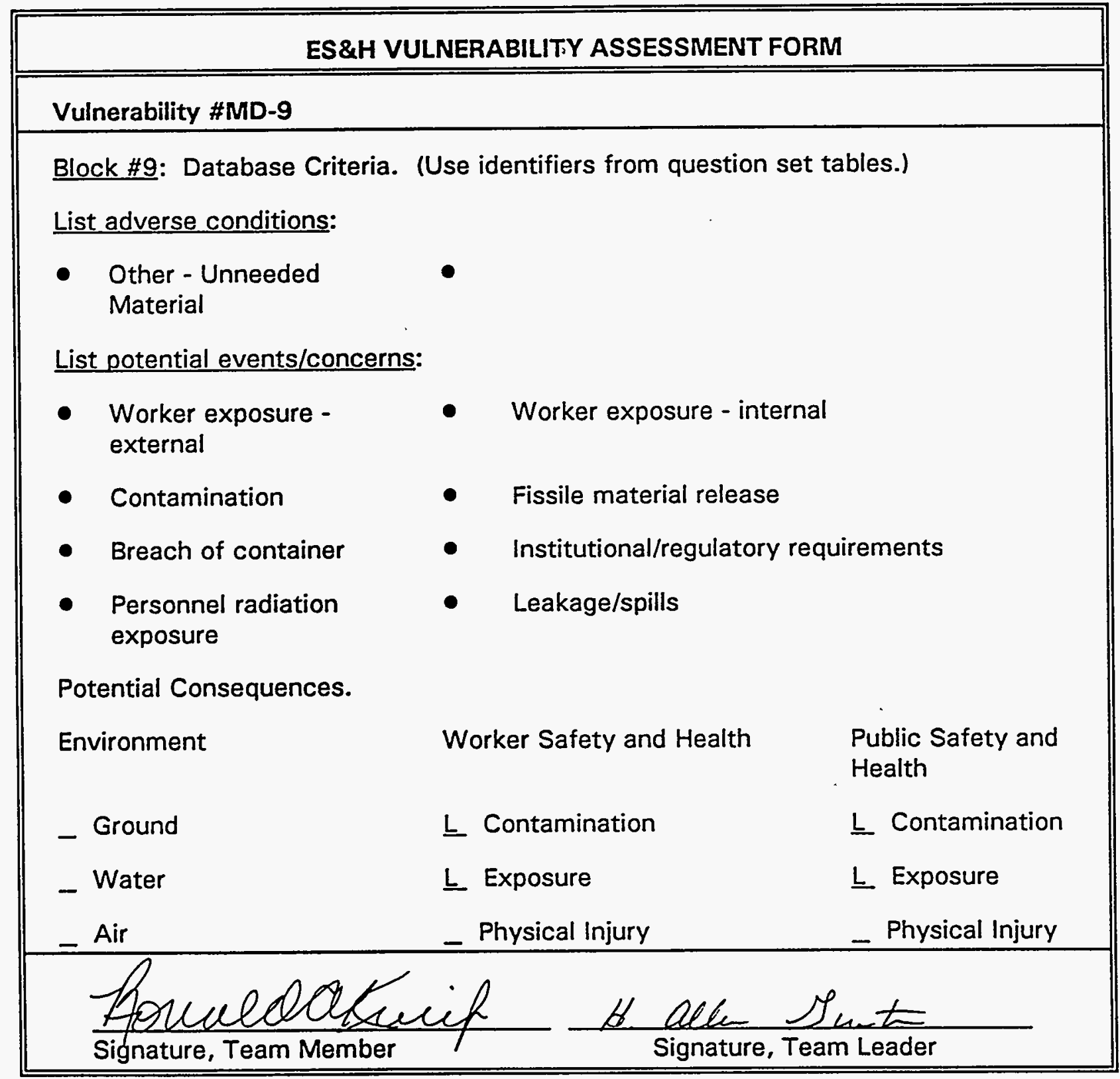


Mound

Vulnerability Assessment Forms for the following are contained in Appendix B, Mound Site Assessment Team Report. The numbers in brackets correspond to the numbers assigned in Appendix B:

MD-10 [1] Packaging Uncertainties

MD-11 [2] Holdup in Process Equipment

MD-12 [3] Response of Facilities to Accidents Caused by Natural Phenomena 
Mound

APPENDIX B

MOUND SITE ASSESSMENT TEAM REPORT

See Volume II, Appendix B

Part 7 
Mound

\section{APPENDIX C \\ WORKING GROUP ASSESSMENT TEAM MEMBERS}

Page C-1

July 18,1994 
Mound

NAME: $\quad$ Ronald R. Borisch

EDUCATION: Master of Science-Metallurgy

EXPERTISE: Plutonium Technology, Process Safety

EXPERIENCE: Mr. Borisch has more than 25 years of experience in engineering and technical management. He is currently employed by Westinghouse Hanford Company, in Transition Program Management, providing program direction in the transitioning of Hanford's old defense weapons plants for decommissioning and nuclear materials management. Mr. Borisch has had technical and programmatic responsibilities in the U.S. Department of Energy's cleanup efforts at Hanford in WA., West Valley in New York, and Three Mile Island in PA. Previous to the current position he spent a year as engineering manager at Hanford's Plutonium Finishing Plant and seven years in charge of project engineering for all of West Valley's High Level Waste cleanup projects.

NAME: $\quad$ H. Allen Gunter

EDUCATION: B.S., Ceramic Engineering

EXPERTISE: $\quad$ Plutonium Operations, Maintenance, and Management

EXPERIENCE: Mr. Gunter has over 12 years experience in plutonium operations. He currently works for the U.S. Department of Energy, Savannah River, as the Team Leader for the Plutonium Program providing technical support for the overall operations including operations, maintenance, safety, environment, etc.. Mr. Gunter has served on various committees for DOE evaluating production and safety issues for plutonium operations within the Weapons Complex. Mr. Gunter has also served as the Lead Engineer for Savannah River for operations and the shipment of product for the uranium processing facilities. 
Mound

NAME: $\quad$ Ronald A. Knief

EDUCATION: B.A., Physics, Mathematics, \& Economics

Ph.D., Nuclear Engineering

EXPERTISE: Nuclear Criticality Safety, Safety Analysis

EXPERIENCE: Dr. Knief has more than 28 years experience in nuclear safety assessment, management-system evaluation, and performance-based training. He is currently employed by Ogden Environmental and Energy Services as principal consultant. Dr. Knief has conducted safety and management evaluations and served on safety committees for Department of Energy contractor and Nuclear Regulatory Commission licensee organizations. He alșo managed a radiological assessment, performed criticality and radiation-dose calculations for safety analysis reports, and prepared a report validating the criticality alarm exemption for the Pantex Plant. His previous experience includes six years as professor of chemical and nuclear engineering at the University of $\mathrm{New}$ Mexico and ten years managing various training and technical activities at the Three Mile Island Nuclear Station. Dr. Knief also is author of textbooks on nuclear engineering and nuclear criticality safety, editor of two books on risk management, developer and lead instructor for the University of New Mexico Nuclear Criticality Safety Short Courses, and an active member of the American Nuclear Society's Nuclear Criticality Safety and Education \& Training Divisions.

NAME: $\quad$ Robert A. Marshall

EDUCATION: Master of Business Administration

EXPERTISE: Safeguards and Security

EXPERIENCE: Mr. Marshall has 12 years experience in the nuclear security field. in addition to his extensive management and nuclear background, he has broad hands-on experience with ASSESS, VISA, timeline analysis and table-top modeling. He was the lead analyses for the Safeguards and Security Vulnerability Assessment ASSESS for Rocky Flats Plant Building 771 and assisted in the VA for Rocky Flats Plant Building 371. He was the lead analyst for the Summary Vulnerability Assessment Report for the Pu Brushing Operation Health Safety Program (HSP) 31.11 for Building 779 and was selected to lead a second HSP $31.11 \mathrm{VA}$ in July 1993. He assisted in the completion of Summary Variance Analysis Reports on the One Person Rule for Building 771 and the movement and storage from Building 991 to Building 371 . He also has an extensive background in performance testing from the Army and Rocky Flats Plant.
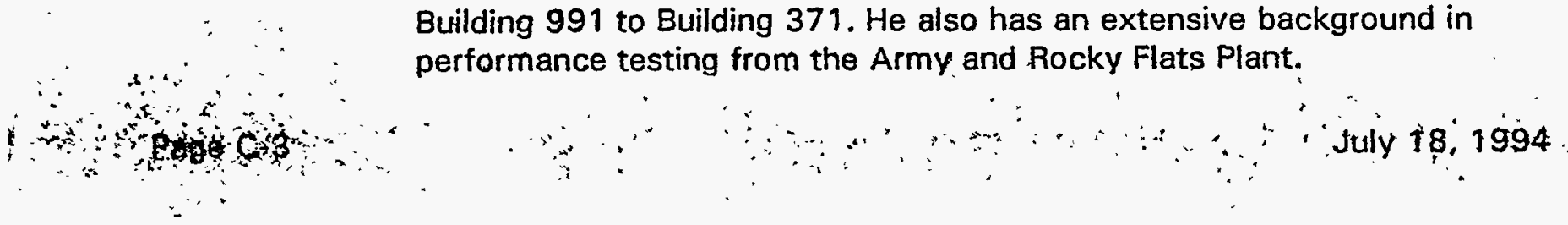
Mound

NAME: $\quad$ Richard W. Miller

EDUCATION: B.S. Physics

EXPERTISE: Nuclear Safety

EXPERIENCE: Over 38 years experience in nuclear safety, safety analysis, nuclear reactors, nuclear experimental programs, technical management, nuclear sciences, environmental and waste management projects, Environmental Protection Agency (EPA) Regulation, Department of Energy and Nuclear Regulatory Commission special projects, and technical management. Currently principal program specialist at the Idaho National Engineering Laboratory. Mr. Miller served on the steering group for DOE initiatives to determine vulnerabilities of spent nuclear fuel; DOE-NE study to strengthen DOE Standards (Orders, Rules, Standards, SEN notices, etc.); management of Technical Services to Rocky Flats Nuclear Safety Department; co-investigator for DOE-DP Generic Issues Program, and DOE-EH Progress Assessments Program.

NAME: $\quad$ Paula Olson

EDUCATION: Legal Secretary, Certified

EXPERTISE: Administrative specialist coordinating on/off-site teams

EXPERIENCE: Ms. Olson has more than 5 years experience in providing organizational support. Ms. Olson is currently employed at the Idaho National Engineering Laboratory as a senior administrative specialist with the Department of Energy and Nuclear Regulatory Commission Support Programs, providing support to an immediate staff of thirty. Active participant on Type A accident investigation boards in producing event and causal factor charts and MORT charts. 
Mound

NAME: $\quad$ Jose H. Saloio, Jr.

EDUCATION: B.S., Chemical Engineering

M.B.A., Finance \& Economics

EXPERTISE: Safety Analysis

EXPERIENCE: Mr. Saloio has 11 years of experience performing system analysis and risk assessment studies of several applications of nuclear and chemical technology, including weapon manufacturing and dismantlement, power plant operations, and other research and production processes at U.S. Department of Energy and U.S. Nuclear Regulatory Commission licensed facilities. He has performed and managed safety analysis efforts at several DOE facilities and maintains a current understanding of DOE safety and risk analysis policy. Mr. Saloio is currently employed by Ogden Environmental and Energy Services Company as a senior consultant, providing technical support to the DOE and its contractors in the areas of safety/risk analysis, weapons dismantlement, waste minimization, and optimization modeling.

NAME: James M. Shuler

EDUCATION: M.S., Radiation Science (Health Physics Option)

M.A., Management \& Supervision

B.S., Botany

EXPERTISE: Hèalth Physics, Transportation and Packaging

EXPERIENCE: Mr. Shuler has over 19 years experience in radiation protection. He currently works for the U.S. Department of Energy, EH-332, as a physical scientist. Previously, Mr. Shuler was a Senior Health Physicist with DP-9 and DP-35 where he served as a mentor to the Los Alamos National Laboratory. Mr. Shuler has also worked at the Savannah River Field Office, U.S. Department of Transportation, Applied Technology of Barnwell, Inc., Chem Nuclear Systems, Inc., and Allied-General Nuclear Services. Mr. Shuler is a Registered Radiation Protection Technologist, a Certified Hazardous Materials Manager, a Certified Hazard Control Manager, a Certified Environmental Trainer and a Registered Environmental Manager. 
Mound

NAME: $\quad$ William C. White

EDUCATION: B.A., Government

M.A., Public Administration

EXPERTISE: Plutonium Management, Operations and Maintenance

EXPERIENCE: Mr. White has 19 years experience in the nuclear field. He is currently employed as a program analyst, in the Office of Nuclear Weapons Management, Office of Defense Programs, U.S. Department of Energy. $\mathrm{He}$ is a materials manager (Plutonium), and manages economic discard limit, and surplus nuclear material disposition. Mr. White served on the Plutonium Strategy Task Force, and represented his office on the joint Mixed Waste Residue Program. Mr. White's previous experience includes serving as an assistant to the Secretary of the U.S. Nuclear Regulatory Commission and as a senior accountant for the Controller, U.S.

Department of Energy, in the area of financial policy of Defense issues. 
. 
Mound

APPENDIX D

VULNERABILITY EVALUATION MATRIX

This appendix contains; 1) matrix graphically portraying consequence-versus-probability for each recipient (worker, public or environment) to indicate severity of each vulnerability; and 2) the relative prioritization of each vulnerability found at Mound.

Worker Safety and Health Priorities

\begin{tabular}{|c|c|c|c|}
\cline { 2 - 4 } \multicolumn{1}{c|}{} & High & Medium & Low \\
\hline \hline High & & & 1,7 \\
\hline Medium & & & \\
\hline Low & $2,9,10$ & 6 & $3,4,5,8,11,12$ \\
\hline N/A & & & \\
\hline
\end{tabular}

$\uparrow$ Increasing

Likelihood

Public Safety and Health Priorities

\begin{tabular}{|c|c|c|c||}
\cline { 2 - 4 } \multicolumn{1}{c|}{} & High & Medium & Low \\
\hline \hline High & & & \\
\hline Medium & & & $3,4,5,6,8,11,12$ \\
\hline Low & $2,9,10$ & & \\
\hline N/A & 1,7 & & Increasing Consequences \\
\hline
\end{tabular}

$\uparrow$ Increasing

Likelihood 
Environmental Damage Priorities

\begin{tabular}{|c|c|c|c|}
\cline { 2 - 4 } \multicolumn{1}{c|}{} & High & Medium & Low \\
\hline \hline High & & & \\
\hline Medium & & & $3,4,5,6,8,11,12$ \\
\hline Low & $2,9,10$ & & \\
\hline N/A & 1,7 & & \\
\hline
\end{tabular}

$\uparrow$ Increasing Likelihood 
Mound

The following table provides the prioritization by the WGAT of the identified vulnerabilities.

\begin{tabular}{|c|c|c|}
\hline \multirow{2}{*}{$\begin{array}{l}\text { Priority } \\
\text { Ranking }\end{array}$} & \multicolumn{2}{|r|}{ Vulnerability } \\
\hline & $\begin{array}{l}\text { Identification } \\
\text { Number }\end{array}$ & Title \\
\hline 1 & MD-9 & Unneeded Plutonium Stored On-Site \\
\hline 2 & $M D-10$ & Packaging Uncertainties \\
\hline 3 & MD-2 & Uncertain Material Composition \\
\hline 4 & MD-8 & Loss of Institutional Memory \\
\hline 5 & $\mathrm{MD}-1$ & Safeguards and Security Versus Radiological Safety \\
\hline 6 & MD-5 & Incomplete Authorization Basis \\
\hline 7 & MD-4 & Lack of Thorough Assessment of Consequences \\
\hline 8 & MD-3 & $\begin{array}{l}\text { Lack of Analysis for Potential Plutonium Release in } T \\
\text { Building }\end{array}$ \\
\hline 9 & MD-12 & $\begin{array}{l}\text { Response of Facilities to Accidents Caused by Natural } \\
\text { Phenomena }\end{array}$ \\
\hline 10 & MD-6 & Excess Fire Loading in Buildings 38 and SW/R \\
\hline 11 & MD-11 & Holdup in Process Equipment \\
\hline 12 & MD-7 & Non-Adherences to Existing ALARA Program \\
\hline
\end{tabular}




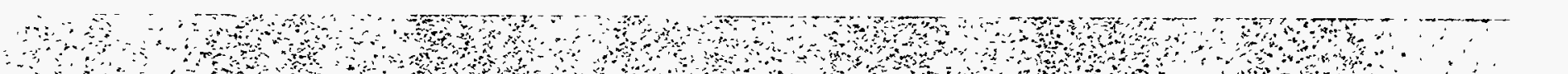


Mound

\author{
APPENDIX E \\ PUBLIC PARTICIPATION
}

Participation of the public, particularly stakeholders, was encouraged by the Department from the outset of this project, and built into the Project Plan [Ref. 1]. Implementation of this policy takes place at each of the visited sites. Field Offices issue public notices of the upcoming assessments, and stakeholders of record are notified directly and invited to attend the In-briefing and Exit-Briefing meetings, and to participate in the meetings to ensure that their concerns are expressed. The following are reviews of the proceedings of those two meetings at Mound.

In-Briefing:

Three public stakeholders attended the In-Briefing which took place at 1:00 PM on Monday, May, 23, 1994. They were:

- Velma Shearer representing "Neighbors in Need"

- Sharon Cowdrey representing the "Miamisburg Environmental Safety and Health," and

- Jeff Smith representing the Ohio Environmental Protection Agency (EPA).

The meeting was introduced by Mr. Tim Frazier of the local DOE office who then introduced the leader of the Working Group Assessment Team, Mr. Allen Gunter. Mr Gunter spoke from a set of slides (reproduced below) which described the background, purpose and modus operandi of the plutonium vulnerability ștudy. The following is an effort to characterize the nature of the audience participation during and after the presentation by $\mathrm{Mr}$. Gunter. Although most of the questions asked or comments given during the meeting (usually by a stakeholder), are represented here on a best effort basis, no claim is made here that this accounting of the meeting is either total or accurate. Each comment or question is followed usually by a summary of the response (in parentheses) given either by the principal speaker or a representative of Mound. Stakeholders are referred to as "visitors." (Where the originator of a comment or question is not given, a "visitor" is implied.)

\title{
Comments and Questions:
}

- Referring to a slide showing plastic bottles used to store plutonium at another site, a visitor asked the size of the bottles. (Answer: one to one and one half liter)

- asked how many stakeholders had actually been invited to the In-Briefing (Answer: 28). 
Mound

- thought that there were only 4 to 7 sites to be visited. (There are 11)

- asked that the isotopes of interest to the assessment be listed again. (This was done)

- wanted additional information on why the eleven sites were selected. (This was done.)

- $\quad$ asked if the stakeholders could participate in the actual assessment, that is, beyond the In-Brief. (Answer: No, due to classified nature)

- $\quad$ asked if any other organizations be involved.

- asked what documents the WGAT will be looking at. (The speaker listed several, including SARs, BIOs...)

- implied that the Team would not actually WALK the site. (yes, the team will walk the site)

- asked if she could see the draft SAT report of vulnerabilities. (told, no, that the report was in rough draft form not ready for public release. However, at this point, the DOE Site Manager asked if the draft report was classified, and on finding that it was not, instructed that the draft be supplied to the stakeholders who want it.)

- asked, "You really don't know how much plutonium you have?" (Answer: Yes we do.)

- Do you have more metal or oxide? (Answer: oxide)

- Do you have any Americium-241? (Answer: not heard)

- Will there be any resources for corrective action? (Answer: Yes, there will be corrective action plans, and resources will be allocated based upon priority.)

- $\quad$ asked if this assessment will address only the quantities of material on the site at this time. (Answer: yes, it's a snapshot.)

- noted that plutonium burns easily. Will (this property) be considered? (Answer: Yes)

- asked how many firefighters Mound has. (Answer 15, plus Mound has a Memorandum of Understanding with the Miamisburg Fire Department to provide additional assistance.) 
Mound

- asked if the Miamisburg fire department was adequately trained. (Answer: yes)

- asked if the study will cover movement of the materials. (Answer: We're looking to move all the materials off-site. Therefore, any vulnerabilities we have will go away!)

At this point the In-Briefing came to a close. Additional informal discussions took place.

\section{Exit-Briefing:}

The Exit-Briefing was held at the same location as the In-Briefing, at 1:00 PM on Thursday, June 2, 1994. Stakeholders present at the meeting were the same as at the In-Briefing. Again, the following represents a best efforts basis to recapture proceedings of the meeting, and no guarantees are made or implied that the statements here are correct, complete or accurate.

The meeting began at 10:06 AM. Opening remarks were made by Tim Frazier who then introduced the principal speaker, Mr. Allen Gunter, Team Leader from Savannah River Plant. Mr. Gunter spoke from a set of slides (reproduced below) which were also duplicated and provided to meeting attendees as a handout. Appendix $E$ of this report contains the slides used for this presentation.

Mr. Gunter:

- thanked the Mound management and the SAT for great cooperation and assistance

- reiterated the definition of a vulnerability and the scope of project

- explained that this was not an audit, and that

- the assessment included all transuranic fissionable isotopes, and

- all facilities identified by the SAT which were SW/R, T, 38, and 50

- indicated on an aerial photograph the locations of the buildings identified;

- Summarized the WGATs activities which included: receiving and studying the SAT draft report, conducting walkdowns of the identified facilities, conducting interviews of key personnel, conducting Table Top face-to-face discussions with the SAT regarding their report, and producing a final report

- indicated that the WGATs overall perception of Mound is that it has only a very small quantity of plutonium, and that with the care given to this material by the Mound organizations, Mound represents only a small risk relative to other sites in the DOE complex such as Rocky Flats or Savannah River Plant. 
- two of the visitors asked what this meant. How much plutonium does Mound Have. They expressed that it doesn't make them feel good at all to have Mound compared to such sites. (A Mound representative answered by stating that the amount of material at Mound is classified but that he could state that Mound has less than 100 grams of unencapsulated plutonium.)

- Allen Gunter continued by showing a photo of the OSR board in Building 38 as an indication of a good practice. (Photo in handout.)

- Is it done daily? (yes.)

- Because the board is erasable, is a record kept? (yes.)

- $\quad$ Allen then proceeded to review the 12 vulnerabilities identified for the Mound site. He stated that the list was not in any particular order and should not be construed as a priority rating. [The Vulnerabilities are identified in the following by number, i.e. MD-1, MD-2, etc. The full text of these vulnerabilities is found in Appendix A of this report.]

- MD-1 was explained. No comments or questions received.

- MD-2 was explained.

- Will corrective actions take place? (response by DOE representative: Yes. He explained how DOE might handle funding for this.)

- MD-3 was explained. Allen explained that Mound has determined that risk is bounded by tritium, but that the vulnerability is that there are no specific calculations of plutonium accidents to confirm this analysis.

- Question by Site Manager: Are you stating that tritium risk exceeds the plutonium risk? (yes.)

- Is the tritium in the same area? is it a question of them [the tritium and the plutonium] being together? (No. We're not saying that plutonium is worse than tritium.)

- MD-4 was explained. No comments or questions were received.

- MD-5 was explained. No comments or questions were received.

- MD-6 was explained. 
- Question by Kirkman (Dayton Area Office Manager) can you quantify or explain? (It's difficult. We have photos [to illustrate], there were, for instance, numerous layers of gloves, etc. in one glovebox.)

- MD-7 was explained. No comments or questions were received.

- MD-8 was explained. No comments or questions were received.

- MD-9 was explained. No comments or questions were received.

- MD-10 was explained and a photograph was shown.

- noted that the picture showed oxidation? [NOTE: the photograph showed several containers, one of which seemed to show corrosion ad indicated by coloration on the external surface.] (Response by DOE: It's on the outside, not from the inside-out. Some external oxidation will occur because of the heat.)

- is there any lost inventory? (We did not examine inventory differences - we looked at conditions of the stored material.)

- MD-11 was explained.

- What do you mean by "processing lines?" (by DOE: There are old process lines left over from encapsulating [work] years ago - there are ducts and lines still not decommissioned and decontaminated. This will be done later when the whole building is decommissioned and decontaminated.)

- MD-12 was explained. No comments or questions were received.

This completed the review of the 12 draft vulnerabilities. Allen Gunter then showed the slide on Concluding Activities, and the presentation concluded at 10:30 AM. T. Frazier (Dayton Area Office, DOE) then stood and asked if there were any further questions.

- If you have to have it [the entire vulnerability study] done by September 30 , 1994, why did it take an extra week to do a small site like Mound? (by Gunter: This was the team's first site. It took extra time for us to plan and execute our work. There was a learning curve for the team. T. Frazier volunteered that "We underestimated the time necessary to tour facilities."

- Will the same team visit all of the sites? (No. This team goes only to Oak Ridge National Laboratory from here. There are 9 teams for the thirteen sites to be visited.) 
- So what happens if you're at the bottom of the list? [The question is in reference to the apparent low priority to be assigned to the vulnerabilities at Mound.] (by a Mound person: It doesn't [mean] that the site can't make corrective actions on its own.) (by another Mound Manager: "Sure, like the gloveboxes, we're not going to wait for the Secretary of Energy [before we correct that situation]. We're also trying to get rid of the material as soon as we can. We're actively pursuing getting rid of it.") (by another Mound manager:

"We have a meeting tomorrow. I am convinced the best answer is to get rid of it as quickly as possible. We don't want it. But then nobody else wants it either. This site has now been identified as a site to be converted to the private sector.")

- So it's not just the quantity but also the square footage? (by a Mound manager: "DOE is also looking at cost. We can reduce cost by consolidating this material. They have made the decision not to use Mound as a weapon site any longer.")

- [The visitor was concerned that DOE might decide to use the expertise at Mound for encapsulation work and therefore bring more plutonium here.] (by a Mound manager: That will never happen here. For instance Savannah River Plant has the capability too....)

- [The visitor stated that she was concerned about the loss of institutional memory and the consequent use of outside contractors which she characterized as "scary." (by a Mound manager: stated that such work can be done faster if we supplement our own people with outside contractors. It provides us the ability to accelerate our work. It's not just turning over our work without appropriate oversight.)

- Comment: The handouts need an acronym list.

The meeting was adjourned at 10:43 AM 


\title{
PLUTONIUM ES\&H VULNERABILITY ASSESSMENT
}

\author{
In-Briefing \\ By \\ Working Group Assessment Team
}

MOUND

May 23, 1994 


\section{WGAT IN-BRIEFING}

- Background

- Non-proliferation

- ES\&H Plutonium Events

- Project Purpose and Authorization

- Project Organization

- How it works

- Project Scope and Schedule

- Assessment Approach

- WGAT Site Activities

- Concluding Activities of the Working Group 


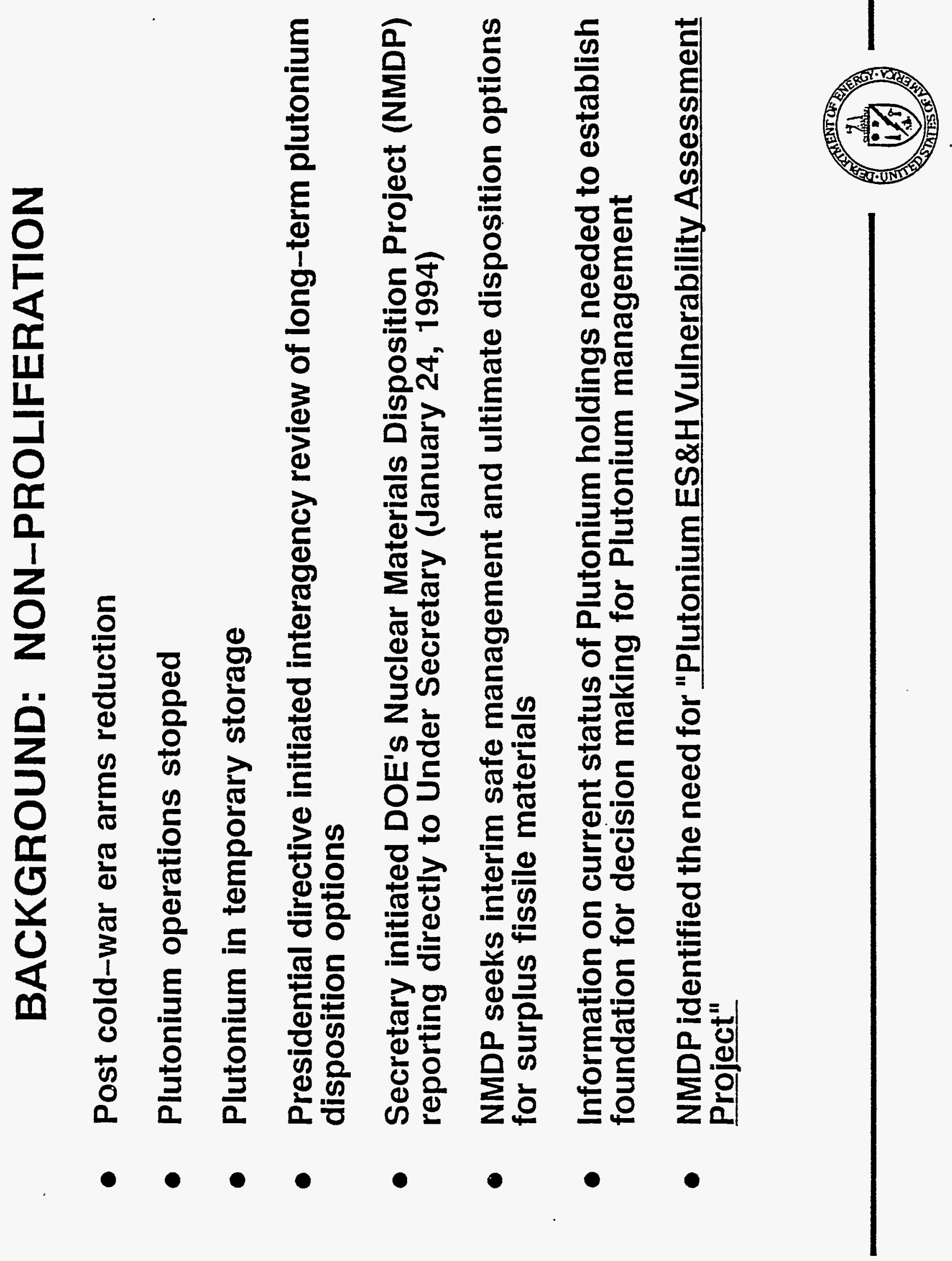




\section{BACKGROUND: ES\&H PLUTONIUM EVENTS}

- Rocky Flats

- Leaks of Plutonium-containing solutions (1990 - Present)

- Deferred inspections (April 1993)

- Oxidized metal (January 1994)

- Los Alamos

- Failed container (December 1992)

- Contamination of gloves/protective clothing (November 1993)

- Savannah River

- FB Line bulged container (February 1994)

- Oxidized metal (November 1993)

- Consequences

- Impacts on safety envelope

- Impacts on operations 


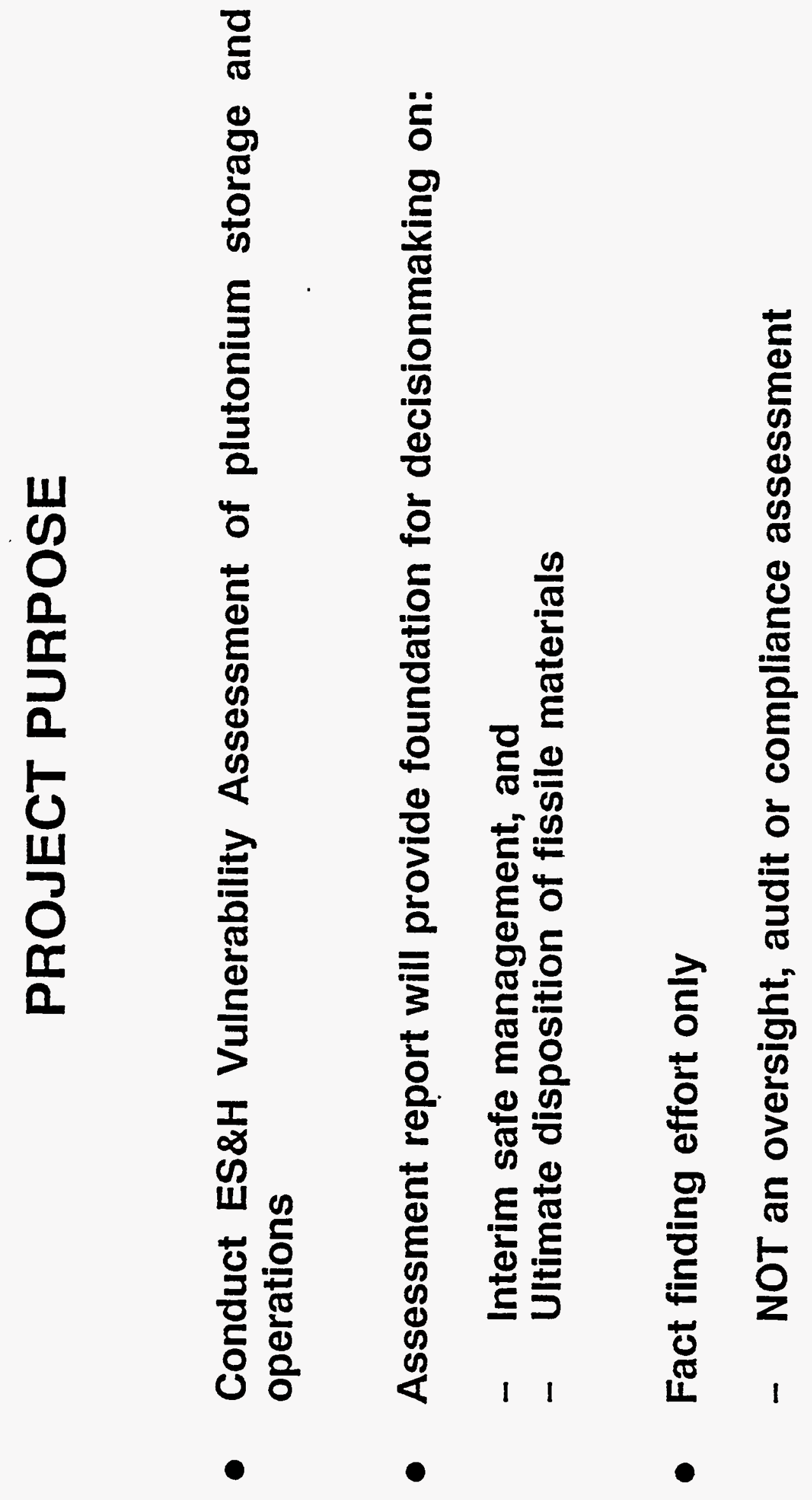




\section{DEFINITION OF ES\&H VULNERABILITY}

"Conditions or weaknesses that could lead to unnecessary or increased radiation exposure of workers, release of radioactive materials to the environment, or radiation exposure of the Public." 


\section{AUTHORIZATION}

- Secretary of Energy initiated the Nuclear Materials Disposition Project (NMDP) $(1 / 24 / 94)$

- Secretary of Energy initiated the Plutonium Vulnerability Assessment $(3 / 15 / 94)$

- Secretary of Energy directed the Office of EH to coordinate and CSO's, Operations Office managers and $M \& O$ Contractors to fully participate in the project

- Secretary of Energy directed that external stakeholders be involved in the assessment

- Assistant Secretary for EH established the Plutonium ES\&H Vulnerability Assessment Project 


\section{PROJECT ORGANIZATION}

- $\quad$ "Working Group" (WG) formed by EH to steer project

- Held first meeting on March 28-30, 1994

- WG consists of plutonium experts, operations experts, and other highly experienced people from DOE, M\&Os, expert consultants from private sector, and both internal and external stakeholders

- Working Group developed:

- Project Plan

- Assessment Plan

- Assessment process calls for 2 teams for each major site:

- $\quad$ Site Assessment Team (SAT)

- Working Group Assessment Team (WGAT) 


\section{HOW IT WORKS}

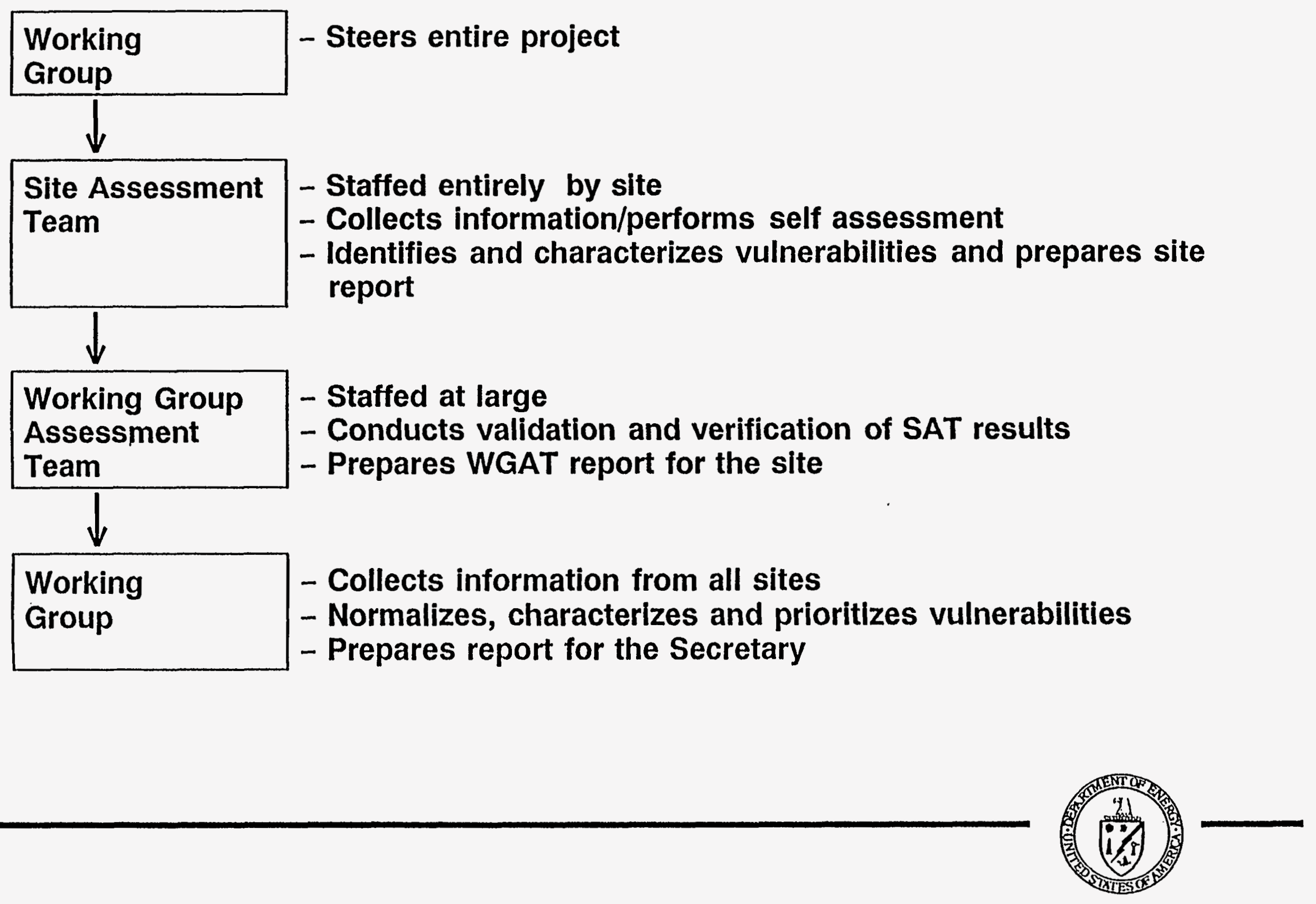


4
0
0
0
0
0
0
0
0
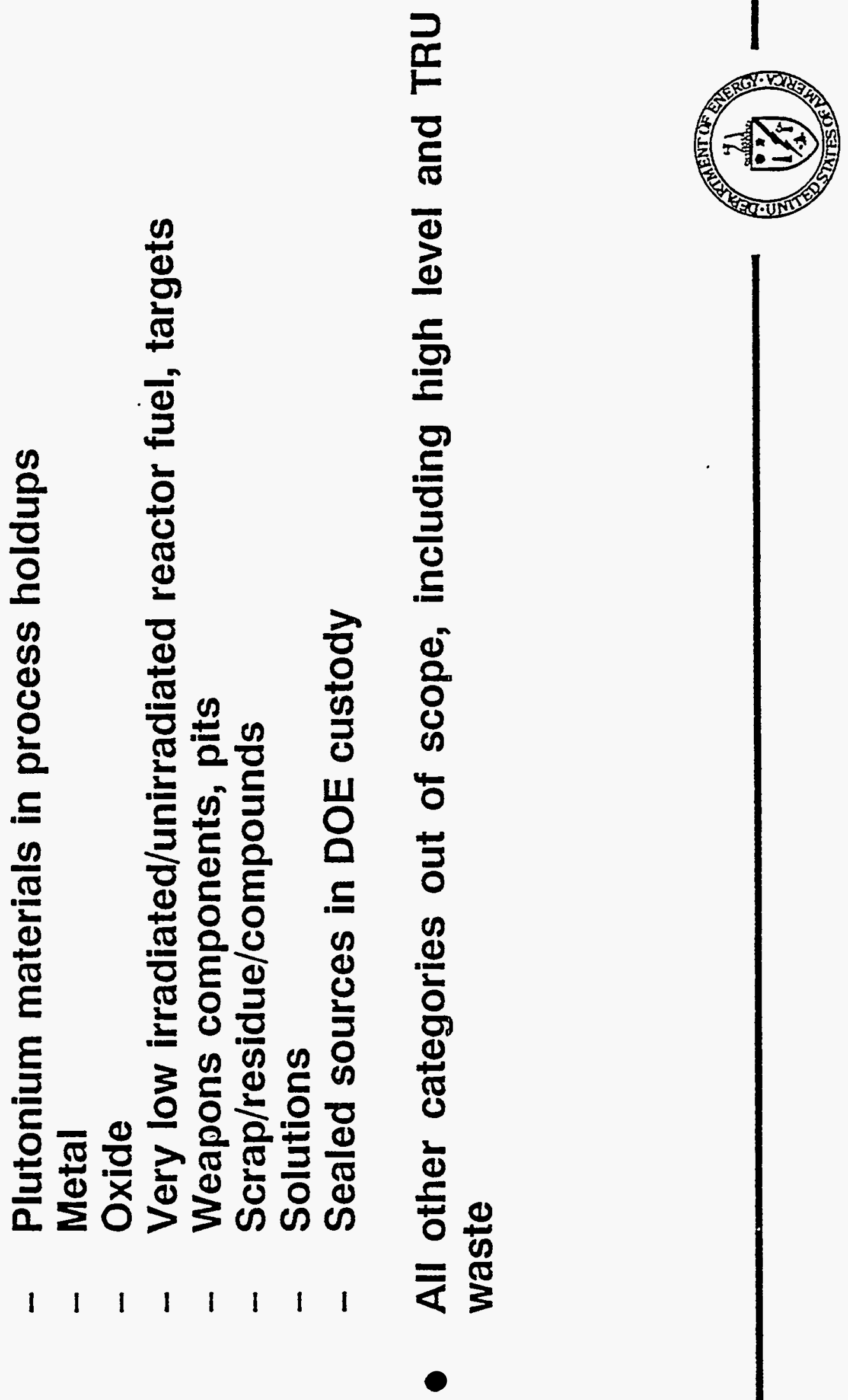

8

!

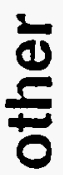

흘

ய

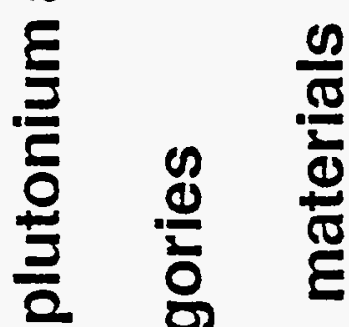

†

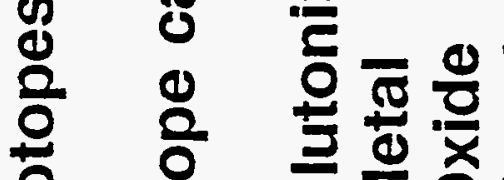

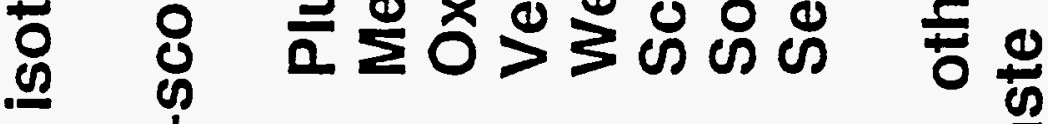

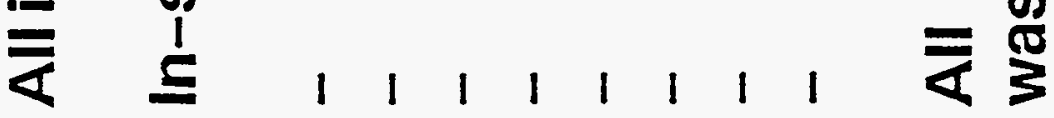

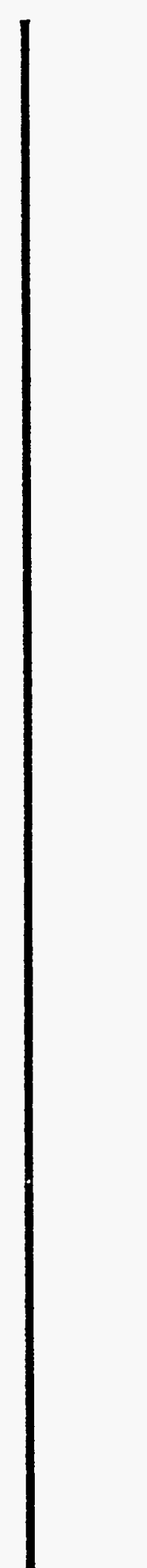




\section{SITES SELECTED FOR TEAM VISITS}

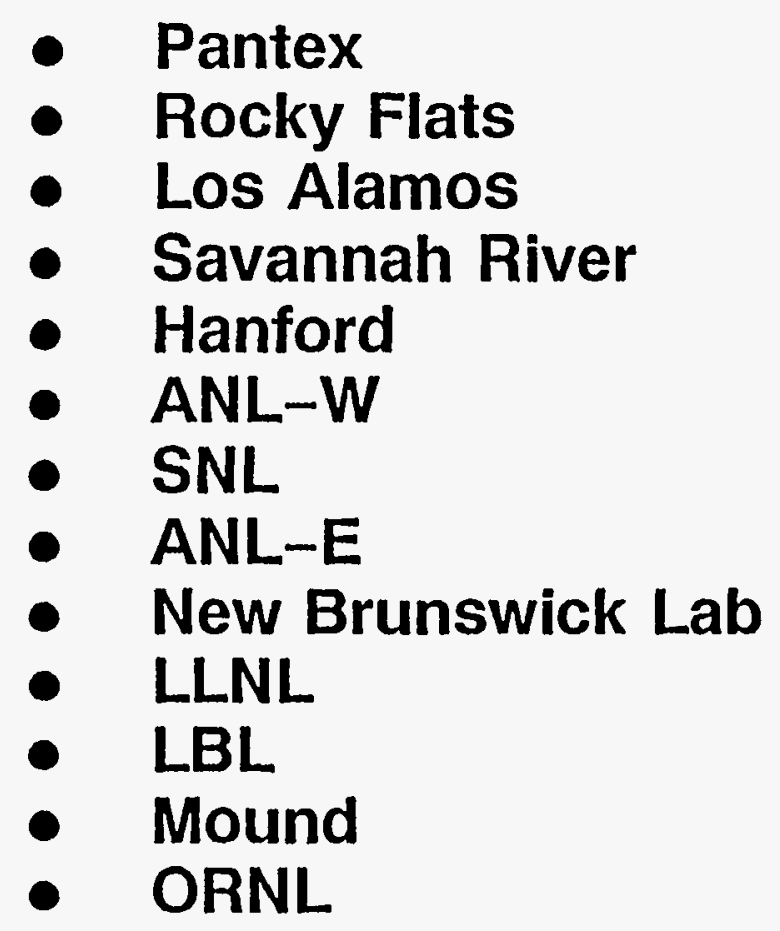

Other sites may be visited after review of their self-assessment report 
Plutonium ES\&H Vulnerability Assessment Project Schedule

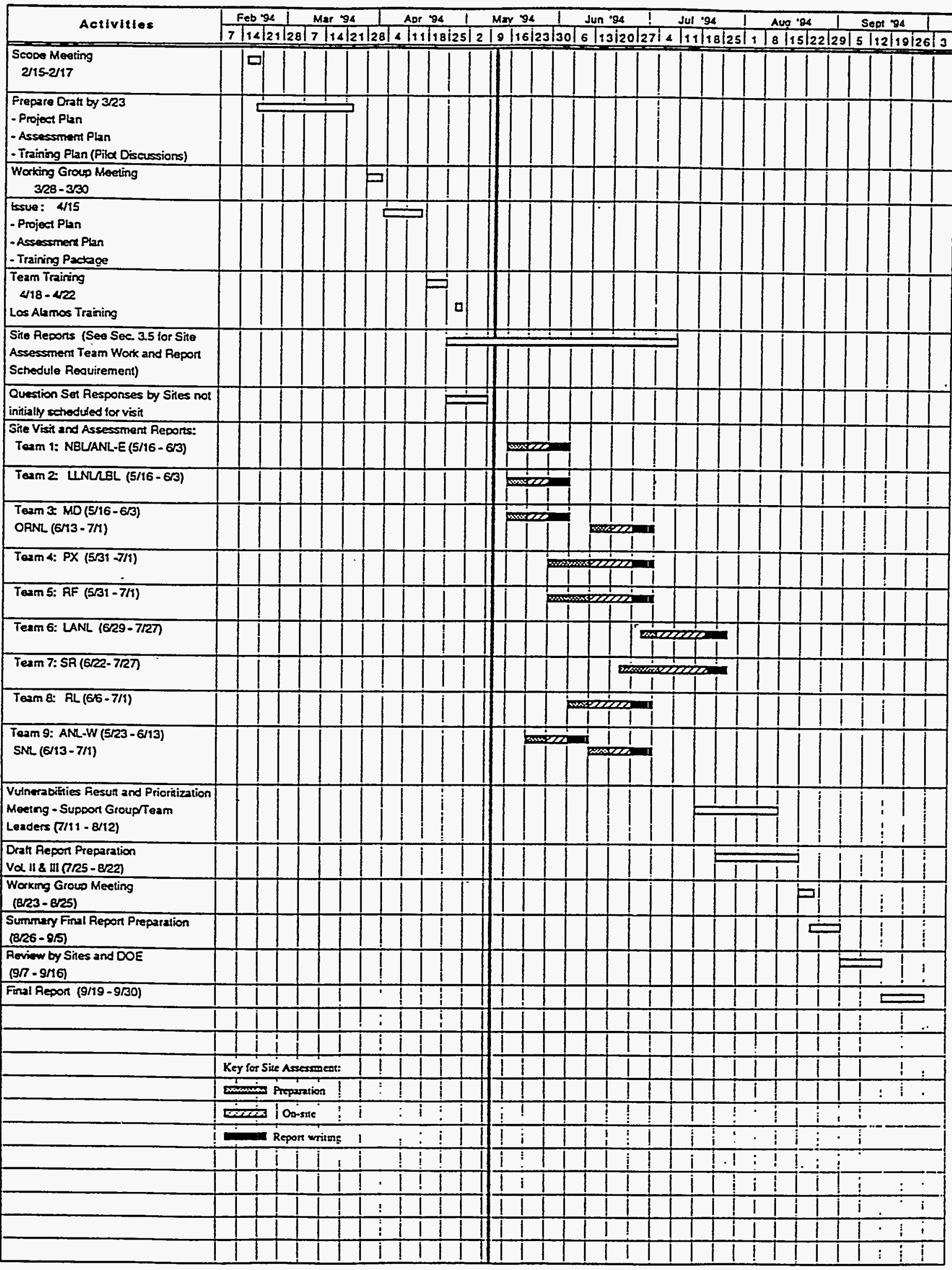




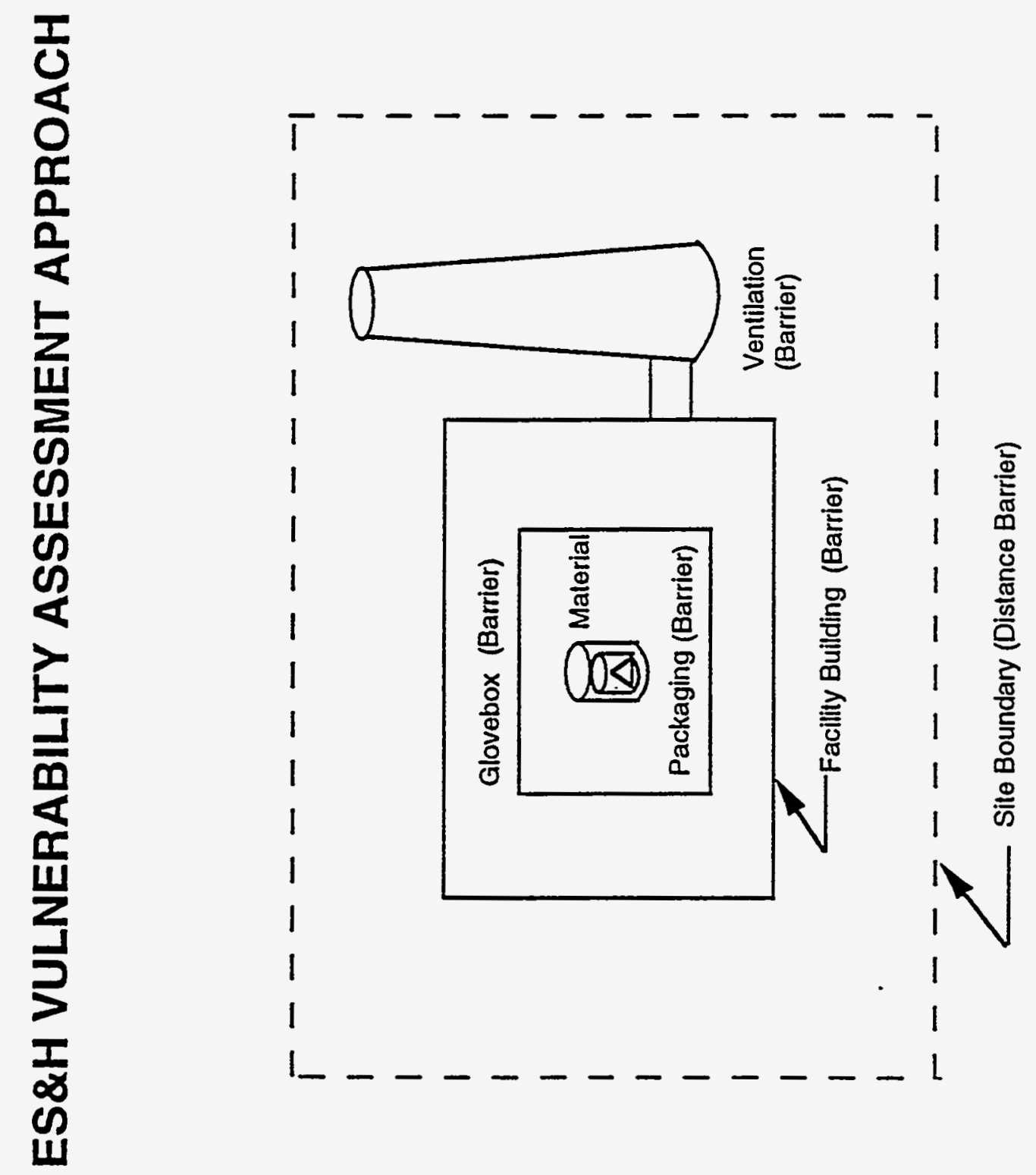




\section{ES\&H VULNERABILITY ASSESSMENT APPROACH}
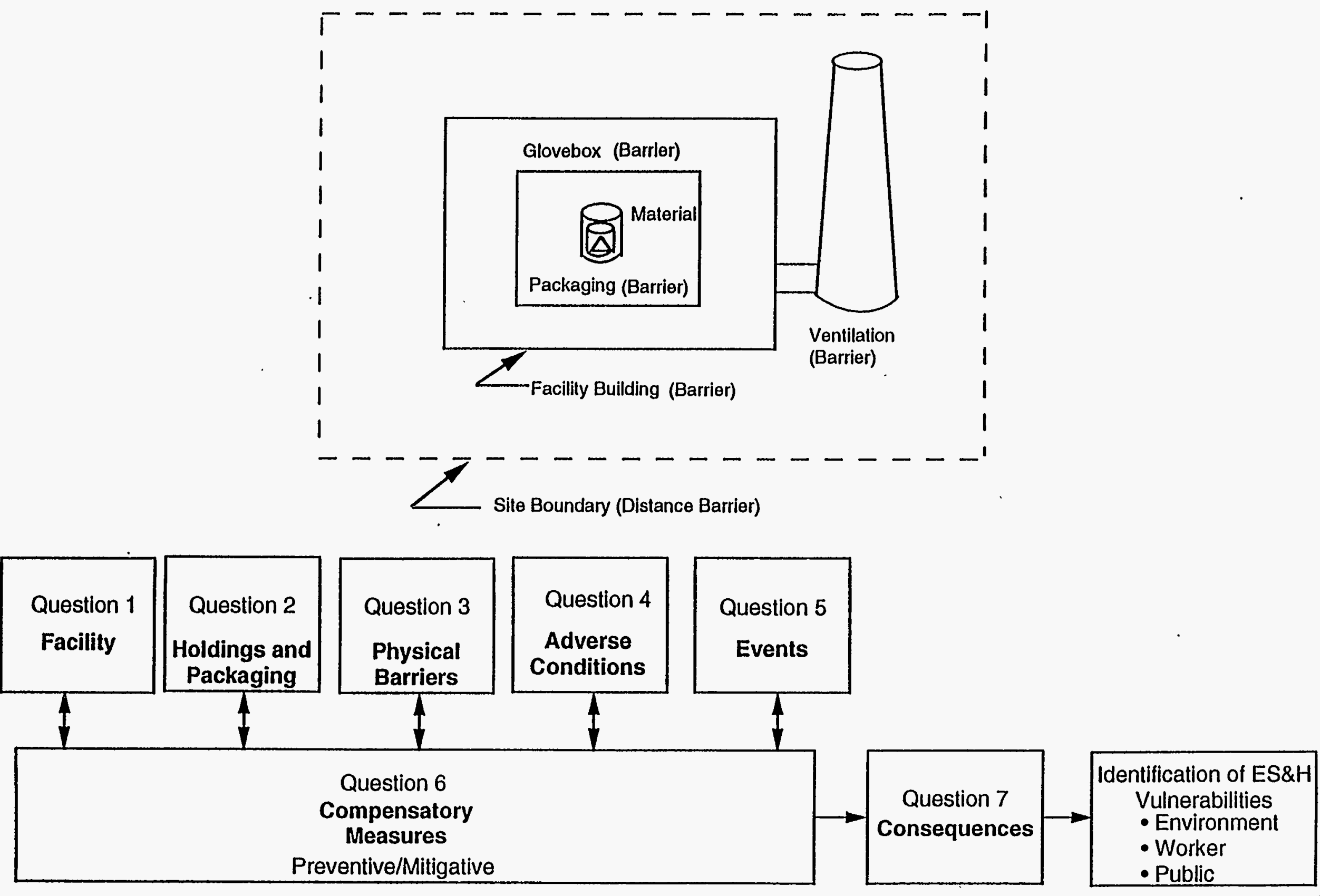


\section{WGAT SITE ACTIVITIES}

- In-briefing

- Review of Site data and responses to Question Set

- Review of other reports and technical information

- Discussions with Site Assessment Team regarding current and potential vulnerabilities

- Walkdown of facilities and discussions with Site Assessment Team and operations personnel

- Reconciliation of differences between the Site Assessment Team and the Working Group Assessment Team findings

- Exit briefing

- SAT and WGAT finalize their results and reports 


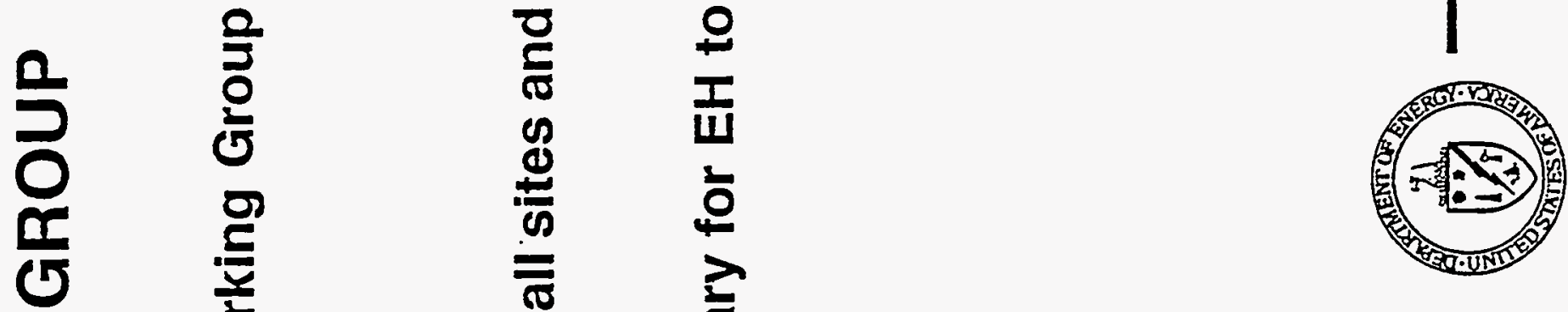

II

हू

1 \&

0

$\infty$

世

尔

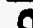

बㅇ

용 를

$\pm$

N

은 을 를

$\sum \frac{5}{0}$

으르ำ

ह

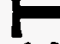

4

$\sigma$

$\stackrel{2}{\circ}$

里

흥흥

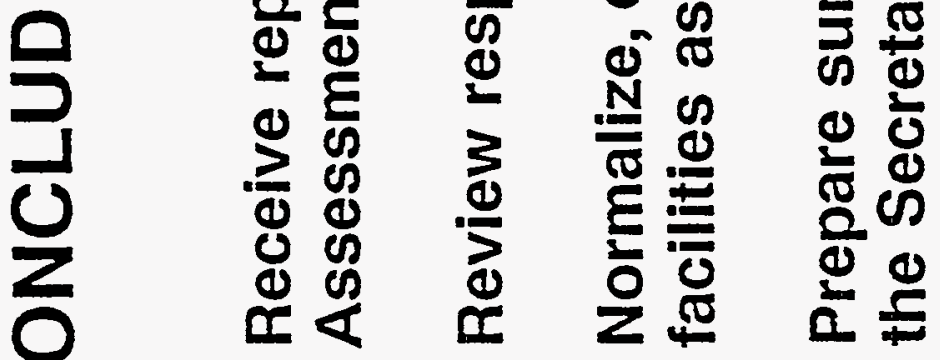

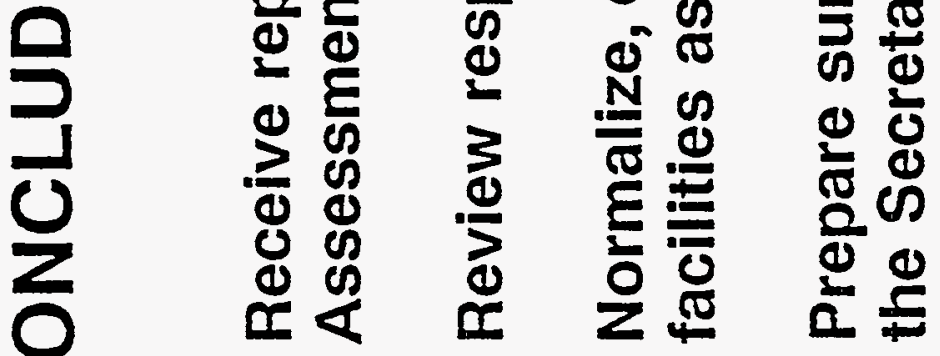

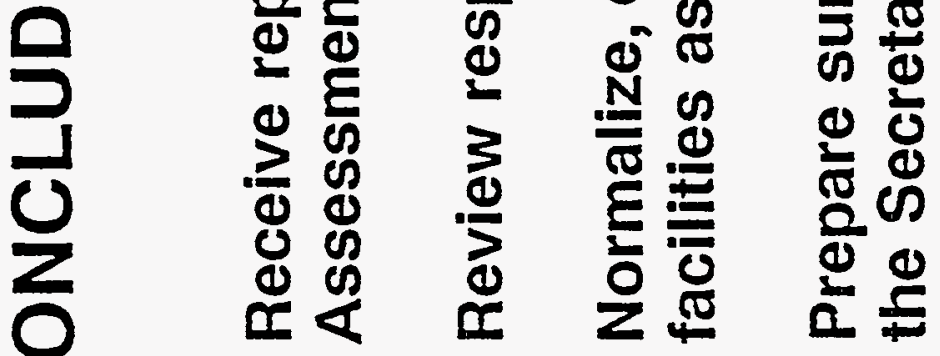

0

응 응

는 0

E

$E$

$\bullet$

0

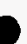




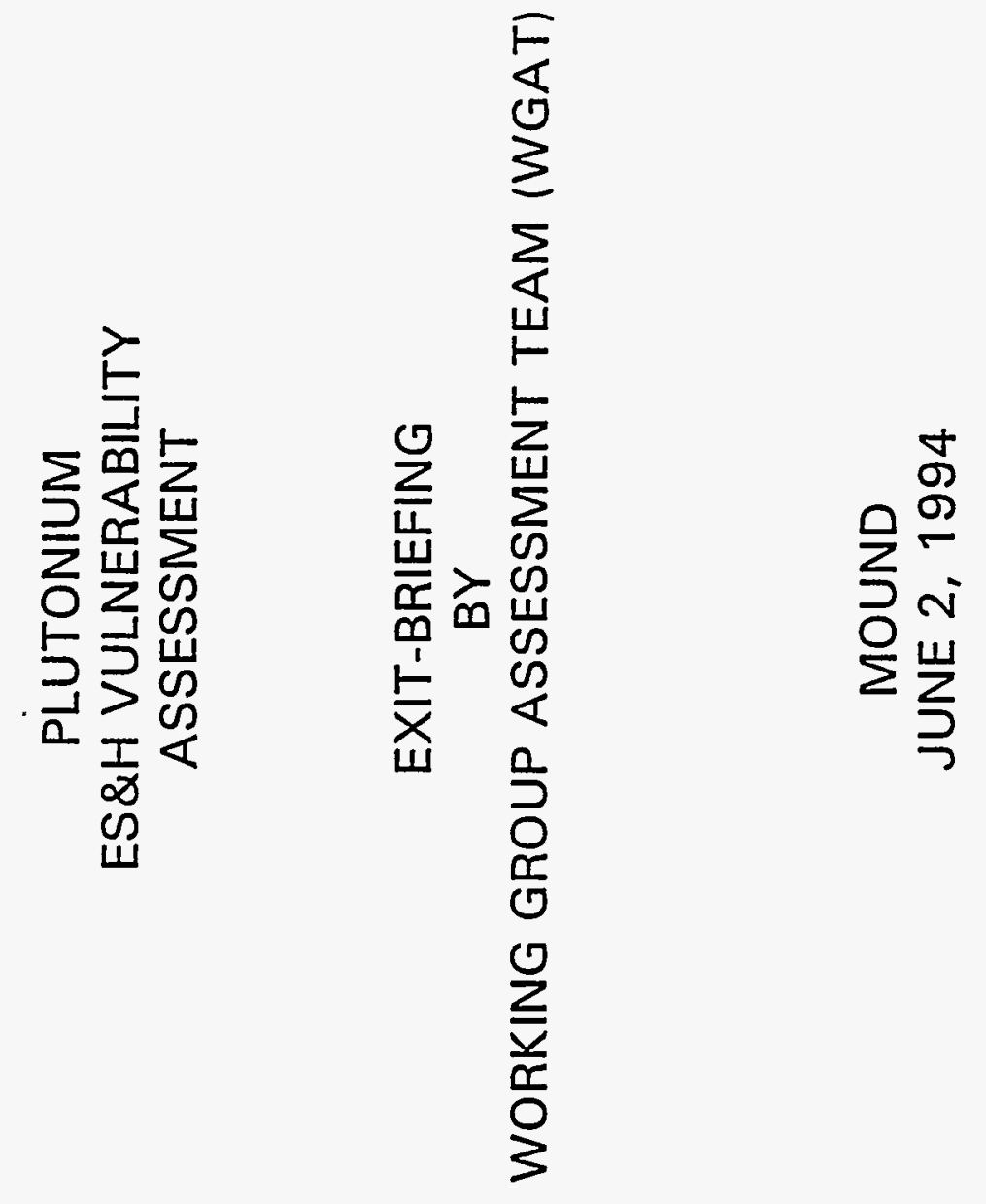


Mound

\author{
AGENDA \\ Plutonium ES\&H Vulnerability Assessment \\ Exit-Briefing
}

Welcome

WGAT Exit-Briefing

External Stakeholders Comments

Adjourn
Site Team Leader

Tim Frazier

WGAT Team Leader

H. Allen Gunter

Open 


\section{DEFINITION OF ES\&H VULNERABILITY}

Conditions or weaknesses that could lead to unnecessary or increased radiation exposure of workers, release of radioactive materials to the environment, or radiation exposure of the public. 
Mound

\section{PROJECT PURPOSE}

- Conduct ES\&H Vulnerability Assessment of plutonium storage and operations

- Assessment report will provide foundation for decision making on:

- Interim safe management, and

- Ultimate disposition of fissile materials

- Fact finding effort only

- NOT an oversight, audit or compliance assessment 
Mound

\section{PROJECT SCOPE}

- All isotopes of plutonium and other co-located transuranic elements

- In-scope categories

- Plutonium materials in process holdups

- Metal

- Oxide

- Very low irradiated/unirradiated reactor fuel, targets

- Weapons components, pits

- Scrap/residue/compounds

- Solutions

- Sealed sources in DOE custody

- All other categories out of scope, including high level and transuranic waste 
Mound

\section{FACILITIES EVALUATED}

- The Site Team had identified 4 facilities containing in-scope plutonium.

- SW/R Building

- $\quad$ T Building

- Building 38

- Building 50 


\section{WORKING GROUP SITE ACTIVITIES}

- Evaluated Site Team report.

- Conducted facility walkdowns for the areas containing Pu in the 4 buildings.

- Conducted interviews with site subject-matter experts.

- Reviewed pertinent documents.

- Safety Analysis Reports

- Operational Safety Requirements

- Draft BIO

- Emergency Preparedness \& Plans

- Technical Manuals 


\section{OVERALL PERCEPTION}

- Mound has a very small quantity of unencapsulated plutonium on-site which presents a very minor risk to the public.

- The Working Group Assessment Team recognized several noteworthy practices while conducting facility walkdowns:

- Frank, open discussions between site personnel and working group.

- Very knowledgeable facility managers and support staff

- Good housekeeping throughout except for two identified locations.

- Use of Limiting Conditions for Operation status board

- The few vulnerabilities identified by the site assessment team and the working group assessment team are discussed on the following slides. 


\section{IDENTIFIED DRAFT VULNERABILITIES}

MD-1. Safeguards and security versus radiation safety

Conflicts between DOE Albuquerque approved safeguards and security requirements and safety. Safeguards and security procedures and practices for entry and surveillance of the $T$ Building vaults require an excessive number of personnel to be present. The exposures received by such personnel are inconsistent with the radiological-safety principle of keeping exposures ALARA.

MD-2. Uncertain material composition

In a small number of containers, uncertainty exists about potential constituents that may be packaged with stored plutonium.

MD-3. Lack of analysis for potential plutonium release in $\mathrm{T}$ Building.

The potential for plutonium release from storage and staging operations in $T$ Building is not addressed in the safety analysis report. 
Mound

\section{IDENTIFIED DRAFT VULNERABILITIES (Continued)}

MD-4. Lack of thorough assessment of consequence.

Several accident scenarios do not have quantitative assessments for all potential recipients (e.g., workers, the public, and the environment). Although off-site radiological consequences are analyzed quantitatively, potential consequences to on-site recipients are only assessed qualitatively in the safety analysis reports.

MD-5. Incomplete authorization basis.

The authorization basis for Buildings T, SW/R, and 38 are unclear due the lack of approved SAR, and lack of approved BIO documents. The approved SARs that do not contain current required analyses. 


\section{IDENTIFIED DRAFT VULNERABILITIES (Continued)}

MD-6. Excess fire loading in Buildings 38 and SW/R.

Excessive fire loading in the A-Line glovebox in Building 38 and a glovebox in one room in Building SW/R exist as a result of inadequate limits and procedures, practices, or limits, and as a result of failure in conduct of operations.

MD-7. Non-Adherences to existing ALARA Program.

Some observations show a conflict with the site's existing ALARA program that may cause unnecessary exposure to on-site workers. Examples:

- A vault in Building 38 was not visibly posted as a high radiation area.

- Lack of attentiveness to the most advantageous place to conduct business to reduce exposure.

- Out-dated radiological survey results posted on the face of gloveboxes in A-Line in Building 38. 


\section{IDENTIFIED DRAFT VULNERABILITIES (Continued)}

MD-8. Loss of institutional memory

Loss of experienced personnel and their knowledge of processes and facilities (i.e., their "institutional memory," could increase the potential for errors with potential safety consequences. In addition, critical expertise may no longer be adequate to provide internally key functions such as safety analysis.

MD-9. Plutonium stored on-site which is no longer needed to support existing site missions

Pu-238 and Pu-239 materials remain stored on-site which is no longer needed to support any identified missions at the Mound Site. DOE has no approved plan to relocate this material to another site with existing, large inventories of like material. 


\section{IDENTIFIED DRAFT VULNERABILITIES (Continued)}

MD-10. Packaging Uncertainties

- There are approximately 90 packages that are old. Records of packaging details do not provide sufficient information to firmly support the packaging layers as reliable barriers for the protection of workers, off-site personnel, or the environment.

MD-11. Hold-up in Process Equipment

- There are processing lines or areas in the SW/R Building and Building 38 that potentially contain plutonium hold-up in small unmeasured quantities.

MD-12. Response of Facilities to Natural Phenomena Accidents

- The potential exists for stack failure onto the SW/R and 38 Buildings in either a design basis earthquake or tornado. Roof supports of Building 38 may to fail during a design basis earthquake and design basis tornado. 
Mound

\section{CONCLUDING ACTIVITIES OF THE WORKING GROUP}

- Receive reports from each Site Assessment Team and Working Group Assessment Team.

- Review responses from sites not visited.

- Normalize, characterize and prioritize vulnerabilities across all sites and facilities assessed.

- Prepare summary report for submittal by Assistance Secretary for EH to the Secretary of Energy and Nuclear Materials Disposition Project (NMDP). 
APPENDIX F

PHOTOGRAPHS

Appendix F contains selected photographs of facilities and storage practices at Mound.

\section{Page F-1}

July 18,1994 


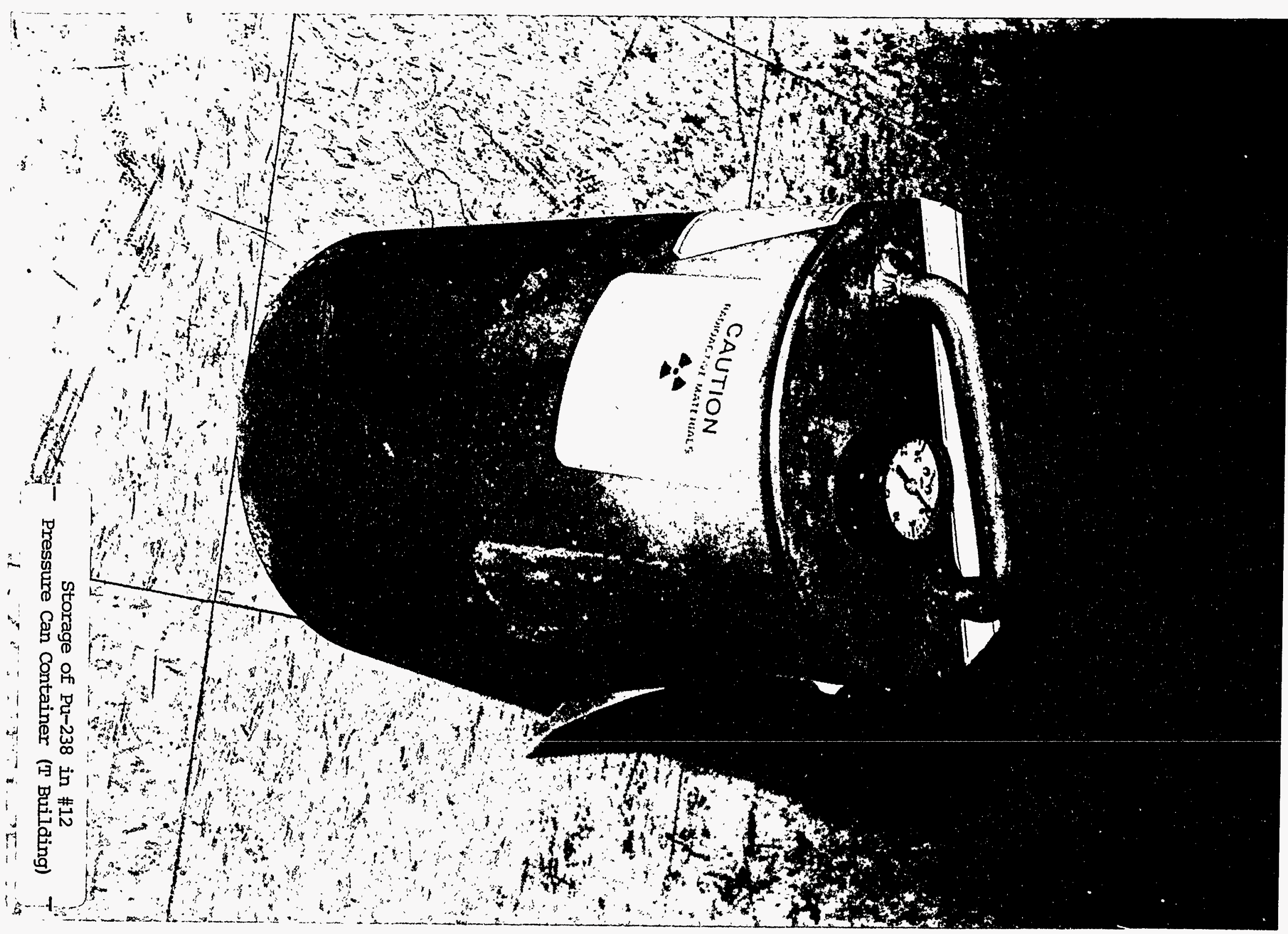




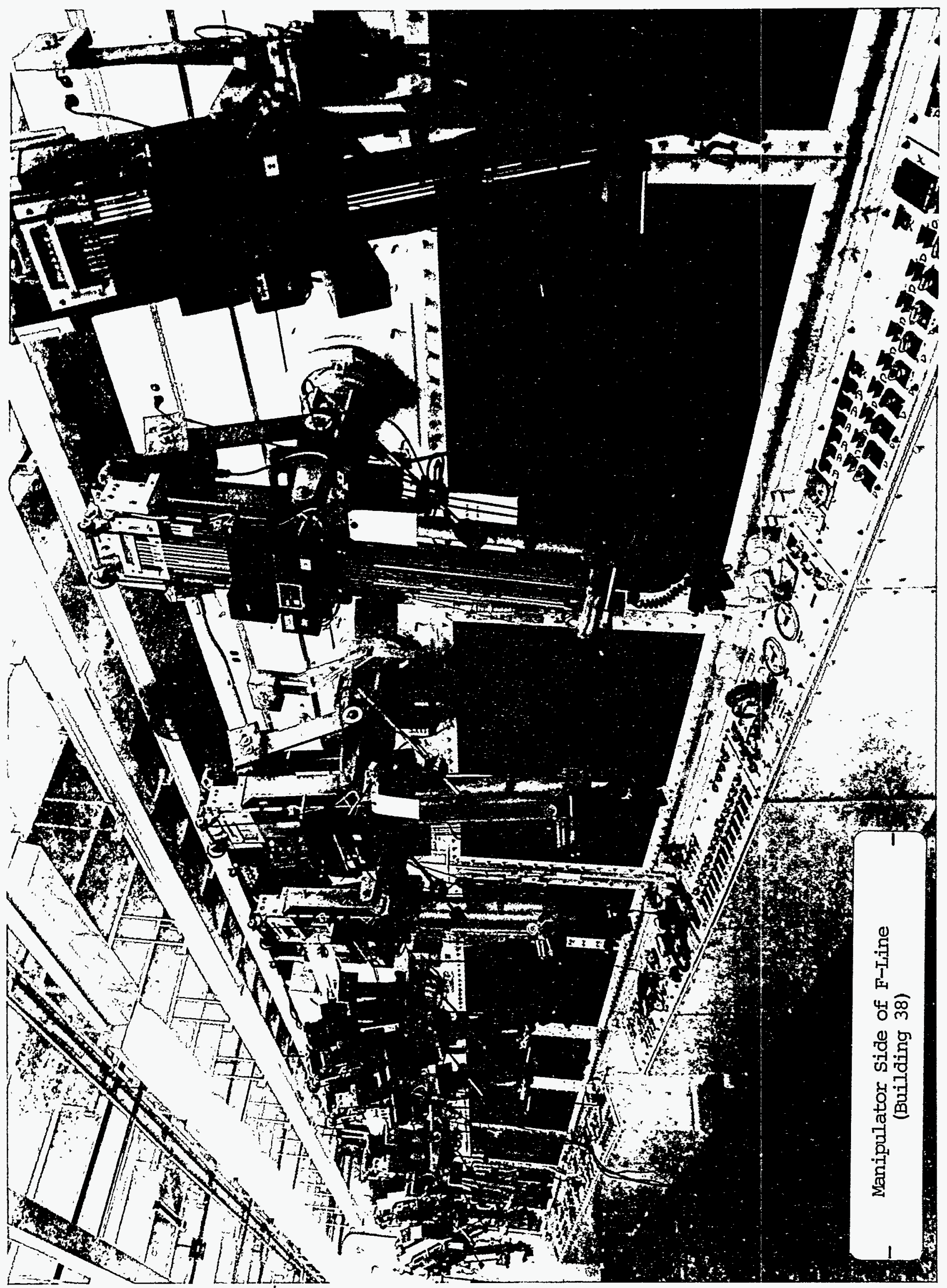




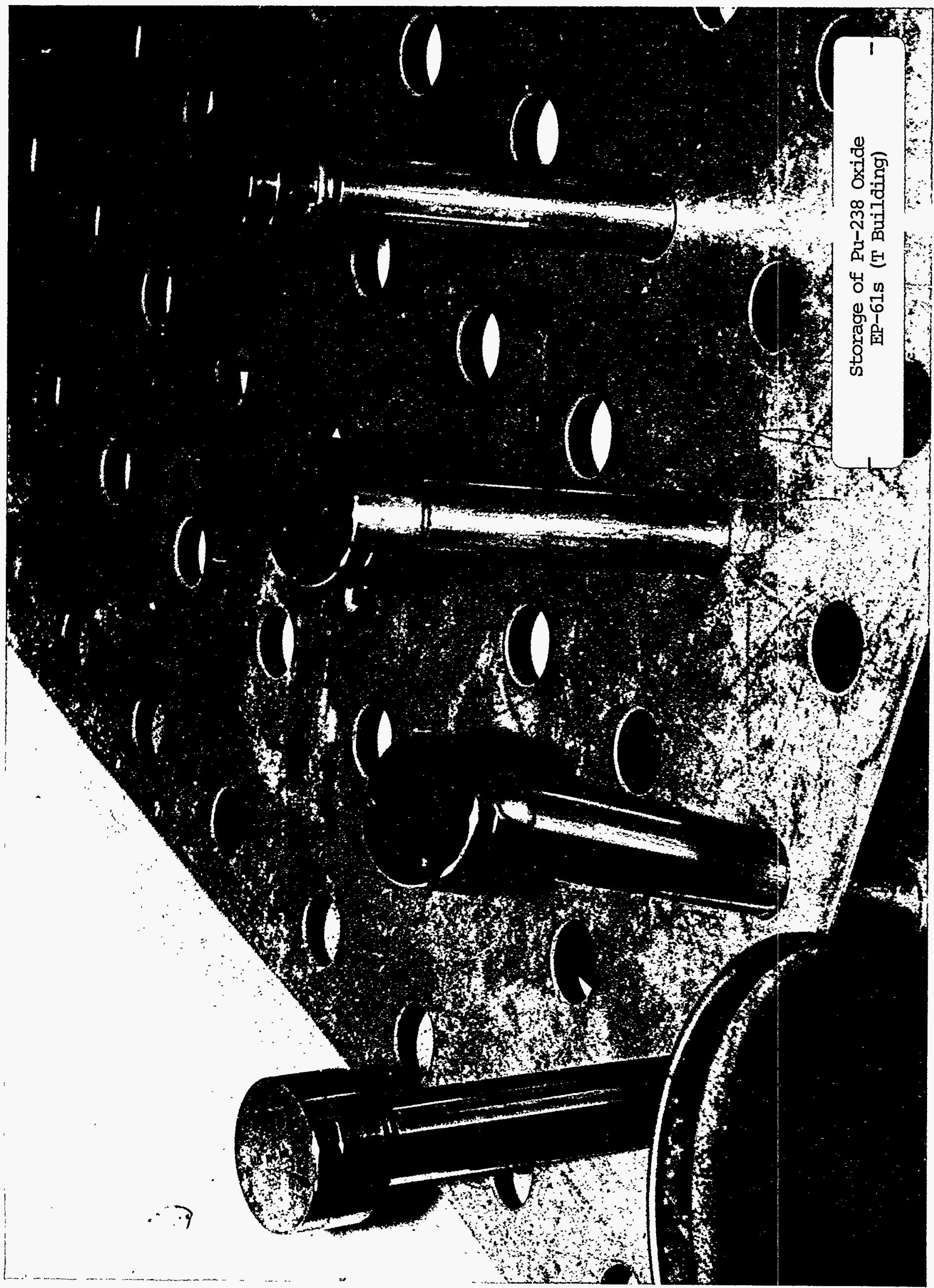




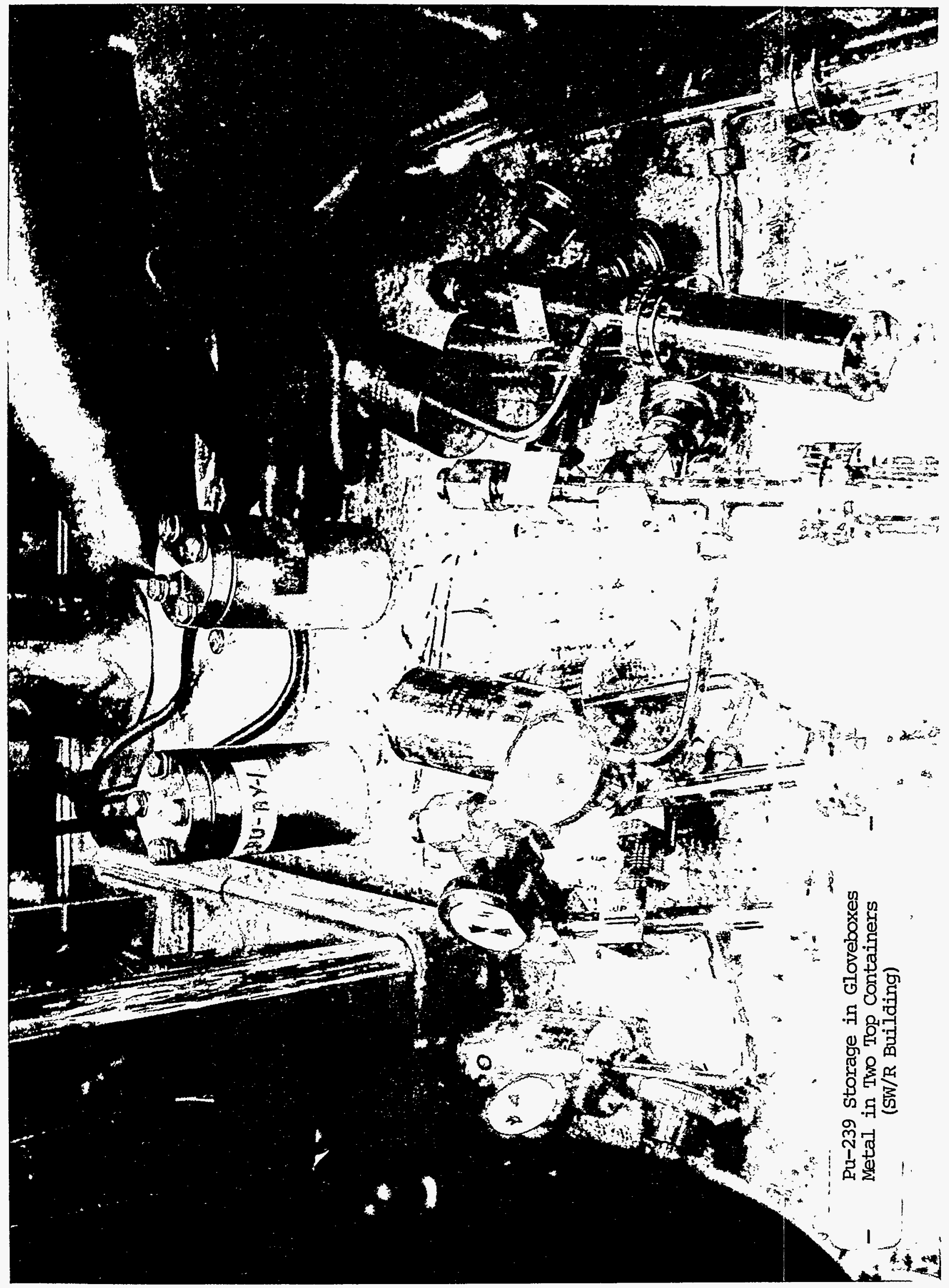


Mound

APPENDIX G

REFERENCES

The following are Mound-specific references made available to the WGAT during its visit to the site.

\begin{tabular}{|c|c|c|}
\hline TITLE & MOUND \# & DATE \\
\hline $\begin{array}{l}\text { Mound Facility Risk Review } \\
\text { Volume I }\end{array}$ & JBFA-147-91 & September, 1993 \\
\hline $\begin{array}{l}\text { Mound Facility Risk Review } \\
\text { Volume II }\end{array}$ & JBFA-147-91 & September, 1993 \\
\hline $\begin{array}{l}\text { Mound Facility Risk Review } \\
\text { Volume III }\end{array}$ & JBFA-147-91 & September, 1993 \\
\hline $\begin{array}{l}\text { Mound Engineering Department Authorization } \\
\text { of Engineering Services }\end{array}$ & & January, 1992 \\
\hline $\begin{array}{l}\text { Mound Project Management } \\
\text { Volume I }\end{array}$ & & December, 1993 \\
\hline $\begin{array}{l}\text { Mound Project Management } \\
\text { Volume II }\end{array}$ & & May, 1992 \\
\hline $\begin{array}{l}\text { General Requirements for A-E Works } \\
\text { Volume II }\end{array}$ & & March, 1990 \\
\hline $\begin{array}{l}\text { Mound Facility Risk Review } \\
\text { Volume IV }\end{array}$ & JBFA-147-91 & September, 1993 \\
\hline Mound Safety \& Hygiene Manual & MD-10286 & October, 1978 \\
\hline Mound Radiological Protection Manual & MD-10019 & July, 1992 \\
\hline $\begin{array}{l}\text { Operational Safety Requirements for Building } \\
38\end{array}$ & MD-10305 & March, 1991 \\
\hline EG\&G Mound Conduct of Operations & MD-10361 & February, 1993 \\
\hline Final Safety Analysis Report - Building 38 & & January, 1975 \\
\hline DOE 5480.EO Equipment Qualification & & May, 1992 \\
\hline DOE 5480.22 Technical Safety Requirements & & March, 1992 \\
\hline Mound Facility Maintenance & & March, 1994 \\
\hline Final Safety Analysis Report - Building 38 & & May, 1989 \\
\hline Final Safety Analysis Report - Building 38 & & October, 1992 \\
\hline $\begin{array}{l}\text { Final Safety Arialysis Report - SW Tritium } \\
\text { Complex }\end{array}$ & & February, 1992 \\
\hline BIO - T Building & & November, 1993 \\
\hline
\end{tabular}


Mound

TITLE

BIO - Building 38

BIO - SW/R Building

System Manual 814 Facilities Engineer Inspection Manual

Emergency Preparedness Systems:

Response 1 and 3 through 16

Quality for Engineering Projects

Technical Manual Custodian's Handbook Nuclear Materials Safeguards and Accountability

T. P. McLaughlin to J. J. Schinkle, Report to the Albuquerque Operations Office Weapon Criticality Committee, Los Alamos National Laboratory

D. R. Smith to K. E. Elliott, Letter (Attachment to above report)

Compliance Schedule Approval Request [CSR] Number EGGM-DOE-5480.4-CAS-7A:

Conformance with ANSI/ANS Standard 8.11983, Nuclear Criticality Safety in Operations with Fissionable Materials Outside of Reactors, EG\&G Mound Applied Technologies

Technical Manual MD-10038, Issue 7, Nuclear Criticality Precautions

Technical Manual MD-10038, Revision 8, Nuclear Criticality Precautions (working draft)

A. Shapiro, Evaluation of Criticality of Storage Areas, University of Cincinnati College of

Engineering

SW Building - Occurrence Report

CAM False Alarm SW139 Corridor

SW Building - Occurrence Report

CAM Alarm SW22

SW Building - Occurrence Report CAM Alarm SW140
MOUND \#

HSE-6-91-124

May 22, 1991

EGGM-DOE-

5480.4-CSA-7A

MD-10038

October 6, 1986

MD-10038

ALO-DA-EGGM-

EGGMATO2-

1992-0013

ALO-DA-EGGM-

EGGMATO2-

1992-0020

ALO-DA-EGGM-

EGGMATO2-

1992-0021
May 27, 1994

October 1993

1992 1992

1992

1992
September 29, 
Mound

TITLE

SW Building - Occurrence Report

CAM False Alarm in SW Cave Area

SW Building - Occurrence Report

Continuous Alpha Monitor Sample Line

Disconnected

SW Building - Occurrence Report

CAM False Alarm in SW22

SW Building - Occurrence Report

Air Sampling System Failure in Building 58

SW Building - Occurrence Report

Criticality False Alarm, SW/R Building

SW Building - Occurrence Report

Los of Air Handling System

SW Building - Occurrence Report

Freezing of Fire Suppression Filter Bank Deluge System

Building 50 - Occurrence Report

Alpha Continuous Air Monitor (CAM) Alarm, Bldg. 50, Corridor 118

Building 50 - Occurrence Report

Alpha Continuous Air Monitor (CAM) Alarm, Bldg. 50, Corridor 118

Building 50 - Occurrence Report

CAM Alarm Alpha Continuous Air Monitor,

Bldg. 50, Filter Bank Area

Building 50 - Occurrence Report

Building 50 Stack Alarm

Building 50 - Occurrence Report

CAM Alarm in Building 50, Room 116

Building 50 - Occurrence Report

CAM Alarm Building 50 Stack
MOUND \#

ALO-DA-EGGM-
EGGMATO2-
$1992-0022$

ALO-DA-EGGMEGGMATO2-

1993-0001

ALO-DA-EGGMEGGMATO21993-0005

ALO-DA-EGGMEGGMATO21993-0006

ALO-DA-EGGMEGGMATO21993-0014

ALO-DA-EGGMEGGMATO21994-0002

ALO-DA-EGGMEGGMATO21994-0003

ALO-DA-EGGMEGGMATO21992-0005

ALO-DA-EGGMEGGMAT021992-0007

ALO-DA-EGGMEGGMAT021992-0014

ALO-DA-EGGMEGGMATO21992-0016

ALO-DA-EGGMEGGMATO21992-0023

ALO-DA-EGGMEGGMATO21992-0024

DATE

1992

1993

1993

1993

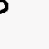


Mound

TITLE

Building 50 - Occurrence Report

CAM False Alarm in Building 50

Building 50 - Occurrence Report

Air Handling System Failure Building 50

Building 50 - Occurrence Report

Communication System Failure Building 50

Building 50 - Occurrence Report

Loss of Air Handling System

Building 50 - Occurrence Report

Performance Degradation of Class "B"

equipment

Building 50 - Occurrence Report

CAM False Alarm Building $\mathbf{5 0}$

Building 50 - Occurrence Report

Rapture of Water Shielded Window

Building 38 - Occurrence Report

Alpha Continuous Air Monitor (CAM) Alarm, PP Stack

Building 38 - Occurrence Report

Bldg. 38, Room 142E CAM False Alarm

Building 38 - Occurrence Report

CAM False Alarm

Building 38 - Occurrence Report

Bldg. 38 CAM Malfunction

Building 38 - Occurrence Report

CAM Alarm in Building 38

Building 38 - Occurrence Report

Stack CAM Building 38

\begin{tabular}{l} 
MOUND \# \\
\hline ALO-DA-EGGM- \\
EGGMATO2- \\
1992-0025
\end{tabular}

ALO-DA-EGGM-

EGGMATO2-

1993-0009

ALO-DA-EGGM-

EGGMATO2-

1993-0011

ALO-DA-EGGM-

EGGMATO2-

1993-0018

ALO-DA-EGGM-

EGGMATO2-

1994-0005

ALO-DA-EGGM-

EGGMATO2-

1994-0006

ALO-DA-EGGM-

EGGMAT02-

1994-0007

ALO-DA-EGGM-

EGGMATO2-

.1992-0006

ALO-DA-EGGM-

EGGMATO2-

1992-0009

ALO-DA-EGGM-

EGGMATO2-

1992-0018

ALO-DA-EGGM-

EGGMATO2-

1992-0018

ALO-DA-EGGM-

EGGMATO2-

1992-0019

ALO-DA-EGGM-

EGGMATO2-

1993-0008
DATE

1992

1993

1993

1993

1994

1994

1994

1992

1992

1992

1992

1992

1993 
Mound

TITLE

Building 38 - Occurrence Report

Air Handling System Building 38

Building 38 - Occurrence Report

AM Failure Building 38

Building 38 - Occurrence Report

CAM False Alarm, Building 38

Building 38 - Occurrence Report

Plutonium Exposure to Rad Worker

T Building - Occurrence Report

T227 CAM False Alarm

T Building - Occurrence Report

CAM False Alarm T227

T Building - Occurrence Report

CAM Alarm T214

$T$ Building - Occurrence Report

T Building Tunnel CAM False Alarm

\begin{tabular}{lc}
\multicolumn{1}{c}{ MOUND \# } & \multicolumn{1}{c}{ DATE } \\
\cline { 1 - 1 } $\begin{array}{l}\text { ALO-DA-EGGM- } \\
\text { EGGMATO2- }\end{array}$ & 1993 \\
1993-0010 & \\
ALO-DA-EGGM- & 1993 \\
EGGMATO2- & \\
1993-0012 & \\
ALO-DA-EGGM- & 1993 \\
EGGMATO2- & \\
1993-0013 & \\
ALO-DA-EGGM- & \\
EGGMATO2- & \\
1993-0017 & \\
ALO-DA-EGGM- & \\
EGGMATO2- & \\
1992-0008 & \\
ALO-DA-EGGM- & \\
EGGMATO2- & \\
1992-0011 & \\
ALO-DA-EGGM- & \\
EGGMATO2- & \\
1992-0012 & \\
ALO-DA-EGGM- & \\
EGGMATO2- & \\
1992-0015 & \\
\end{tabular}




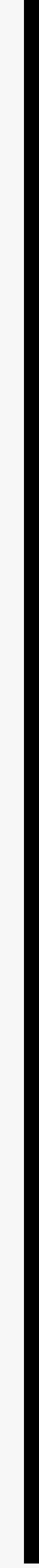




\section{Site Assessment Team Members}

\section{Rocks Flats}

Steven Browdy, CO-TEMM LEADER

Jeff Kemidge, CO-TENM LEADER

R. J. Balknger

R. W. Blais

P. A. Burdeaux

B. G. Campbell

M. R. Coubrough

L. D. Danio

S. H. Davies

D. F. Dustin

A. A. Dye

P. F. Ervio

R. A. Falter

K. P. Fertera

W. B. Fieming

C. J. Freiboth

J. A. Geis

J. W. Goggin

A. R. Harper

A. J. Holifield

F. G. Hudson

B. D. Larson

J. P. Moore

R. L. Moore

K. A. Sarafin

R. J. Schmid

R.J. Siroder

A.C. Stallser

G. M. Ṫieste

S. L Wilsoo

S. L. Yela

\section{Hanford}

D. A. Dickman, CO-TEAM LEADER R. L. Guillen, CO-TEAM LEADER

S. C. Schlegel, Co-TErM Leader

R. W. Szempruch, CO-TEAM LEADER

W. C. Alaconis

L. K. Aldrich

R. E. Barker

W. D. Bartett

J. A. Comptor

T. D. Cooper

M. A. Copeland

L. C. Daverport

A. L. Doberty

L. E. Edvalson

R. A. Eschenbaum

L. Faust

K. O. Goodey

D. O. Hess

R. P. Koight

J. W. Kolb

W. E Matheison

B. C. Meese

R. J. Migliory

E. C. Mincey

P. R. Prevo

J. J. Roemet

W. G. Ruff

B.J. Saureressig

J. M. Siemer

R. L Strain

J. A. Teal

A. B. Webb

G. A. Westsik

Los Alamos National Laboratory

P. Berglund CO-TENM LeAdtr

K. K. S. Fillay, CO-TEAM LEADER

Sleven S. Payde, Coordonator

George Biggs

Tom Bium
Amy Ecclesine
John Elder
Tim Hayes
Lamy Haynes
Dave Horrell
Hillard How ard
Sue Jones
Fernan Kelso
Vicki Longmire
Audrey Martinez
Tom MeLaughlin
Gnthrie Miller
Evelyn Mullen
Nora Rỉn
Pat Rood
Rene Sanchez
John Scblesser
Ron Stafford
Carolyn Sutcliffe

\section{Savannah River Site}

Donald Bridges, Co-TeaM LEADER

Edward Moore, Co-TeAM LEAdER

J.S. Alleader

S. R. Beck-Montgomery

G. W. Becker

W. E Bickford

B. A. Clinton

M. J. Dopohue

J.S. Evans

R. L. Frontroth

R. L. Geddes

F. R. Grabam

W. E. Hartis

H. Inbaber

D. R. Johnson

A. Joshi

W. N. Kendedy

F. Key

M. J. Lewezyk

W. S. Loring

D. C. Losey

J. M. Low

J. W. McClard

F. E. McKay

K. A. Menger

S. J. Mentrup

A. P. Mock

C. E. Olson

L. W. Reynolds

R. W. Saylor

J. B. Schade

J. R. Sessions

L. K. Sondenberg

W. B. Sumner

S.P. Tinnes

J. T. Tomac

T.E.Worth

S. A. Yano

R. L. Yourcbak

Argenne National Laboratorg-West

D. C. Crapford, Co-Team Leader

E. J. Hughes، CO-Tram LEADER

C. D. Griffí, Alternate Co-Tenm Leader

E. A. Beverly

B. A. Brush

C. G. Bushaell

A.S. Garcia

R. D. Haga

H. A. Harper

F. R. Hunt

J. R. Krsu
S. D. Mousseau

D. N. Oisen

R. L. Parks

R.W. Swanson

S. R. Wilde

T. P. Zah

Lawrence Livermore National Laboratory

Brent Ives, Co-Team Leaper

Dawn Wechsler, Ca-Team Leader

Doug Eddy, OAKLAND CoORDNATOR

Don Alves

Shawn Canllin

Jim Carlson

Steve Chin

Karen Dodson

Jobn Lietzke

Jim Mecozzi

Art O'Grady

Mary Singleton

\section{Mound}

Wayde Amos, Co-Tzam LaAder

Tim Frazier, CO-TEAM LEADER

David Billing

Douglas Draper

Tom Flannagan

Clyde Gallaher

Tom Grice

Errie Jobnson

Don Rogers

Mel Williams

Argonne National Laboratory-East

Steve Ludwig, Co-TEnM LEAdar

Ray Wolson, Co-Team LEader

Tom Barkalow, DerUTY TEAM LEADER

Jon Neuhoff, DefuTY TEAM LEADER

Theodere Bauer

Delbert Bowers

Kendeth Kemp

Joyce Leggett

James Morman

William Munyon

Kenneth Poupa

Kay Shields

Martin Steindler

Paul Vanderwall

New Brunswick_Laboratory

Margaret Lachman, Team Leader

Eric Dallman

Diana Hayes

Bob Mason

Marty Thomas

Qak Bidge Site

Calvin Hopper, Team LenceER

Garknd Proco, OAK RIDGE COORDNATOR

W.S. Aaron

M. L. Baver

. E Bigelow

J. A. Chapman

W. G. Craddick

E C. Crume, Ir.

R. D. Dabbs

C. E. DeVore

G. M. Dick

C. S. Dudney

M. L. Evans

L. Felker

D. E Fowler
M.D. Galloway

K. R. Geber

F.E. Getbers

K. R. Givens

J. H. Greene

R. E. Hallbbrton

W. A. Heinelien

L. G. Hill

C. M. Jones

J. M. Keller

A. J. Kubaida

D. C. Larson

A. W. Lewis

B. MeClelland

M. F. Osborne

R. J. Robsod

B.W. Ross

C. A. Sampson

F. J. Schultz

C. Scott

F. J. Smith

R. G. Stacy

R.E. Swaja

D. W. Tumer

J. E. Vatb

C. G. Walker

J. A. Willians

Sandia National Laboratories - New Mexico

Terri Lovato, Co-Tram Leade

Jobn Retelle, Co-Tram Leaders

Steven Payde, Alrugutrous COORDnNator

Donald Brags

Ron Fanter

Larry Garcia

Bill Rhodes

Arthur Shanks

Lih-Jend Stryr

Jobn Sichler

Lamrence Berkeleg Laboratory

Ted Decastro, Co-Tram Leader

Ken Rivera, Co-Tram Lrader

Doug Eddy, OAKLaNd COORDENaTOR

Katbleea Dinde?

Norm Edelstein

Glen Garabedian

Roger Klcepping

Henrietta Lee

Betle Mubammad

Pantex

Hector Chavez, Co-Tenm Leadgr

Robb Wight Co-Tpam Leapgr

C. David Lovell, DepUTY TEAM LEADgR

Steven A. Boode

Peggy E. Finney

Micbael S. Ford

Helen C. Hatl

Barbara F. Hammock

Dong R. Kaczmarek

Stella Maes

Helen E Malacara

Ruben C. McGilvary

Paul W. Parker

Michael Pikula

Everell E Poore

Robert C. Schuster

Penny A. Shamblin

Steven D. Troyer

Cassie J. Tumer 